\title{
LDA and CTA in-cylinder measurements of intake-generated turbulence for steady flow around a centrally located valve
}

Gearle Ray Bailey Jr.

West Virginia University

Follow this and additional works at: https://researchrepository.wvu.edu/etd

\section{Recommended Citation}

Bailey, Gearle Ray Jr., "LDA and CTA in-cylinder measurements of intake-generated turbulence for steady flow around a centrally located valve" (2001). Graduate Theses, Dissertations, and Problem Reports. 1186.

https://researchrepository.wvu.edu/etd/1186

This Thesis is protected by copyright and/or related rights. It has been brought to you by the The Research Repository @ WVU with permission from the rights-holder(s). You are free to use this Thesis in any way that is permitted by the copyright and related rights legislation that applies to your use. For other uses you must obtain permission from the rights-holder(s) directly, unless additional rights are indicated by a Creative Commons license in the record and/ or on the work itself. This Thesis has been accepted for inclusion in WVU Graduate Theses, Dissertations, and Problem Reports collection by an authorized administrator of The Research Repository @ WVU. For more information, please contact researchrepository@mail.wvu.edu. 


\title{
LDA and CTA In-Cylinder Measurements of Intake-Generated Turbulence for Steady Flow Around a Centrally Located Valve
}

\author{
Gearle R. Bailey, Jr. \\ Thesis submitted to the \\ College of Engineering and Mineral Resources \\ at West Virginia University \\ in partial fulfillment of the requirements \\ for the degree of \\ Masters of Science \\ in \\ Aerospace Engineering \\ John Kuhlman, Ph.D., Committee Chairman \\ Gary Morris, Ph.D. \\ Wade Huebsch, Ph.D. \\ Department of Mechanical and Aerospace Engineering
}

Morgantown, West Virginia

2001 


\section{Abstract}

\section{LDA and CTA In-Cylinder Measurements of Intake-Generated Turbulence for Steady Flow Around a Centrally Located Valve}

\section{Gearle R. Bailey, Jr.}

The purpose of this study was to measure the axial and swirl velocities for steady flow in a cylinder past an intake valve, for two different intake port geometries and two valve lifts, in order to study the effects of swirl and valve lift on turbulence generation. A simple geometry was used for an initial look at the flow past a valve and to setup the Laser Doppler Anemometry (LDA) equipment for future use in a more complex test bed. Constant Temperature Anemometry (CTA) was also used for comparison with the LDA measurements.

A cylinder of $41.3 \mathrm{~mm}$ (1.625-inch) radius and $114.3 \mathrm{~mm}$ (4.5 inches) height with a centrally located valve was used as the test bed. The valve had a diameter of $41.9 \mathrm{~mm}$ (1.65 inches) and was tested at lifts of 4 and $9 \mathrm{~mm}(0.157$ and 0.354 inches). Two intake geometries were tested: a straight intake port and a swirl intake port. A steady flow of air was used for each test case.

A single sensor CTA probe was used to measure profiles of axial/radial and swirl/axial velocities in the cylinder for each intake port geometry with each valve lift. A one-component LDA system was also used to measure profiles of axial and swirl velocities in the cylinder for each intake port geometry with each valve lift.

The mean velocities and standard deviations were calculated for each measurement position by the data acquisition software. Using the instantaneous and 
mean velocities for the CTA data, the autocorrelation coefficient was calculated and used to find the integral length scale and integral time scale for a few select positions.

The LDA and CTA data agreed relatively well. Both showed a conical jet after the valve, which impacted the cylinder wall near $25.4 \mathrm{~mm}(\mathrm{z}=1 \mathrm{inch} ; \mathrm{z} / \mathrm{R}=0.615)$ above the cylinder head. A recirculating flow was seen above the valve for each case. Solid body rotation of the flow was present for the swirl intake flow.

The LDA and CTA data show similar results in areas without flow reversal, proving the LDA equipment was working correctly. However, the CTA results were unable to properly detect the flow reversals seen in the LDA results. The measured flow patterns were validated by use of a laser light sheet for flow visualization. The present LDA data can be used to compare with CFD simulations for the same conditions. Further study with a more realistic, moving piston/valve test bed can now be studied using the LDA equipment. 


\section{Acknowledgements}

I would like to thank the NASA Space Grant Consortium for initially supporting this project through a grant. I would like to thank Dr. Alberto Ayala for hiring me for this project. I would like to thank the Mechanical and Aerospace Department of the College of Engineering and Mineral Resources of West Virginia University for any help with this project after the grant was finished and while I was still here.

I would also like to thank the faculty and staff of the Mechanical and Aerospace Engineering Department. Even though I may have not had direct contact with many of you, you have helped keep the department running which has allowed me to have a place to continue my education. I would like to thank Chuck Coleman, Cliff Judy and Lee Metheney for any help with computers, wiring, tools, equipment and lab space.

I would especially like to thank Dr. John Kuhlman for taking the responsibility of being my advisor after Dr. Ayala left the department. You had a busy schedule before I came along but still found time to fit me in when necessary. Without you and your knowledge of LDA systems I would have never made the LDA system work and made the LDA measurements.

I would like to thank Dr. Gary Morris for his help as the Graduate Advisor and as one of my committee members. You allowed me to TA the Experimental Fluids for three years or as I like to see it, you allowed me to play with the wind tunnels for three years.

I would like to thank Dr. Wade Huebsch for his help as one of my committee members. I would like to thank Brad Seanor for any help in or around the office he may have provided and for being a friend. I would like to thank Debbie Willis for being a joy to speak with any time I needed help with something and for any help she provided. 
Finally I would like to thank my family and friends back home. I would like to thank my Mom and Dad for being my Mom and Dad and for any help they have given me, as I needed it. I would like to thank my sister for being my sister and for any help she has given me. I would also like to thank my grandmother for being my grandmother and the support she has given to me. I wish my grandparents who have passed could be here now to see me finishing. I love you all.

Thank you to any friends or family, which I have not separately acknowledged here.

Thank you. 


\section{Table of Contents}

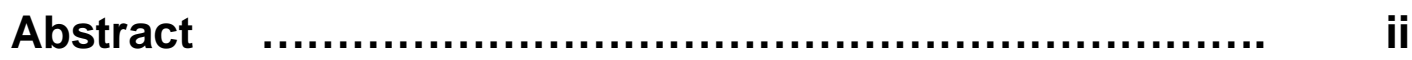

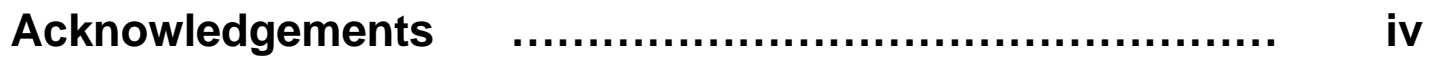

Table of Contents $\quad$.............................................. vi

List of Figures $\quad$....................................................... viii

List of Tables $\quad$................................................... $\quad$ xiv

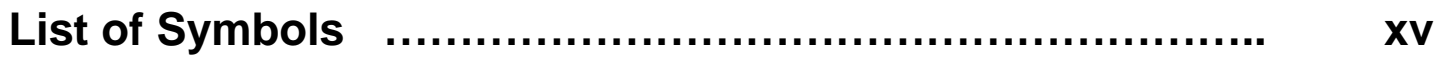

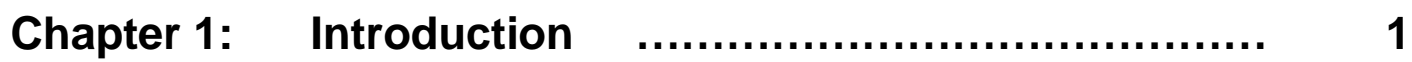

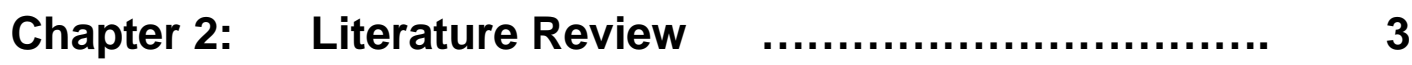

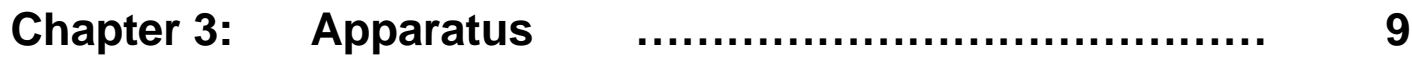

3.1 Straight Intake Apparatus $\quad$............................ 9

3.2 Swirl Intake Apparatus $\quad$............................. 10

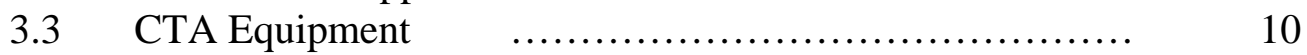

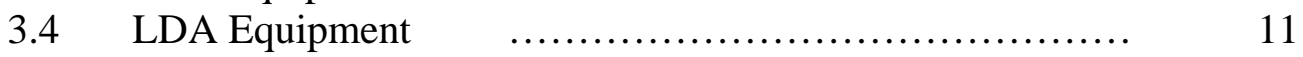

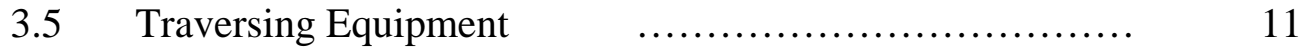

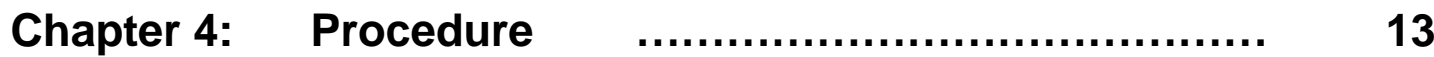

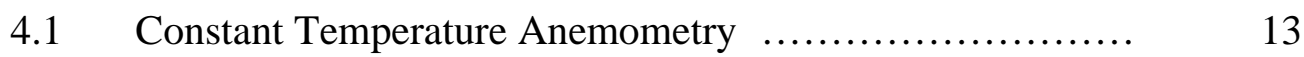

4.1.1 Calibration $\quad$...................................... 13

4.1.2 Experimentation $\quad$.............................. 14

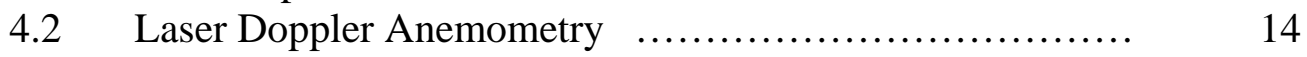

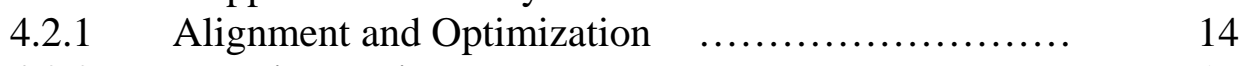

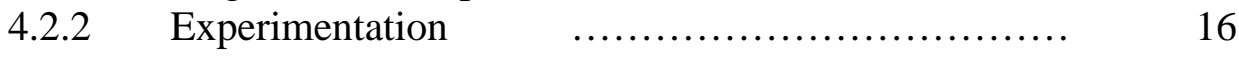

Chapter 5: $\quad$ Presentation and Discussion of Results....... 18

5.1 Presentation of CTA Results .......................... 18

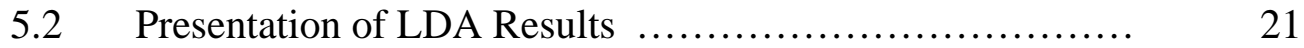

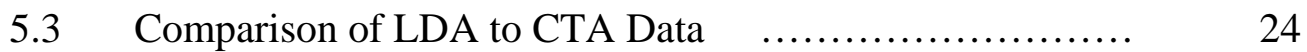

5.4 LDA Absolute Instantaneous Velocity Compared with CTA 28

5.5 Integral Time Scales and Integral Length Scales for CTA Data 31

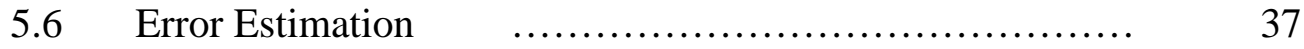

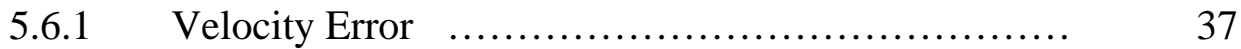

5.6.2 LDA Probe Volume Position Error $\quad$................. 37 


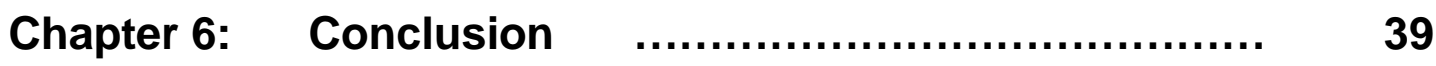

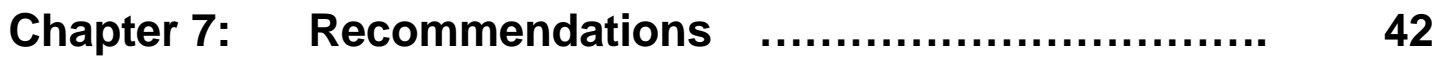

References $\quad$................................................. 43

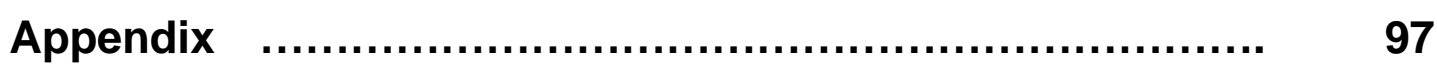




\section{List of Figures}

Figure $\quad$ Page

3.1 Straight intake test apparatus (close-up view) 44

3.2 Straight intake test apparatus (full view) 44

3.3 Micromanometer 45

3.4 Intake valves $\quad 45$

3.5 Swirl intake test apparatus (close-up view) 46

3.6 Swirl intake test apparatus (full view) 46

3.7 Data acquisition computer and IFA $300 \quad 47$

$\begin{array}{lll}3.8 & \text { CTA probe and probe support } & 47\end{array}$

$\begin{array}{lll}3.9 & \text { CTA calibrator } & 47\end{array}$

$\begin{array}{lll}3.10 & \text { LDA optics } & 48\end{array}$

3.11 LDA electronics 49

3.12 Argon-Ion Laser 49

$\begin{array}{llr}3.13 & \text { Laser power supply } & 49\end{array}$

3.14 CTA X-Z traverse 49

3.15 Complete LDA system with X-Y-Z traverse 50

5.1 Axial/radial mean velocity measurements for $4 \mathrm{~mm}$ valve lift and $\quad 51$ straight intake using CTA

5.2 Axial/radial standard deviation measurements for $4 \mathrm{~mm}$ valve lift $\quad 51$ and straight intake using CTA

5.3 Axial/radial mean velocity measurements for $9 \mathrm{~mm}$ valve lift and $\quad 52$ straight intake using CTA

5.4 Axial/radial standard deviation measurements for $9 \mathrm{~mm}$ valve lift $\quad 52$ and straight intake using CTA 
5.5 Axial/radial mean velocity measurements for $4 \mathrm{~mm}$ valve lift and swirl intake using CTA

5.6 Axial/radial standard deviation measurements for $4 \mathrm{~mm}$ valve lift and swirl intake using CTA

5.7 Axial/swirl mean velocity measurements for $4 \mathrm{~mm}$ valve lift and swirl intake using CTA

5.8 Axial/swirl standard deviation measurements for $4 \mathrm{~mm}$ valve lift and $\quad 54$ swirl intake using CTA

5.9 Axial/radial mean velocity measurements for $9 \mathrm{~mm}$ valve lift and swirl intake using CTA

5.10 Axial/radial standard deviation measurements for $9 \mathrm{~mm}$ valve lift and swirl intake using CTA

5.11 Axial/swirl mean velocity measurements for $9 \mathrm{~mm}$ valve lift and swirl intake using CTA

5.12 Axial/swirl standard deviation measurements for $9 \mathrm{~mm}$ valve lift and 56 swirl intake using CTA

5.13 Axial mean velocity measurements for $4 \mathrm{~mm}$ valve lift and straight intake using LDA

5.14 Axial standard deviation measurements for $4 \mathrm{~mm}$ valve lift and straight intake using LDA

5.15 Swirl mean velocity measurements for $4 \mathrm{~mm}$ valve lift and straight intake using LDA straight intake using LDA

5.17 Axial mean velocity measurements for $9 \mathrm{~mm}$ valve lift and straight intake using LDA

5.18 Axial standard deviation measurements for $9 \mathrm{~mm}$ valve lift and straight intake using LDA

5.19 Swirl mean velocity measurements for $9 \mathrm{~mm}$ valve lift and straight intake using LDA 
5.20 Swirl standard deviation measurements for $9 \mathrm{~mm}$ valve lift and $\quad 60$ straight intake using LDA

5.21 Axial mean velocity measurements for $4 \mathrm{~mm}$ valve lift and swirl intake using LDA

5.22 Axial standard deviation measurements for $4 \mathrm{~mm}$ valve lift and swirl intake using LDA

5.23 Swirl mean velocity measurements for $4 \mathrm{~mm}$ valve lift and swirl intake using LDA

5.24 Swirl standard deviation measurements for $4 \mathrm{~mm}$ valve lift and swirl intake using LDA

5.25 Axial mean velocity measurements for $9 \mathrm{~mm}$ valve lift and swirl intake using LDA

5.26 Axial standard deviation measurements for $9 \mathrm{~mm}$ valve lift and swirl 63 intake using LDA

5.27 Swirl mean velocity measurements for $9 \mathrm{~mm}$ valve lift and swirl intake using LDA

5.28 Swirl standard deviation measurements for $9 \mathrm{~mm}$ valve lift and swirl $\quad 64$ intake using LDA

5.29 Comparison between LDA axial mean velocity and CTA axial/radial mean velocity measurements with $4 \mathrm{~mm}$ valve and straight intake

5.30 Comparison between LDA axial mean velocity and CTA axial/radial mean velocity measurements with $9 \mathrm{~mm}$ valve lift and straight intake

5.31 Comparison between LDA axial mean velocity and CTA axial/radial mean velocity measurements with $4 \mathrm{~mm}$ valve lift and swirl intake

5.32 Comparison between LDA swirl mean velocity and CTA axial/swirl mean velocity measurements with $4 \mathrm{~mm}$ valve lift and swirl intake

5.33 Comparison between LDA axial mean velocity and CTA axial/radial mean velocity measurements with $9 \mathrm{~mm}$ valve lift and swirl intake 
5.34 Comparison between LDA swirl mean velocity and CTA axial/swirl mean velocity measurements with $9 \mathrm{~mm}$ valve lift and swirl intake

5.35 Comparison between LDA axial standard deviation and CTA axial/radial standard deviation measurements with $4 \mathrm{~mm}$ valve lift and straight intake

5.36 Comparison between LDA axial standard deviation and CTA axial/radial standard deviation measurements with $9 \mathrm{~mm}$ valve lift and straight intake

5.37 Comparison between LDA axial standard deviation and CTA axial/radial standard deviation measurements with $4 \mathrm{~mm}$ valve lift and swirl intake

5.38 Comparison between LDA swirl standard deviation and CTA axial/swirl standard deviation measurements with $4 \mathrm{~mm}$ valve lift and swirl intake

5.39 Comparison between LDA axial standard deviation and CTA axial/radial standard deviation measurements with $9 \mathrm{~mm}$ valve lift and swirl intake

5.40 Comparison between LDA swirl standard deviation and CTA axial/swirl standard deviation measurements with $9 \mathrm{~mm}$ valve lift and swirl intake

5.41 Comparison between LDA instantaneous absolute axial mean velocity and CTA axial/radial mean velocity measurements with 4 $\mathrm{mm}$ valve lift and straight intake

5.42 Comparison between LDA instantaneous absolute axial mean velocity and CTA axial/radial mean velocity measurements with 9 $\mathrm{mm}$ valve lift and straight intake

5.43 Comparison between LDA instantaneous absolute axial mean velocity and CTA axial/radial mean velocity measurements with 4 $\mathrm{mm}$ valve lift and swirl intake

5.44 Comparison between LDA instantaneous absolute swirl mean velocity and CTA axial/swirl mean velocity measurements with 4 $\mathrm{mm}$ valve lift and swirl intake 
5.45 Comparison between LDA instantaneous absolute axial mean velocity and CTA axial/radial mean velocity measurements with 9 mm valve lift and swirl intake

5.46 Comparison between LDA instantaneous absolute swirl mean velocity and CTA axial/swirl mean velocity measurements with 9 $\mathrm{mm}$ valve lift and swirl intake

5.47 Comparison between LDA instantaneous absolute axial standard deviation and CTA axial/radial standard deviation measurements with $4 \mathrm{~mm}$ valve lift and straight intake

5.48 Comparison between LDA instantaneous absolute axial standard deviation and CTA axial/radial standard deviation measurements with $9 \mathrm{~mm}$ valve lift and straight intake

5.49 Comparison between LDA instantaneous absolute axial standard deviation and CTA axial/radial standard deviation measurements with $4 \mathrm{~mm}$ valve lift and swirl intake

5.50 Comparison between LDA instantaneous absolute swirl standard deviation and CTA axial/swirl standard deviation measurements with $4 \mathrm{~mm}$ valve lift and swirl intake

5.51 Comparison between LDA instantaneous absolute axial standard deviation and CTA axial/radial standard deviation measurements with $9 \mathrm{~mm}$ valve lift ands swirl intake

5.52 Comparison between LDA instantaneous absolute swirl standard deviation and CTA axial/swirl standard deviation measurements with $9 \mathrm{~mm}$ valve lift and swirl intake

5.53 Integral time scales for CTA measurements of straight intake with 4 $\mathrm{mm}$ of valve lift

5.54 Integral time scales for CTA measurements of straight intake with 9 mm of valve lift

5.55 Integral time scales for CTA measurements of swirl intake with 4 mm of valve lift

5.56 Integral time scales for CTA measurements of swirl intake with 9 mm of valve lift 
$\underline{\text { Figure }}$

$\underline{\text { Page }}$

5.57 Integral length scales for CTA measurements of straight intake with 93 $4 \mathrm{~mm}$ of valve lift

5.58 Integral length scales for CTA measurements of straight intake with 94 $9 \mathrm{~mm}$ of valve lift

5.59 Integral length scales for CTA measurements of swirl intake with 4 95 $\mathrm{mm}$ of valve lift

5.60 Integral length scales for CTA measurements of swirl intake with 9 96 $\mathrm{mm}$ of valve lift 


\section{List of Tables}

Table $\quad$ Page

A.1 Test conditions for measurements of straight intake using CTA 98 equipment.

A.2 Test conditions for measurements of swirl intake using CTA 100 equipment.

A.3 Test conditions for axial velocity measurements of straight intake 103 using LDA equipment with $9 \mathrm{~mm}$ of valve lift.

A.4 Test conditions for axial velocity measurements of swirl intake 104 using LDA equipment.

A.5 Test conditions for axial velocity measurements of straight intake 106 using LDA equipment with $4 \mathrm{~mm}$ of valve lift.

A.6 Test conditions for swirl velocity measurements of swirl intake 107 using LDA equipment with $9 \mathrm{~mm}$ of valve lift.

A.7 Test conditions for swirl velocity measurements of swirl intake 108 using LDA equipment with $4 \mathrm{~mm}$ of valve lift.

A.8 Test conditions for swirl velocity measurements of straight intake 109 using LDA equipment with $4 \mathrm{~mm}$ of valve lift.

A.9 Test conditions for swirl velocity measurements of straight intake using LDA equipment with $9 \mathrm{~mm}$ of valve lift. 


\section{List of Symbols}

\section{English}

$\mathrm{N} \quad-\quad$ total velocity samples per CTA test run

r $\quad-\quad$ radial position

$\mathrm{R} \quad-\quad$ cylinder radius (1.625 inches)

$\mathrm{R}_{\mathrm{uu}} \quad-\quad$ autocorrelation coefficient

$\mathrm{u}_{\text {fluct,i }} \quad-\quad$ fluctuation velocity

$\mathrm{u}_{\text {mean }} \quad-\quad$ mean velocity

$\mathrm{u}_{\mathrm{RMS}} \quad-\quad$ standard deviation

x $\quad-\quad$ time difference (in number of samples)

z $\quad-\quad$ axial position

\section{Greek}

$\Lambda \quad-\quad$ integral length scale

$\Lambda_{\tau} \quad-\quad$ integral time scale

$\tau \quad-\quad$ time difference units

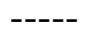

$\mathrm{mm}$

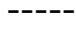

$\mathrm{m} / \mathrm{s}$

$\mathrm{m} / \mathrm{s}$

$\mathrm{m} / \mathrm{s}$

$\mathrm{mm}$

meters

seconds

seconds 


\section{Chapter 1: Introduction}

The subject of this study was the in-cylinder turbulence of a simplified model of an automotive combustion chamber generated by the intake port and intake valve. Turbulence generated during the intake stroke of an internal combustion engine is believed to have a significant effect on the subsequent mixing of air and fuel, and the combustion process.

The purpose of this study was to measure the axial and swirl flow velocities of the flow past an intake valve for two different intake port geometries with two valve lifts using two different methods of velocity measurement in order to study the effect of swirl and valve lift on turbulence generation. A simplified automotive intake port was modeled with only a centrally located intake valve (no exhaust valve). The valve was set at one of two lifts and a steady flow was measured around the valve and through the cylinder. The measured flow velocity statistics were then calculated and compared.

This study has been conducted using two different intake geometries: a straight intake and swirl-inducing intake. For each intake, two valve lifts were tested, of $4 \mathrm{~mm}$ and $9 \mathrm{~mm}$, using two different measurement methods, constant temperature anemometry (CTA) and laser Doppler anemometry (LDA). LDA should produce more accurate results than CTA in this application, since it is nonintrusive and can sense flow reversals. Some of the present CTA results have been previously presented in Ayala and Bailey (2000).

The overall aim of this study was to aid in improving the understanding of the mixing characteristics of the two intake geometries. Better mixing of the air/fuel mixture 
in an internal combustion engine should result in more power, more complete combustion, and lower emissions from the engine. 


\section{Chapter 2: Literature Review}

Much work has been performed to study the flow patterns in the combustion chamber of an internal combustion engine. The effects of different designs and geometries on the flow patterns have also been studied. A comprehensive analysis and report of previous work has been written by Heywood (1987). An overview of this work, summarized from Heywood is presented below.

To emphasize the importance fluid motion plays in engine performance, Heywood (1987) states, "the flow field within the cylinder of internal combustion engines is the most important factor in controlling the combustion process. Thus it has a major impact on engine operation." Thus, to develop engines with attractive operating and emission characteristics, it is critical to obtain a good understanding of fluid motion in an internal combustion engine.

Previous experiments have shown the importance of turbulence to the engine combustion process. For example, eliminating intake turbulence decreased the rate of flame propagation during combustion. A sufficiently turbulent flow is needed during combustion to ensure rapid flame development and propagation. However, excessive turbulence and mixture motion is undesirable and creates wasted energy (Heywood, 1987).

During the intake stroke, flow past the valve, into the cylinder, forms a conical jet. In the jet, the maximum fluid velocities are about fifteen times the mean piston speed. As the flow enters the cylinder, the conical jet separates from the valve creating shear layers. The shear layers contain large velocity gradients, which create turbulence. Recirculation 
regions past the valve and in the corner between the cylinder wall and cylinder head are created by the jet separation (Heywood, 1987).

Also during the intake stroke, the conical jet impacts the cylinder wall. After impacting the wall, most of the jet travels along the wall toward the piston (away from the cylinder head). A small part of the jet does travel along the wall towards the cylinder head. The interaction of the jet with the cylinder wall produces regions of recirculation in the cylinder. Most of the cylinder is filled with a large ring vortex, which grows in length as the piston moves during the intake stroke, increasing the size of the combustion chamber. The flow in the corners between the cylinder head and cylinder wall creates a smaller ring vortex rotating in the opposite direction of the larger vortex (Heywood, 1987).

The recirculation patterns created by the conical jet and its interaction with the cylinder wall and piston are dependent on the intake port, valve and cylinder head geometries. Simplified test rigs, creating axisymmetrical flows, have been used to more easily view these flow patterns. The presence of similar large scale rotating patterns can also be seen in test rigs with more typical intake valve locations and intake port geometries (Heywood, 1987).

Another method to create turbulence and increase mixing in the cylinder is to induce swirl into the flow. Heywood (1987) states "swirl is more stable than other large scale in-cylinder flows and therefore breaks up later in the cycle giving higher turbulence during combustion." This shows that intake generated swirl can be a better way of achieving faster burn rates. It can also be shown that excessive fluid motion and 
excessive turbulence can create unnecessarily high burning rates and heat transfer that result in performance and efficiency losses (Heywood, 1987).

There are two broad methods to inducing swirl during intake. One is to generate swirl within the intake port, forcing the flow to rotate around the valve axis before entering the cylinder. The other method is to discharge the flow tangentially towards the cylinder wall, where the flow travels sideways and downwards in a swirling motion (Heywood, 1987).

Swirl is used in spark ignition engines to increase turbulent intensity, speeding up the combustion process. Swirl is also used in diesel engines to help mixing of the air and the injected fuel. During induction, flow patterns near the cylinder head are relatively disorganized. In the cylinder away from the cylinder head, the flow patterns closely resemble solid body rotation with the swirl velocity increasing with increasing radius. Swirl generated during intake usually lasts through compression, combustion and even expansion processes (Heywood, 1987).

A more recent study of the steady flow past an intake valve at a fixed valve lift was conducted by Stier and Koochesfahani (1998). The steady flow rig had a quartz cylinder $\left(\mathrm{R}_{\mathrm{o}}=41 \mathrm{~mm}\right)$ with a centrally located intake port $(\mathrm{d}=25.4 \mathrm{~mm})$. A valve in the intake port had a lift of $9 \mathrm{~mm}$ and flow set for a maximum speed of $10 \mathrm{~m} / \mathrm{s}$. Molecular Tagging Velocimetry (MTV) was used for measuring velocity. A laser grid was set to excite the biacetyl molecules in the nitrogen flow.

An annular jet was detected past the valve until contacting the cylinder wall, where the main flow continued up the wall. A returning flow above the valve was also detected. A vorticular structure was seen between the jet and returning flow. Another 
smaller vorticular structure was also seen in the corner above the cylinder head next to the cylinder wall. This structure rotated in an opposite direction than the larger structure.

The MTV measurements were compared to similar LDA measurements by Bicen el al. (1985). The compared results showed consistent features. Both showed the recirculating zone in the corner of the cylinder. The rms fluctuation levels for both were near $18 \%$ of the jet velocity.

An LDA study of intake flow for four intake conditions as conducted by Bicen el al (1985). The four intake conditions included steady and unsteady conditions: steady flow with a stationary valve, stationary valve with a flow provided by a reciprocating piston upstream, stationary valve with flow provided by a reciprocating piston downstream, and a moving valve with flow provided by a reciprocating piston downstream. Three valve geometries were tested in the steady flow case.

Measurements were taken at two different regions for each intake case: near the valve and in the cylinder. Comparing results between each unsteady case and the steady case near the valve showed similar mean flow patterns. This indicated that the main features of the mean flow near the valve remain insensitive to flow unsteadiness, piston interaction and valve operation (Bicen et al., 1985).

The measurements in the cylinder were taken at $15 \mathrm{~mm}$ above the cylinder head. The jet past the valve could be seen with the largest positive velocity. Above the valve, a negative mean velocity was observed, indicating the return flow. Also, a negative mean velocity could be seen near the wall, indicating the presence of another recirculating region in the corner of the cylinder. 
LDA measurements in a reentrant bowl-in piston combustion chamber were made by Auriemma et al. (1998). A piston-cylinder with a bore of $86 \mathrm{~mm}$, a stroke of $75 \mathrm{~mm}$ and a compression ratio of 21:1 was used. Radial (squish) and tangential (swirl) velocities were measured at 2 measurement points located $3 \mathrm{~mm}$ below the engine head. The measurement points were located $16 \mathrm{~mm}$ and $20 \mathrm{~mm}$ respectively from the cylinder axis, which is inside the reentrant bowl at top dead center (TDC). Measurements were taken for three engine speeds of 1000, 1500 and $2000 \mathrm{rpm}$, for a crank angle range of $60^{\circ}$ BTDC (before TDC) to $30^{\circ}$ ATDC (after TDC).

The tangential velocities show a rapid increase as the piston reaches TDC for all three engine speeds at a radial location of $20 \mathrm{~mm}$. The tangential velocities reach a maximum around $15-10^{\circ}$ BTDC. The radial velocities show a radially inward motion, reaching a maximum at about the same crank angle as where the tangential velocity reaches a maximum. The integral time scales for both tangential and radial velocities show a trend of decreasing as the piston reaches TDC. The integral time scales also show a trend of inverse scaling with engine speed for both measurement points.

The normalized Reynolds shear stresses were almost constant during the first part of compression. As the piston reached TDC, the normalized Reynolds shear stresses rapidly increased. The maximum normalized Reynolds shear stresses for the measurement point of $r=16 \mathrm{~mm}$, occurred before TDC while the maximum normalized Reynolds shear stresses for the measurement point of $r=20 \mathrm{~mm}$ was at TDC. This confirms previous work where the turbulence near the combustion wall increased at the end of compression. The normalized Reynolds shear stresses show a similar trend as turbulence intensities. This confirms that transport of momentum, caused by Reynolds 
shear stresses, is much more effective than molecular transport at the end of the compression stroke (Auriemma et al., 1998).

An LDA study of the flow in two in-piston bowls was performed by Corcione and Valentino (1991). A reciprocating engine with a bore of $100 \mathrm{~mm}$ and a stroke of $95 \mathrm{~mm}$ was tested at engine speeds of 600 and $1000 \mathrm{rpm}$. Measurements were taken at three planes below the cylinder head, $\mathrm{z}=4.0,7.5$ and $11 \mathrm{~mm}$, during the last $60^{\circ}$ of compression before TDC. The two in-piston bowls had similar sizes but different wall geometries: straight-sided and reentrant.

At $600 \mathrm{rpm}$, the reentrant bowl had lower velocities than the straight-sided bowl, particularly at a higher depth in the bowl. The turbulence intensities were larger in the reentrant bowl near the bowl wall and had higher values than the straight-sided bowl. The reentrant bowl also had larger integral time scales than the straight-sided bowl, particularly near the bowl wall.

At $1000 \mathrm{rpm}$, the reentrant bowl had larger circumferential velocities near the bowl wall and bottom. This caused the swirl to continue until near or shortly after TDC. The reentrant bowl also had larger tangential velocities near the bowl wall, and the high velocity zone was moved towards the bottom of the bowl. 


\section{Chapter 3: Apparatus}

For comparison of the effects of swirl on intake turbulence generation, two intake geometries were used for the present in-cylinder flow measurements: a straight intake and a swirl intake. A centrally located intake valve was tested at two valve lifts per intake geometry: four millimeters and nine millimeters. This cylinder layout with a centrally located intake valve was designed similar to an apparatus used in a previous study by Stier and Koochesfahani (1998). Two methods or flow measurement were used for each geometric setup: LDA (Laser Doppler Anemometry) and CTA (Constant Temperature Anemometry).

\subsection{Straight Intake Apparatus}

The test apparatus with the straight intake (Figure 3.1) used a test cylinder of 82.6 $\mathrm{mm}$ (3.25 inches) inside diameter and $114.3 \mathrm{~mm}$ (4.5 inches) tall. Airflow was provided by a 12-volt DC aircraft blower connected to a variable DC source (Figure 3.2). Airflow was directed through a $38.1 \mathrm{~mm}(1.5 \mathrm{inch})$ inside diameter flexible hose to a $25.4 \mathrm{~mm}$ (1 inch) inside diameter PVC pipe. A Pitot-Static probe was located $101.6 \mathrm{~mm}$ (4 inches) from the end of the $25.4 \mathrm{~mm}$ ( $1 \mathrm{inch}$ ) pipe to allow setting the same flow rate from run to run. The Pitot-Static probe was connected to a micromanometer (Figure 3.3). The 25.4 mm (1 inch) PVC pipe had a length of $508 \mathrm{~mm}$ (20 inches) and led straight into the test cylinder. A $41.9 \mathrm{~mm}$ (1.65 inch) diameter automotive intake valve was centrally located in the flat bottom of the test cylinder (Figure 3.4).

The test cylinder and operating conditions were set up to mimic the test conditions in a study by Stier and Koochesfahani (1998). Stier and Koochesfahani used a 
rig with a quartz cylinder with an outside radius of $41 \mathrm{~mm}$ and an axisymmetrically located intake port with a diameter of $25.4 \mathrm{~mm}$ (one inch). In the port was an intake valve set to $9 \mathrm{~mm}$ of lift. Steady flow was provided by nitrogen from a pressurized tank. The flow was set to give a maximum jet velocity of $10 \mathrm{~m} / \mathrm{s}$.

\subsection{Swirl Intake Apparatus}

The test apparatus with the swirl intake (Figure 3.5) also used a test cylinder of $82.6 \mathrm{~mm}$ (3.25 inches) inside diameter and $114.3 \mathrm{~mm}$ (4.5 inches) tall. A $41.9 \mathrm{~mm}(1.65$ inch) diameter automotive intake valve was again centrally located in the end of the test cylinder (Figure 3.4). Airflow was provided by the same 12-volt DC aircraft blower (Figure 3.6). Airflow was directed through a $38.1 \mathrm{~mm}$ (1.5 inch) inside diameter flexible hose to a $25.4 \mathrm{~mm}$ (1 inch) inside diameter PVC pipe. A Pitot-Static probe, connected to a micromanometer (Figure 3.3), was located $101.6 \mathrm{~mm}$ (4 inches) from the end of the $25.4 \mathrm{~mm}$ ( 1 inch) pipe. The $25.4 \mathrm{~mm}$ ( 1 inch) pipe then led to a $50.8 \mathrm{~mm}$ ( 2 inch) inside diameter PVC pipe. The $50.8 \mathrm{~mm}$ (2 inch) PVC pipe fed a side port that created swirl in the intake chamber before entering the test cylinder.

\subsection{CTA Equipment}

CTA measurements were made with a TSI (Thermal Systems, Incorporated) IFA 300 with one channel anemometer interfaced to the personal computer (Figure 3.7). The probe used was a Dantec type 55P01 straight, single probe (Figure 3.8). The IFA 300 was connected to the computer with an interface card, TSI model ADC WIN-4. Velocities were calculated by the TSI IFA300 ThermalPro software (ver. 2.03). The CTA equipment was calibrated with a TSI model 1125 calibrator (Figure 3.9). 


\subsection{LDA Equipment}

LDA measurements were made with a TSI 9100 series one-component LDA system, fitted with a Bragg cell (Figure 3.10). The LDA optics consisted of a TSI beam splitter model 9115-2, a rotator model 9178-1 and 9179, a Bragg Cell model 9182-3A controlled by a frequency shifter model 9186A (Figure 3.11), a lens with a focal distance of $103.1 \mathrm{~mm}$, backscatter-receiving optics model 9140. The oscillating light signal was converted to a voltage signal by a photo-multiplier tube (PMT) model 9162 powered by a PMT Power Supply model 9165 (Figure 3.11). The signal was then sent to the TSI Counter Processor model 1980 B (Figure 3.11). The conditioned signal was sent to an oscilloscope for observation while a digital conditioned signal was sent to the computer through an interface card model 6260 (Figure 3.7). Velocities were calculated from the signal by the TSI Flow Information Display (FIND, ver. 4.0) software. The laser used was a 2-Watt continuous output, LEXEL model 95 Argon-Ion laser (Figure 3.12 and 3.13). A Ness ULF-700 theatrical fog machine provided the seed particles. These seed particles have a mean diameter on the order of 1 micron.

\subsection{Traversing Equipment}

Velocity measurements were taken at multiple radial and axial locations for both geometries (straight intake and swirl intake), and for both measurement methods (CTA and LDA). CTA and LDA used different measurement equipment and likewise, used different methods of traversing through the test cylinder. The hot-wire probe had to be placed in the cylinder and traversed to various measurement points for CTA. The LDA method directed the focused laser beams into the cylinder and the equipment had to be traversed from outside the test cylinder. 
The probe for CTA was light and compact and could be traversed with two dial calipers (Figure 3.14). The calipers were connected perpendicular to each other. The probe support was mounted perpendicular to one caliper, but parallel to the motion of the other. This setup was attached above the test cylinder, allowing the probe and probe support to protrude into the test section.

The equipment for LDA measurements was mounted to an optic bench which was mounted to an X-Y-Z traverse (Figure 3.15). The X-Y components of the traverse were made from C-channel rails, rollers, square tubing, and threaded rods. These two sets of rails were positioned perpendicular to each other to allow for $\mathrm{X}$ and $\mathrm{Y}$ movements. The $\mathrm{X}$ and $\mathrm{Y}$ movements were controlled manually by the threaded rods. The $\mathrm{Z}$ component was controlled by a hydraulic scissor lift, Southworth Backsaver Lite Lift model LL05.526, with the X-Y components mounted to the hydraulic lift table. 


\section{Chapter 4: Procedure}

\subsection{Constant Temperature Anemometry}

\subsubsection{Calibration}

The probe, Dantec model 55P01, and probe support were attached to the calibrator, TSI model 1125, with the hot-wire probe mounted perpendicular to the flow. The hot-wire probe was mounted $1.6 \mathrm{~mm}$ (1/16 inch) above the jet opening on the calibrator. The hot-wire probe was connected to the TSI IFA 300 anemometer, which was connected to the computer.

The TSI ThermalPro software was run and set for calibration. Calibration data was obtained for 17 velocities: $0.0,1.7,2.2,2.8,3.3,3.7,4.4,5.0,6.0,8.0,10.0,12.0$, 14.0, 16.0, 18.0, 20.0, and $25.0 \mathrm{~m} / \mathrm{s}$ for the straight intake and $0.0,1.6,2.4,3.2,4.3,5.1$, $5.4,5.7,6.0,8.0,10.0,12.0,14.0,16.0,18.0,20.0$, and $25.0 \mathrm{~m} / \mathrm{s}$ for the swirl intake. A calibration was made before testing to calibrate the CTA for the current atmospheric conditions. The TSI ThermalPro software used Bernoulli's equation to calculated velocity from the static pressure of the calibrator chamber. The chamber pressure was measured with a micromanometer. The first few velocities were set from the lowest measurable pressures in the chamber, and were nominally $0.0,0.007,0.012,0.019,0.026$, 0.033, and 0.045 inches of water for the straight intake and $0.0,0.006,0.013,0.024$, $0.044,0.060,0.067$, and 0.075 inches of water for the swirl intake. The remaining data points were equally spaced by desired velocity. The software computed a fourth order polynomial least square fit calibration curve from the calibration data that was used to convert voltages into velocities. 


\subsubsection{Experimentation}

Six sets of data were recorded with the CTA equipment. Two sets of data were recorded for the axial/radial velocities with the straight intake, at valve setting of $4 \mathrm{~mm}$ and $9 \mathrm{~mm}$ of lift. Two more sets of data were recorded for the axial/radial velocities with the swirl intake, again at $4 \mathrm{~mm}$ and $9 \mathrm{~mm}$ of lift. The final two sets of CTA data were recorded for the axial/swirl velocities with the swirl intake, also at valve settings of $4 \mathrm{~mm}$ and $9 \mathrm{~mm}$ of lift.

Each set of data for $4 \mathrm{~mm}$ of lift contained 5 radial traverses $(\mathrm{z} / \mathrm{R}=0,0.185$, $0.308,0.615$ and 1.231 ). Each radial traverse contained 26 data points except the traverse at $\mathrm{z} / \mathrm{R}=0$, which contained 14 data points. Radial distances between most measurement locations in a traverse were $3.2 \mathrm{~mm}(1 / 8 \mathrm{inch})$. The data sets for $9 \mathrm{~mm}$ of lift contained 4 radial traverses $(\mathrm{z} / \mathrm{R}=0,0.308,0.615$, and 1.231). Again, each radial traverse also contained 26 data points except $\mathrm{z} / \mathrm{R}=0$, which contained 14 data points. Radial distances between most measurement locations were $3.2 \mathrm{~mm}(1 / 8 . i n c h)$

Data for the straight intake was recorded at a sampling rate of $20 \mathrm{kHz}$ for $128 \mathrm{kpts}$ ( $1 \mathrm{kpts}=1024$ data points $)$, equaling a sample time of 6.5536 seconds. A sample time of 6.5536 seconds was also used for the swirl intake. The swirl intake data used a frequency of $10 \mathrm{kHz}$ and a sample size of $64 \mathrm{kpts}$.

\subsection{Laser Doppler Anemometry}

\subsubsection{Alignment and Optimization}

The laser was first mounted to the optic bench, which was mounted on top of the three-axis traversing system. The TSI optics were assembled and mounted to an aluminum plate. The laser was activated at low power level and the optics positioned in 
the laser beam path. The plate with the optics was mounted to the optic bench. Using adjustments on the optic bench, the optics were aligned to be collinear with the laser beam. This was accomplished when the laser beam entered a pinhole on the end of the optics and the two output beams were centered on marks on an alignment mask (TSI model 9104). This was accomplished with the Bragg cell rotated 90 degrees out of the laser beam plane.

The optics now had to be aligned with the Bragg cell inline with the laser beams. Before placing the Bragg cell inline, the alignment mask was removed and the position of the laser beams marked on a wall in front of the optics. The Bragg cell was then rotated into position and the frequency shifter turned on. The Bragg cell created multiple beams from one of the two beams that went through the cell. Powering the frequency shifter on and off, the original laser beam (zero order) was noted. The negative first order beam was desired for use for the velocity measurements. Using the tilt angle adjustment on the Bragg cell, the negative first order beam intensity was maximized. Then, using the wedge angle adjustments on the Bragg cell, the negative first order beam was moved to the original position of the zero order beam without the Bragg cell.

Now with the laser beams in the correct alignment, the receiving optics had to be aligned. The only pieces to be aligned were the PMT position and focus mirror position. This was done using an alignment eyepiece (TSI model 10096). With the laser power turned down to on the order of tens of milliwatts, an object (clear acrylic tube) was placed at the focal point of the two laser beams. While watching through the eyepiece, the focus mirror was adjusted until the focal point of the two laser beams was as clear as 
possible. Finally, the eyepiece was positioned such that the focal point was at the center of the cross hairs.

The PMT was then mounted on top of the optics and turned on. The PMT was connected to the input signal conditioner of the TSI model 1980B counter processor, which was attached to the computer. To check the accuracy of the alignment, a 317.5 mm (12.5 inch) diameter wheel was attached to a DC motor and a small wire (approximately 3 mils thick) or hair was attached to the outside edge of the wheel. Knowing the rotational speed of the wheel (measured with a strobe light) and the radius the wire was from the center of the wheel, the velocity of the wire was calculated. Placing the rotating wire in the focal point of the laser beams, data was collected and the setup alignment, counter processor settings, and software setup verified.

\subsubsection{Experimentation}

Eight sets of data were recorded with the LDA equipment. Two sets of data were recorded for the axial velocities with the straight intake, at valve settings of $4 \mathrm{~mm}$ and 9 $\mathrm{mm}$ of lift. Two more sets of data were recorded for the swirl velocities with the straight intake, again at $4 \mathrm{~mm}$ and $9 \mathrm{~mm}$ of lift. Similarly, for the swirl intake, two sets of data were recorded for the axial velocities, at $4 \mathrm{~mm}$ and $9 \mathrm{~mm}$ of lift. Also for the swirl intake, two sets of data were recorded for the swirl velocities, again at $4 \mathrm{~mm}$ and $9 \mathrm{~mm}$ of lift.

Each set of data for $4 \mathrm{~mm}$ of lift for the axial velocities contained 4 radial traverses $(\mathrm{z} / \mathrm{R}=0.185,0.308,0.615$, and 1.231). For the swirl velocities for $4 \mathrm{~mm}$ of lift, there were 5 radial traverses $(\mathrm{z} / \mathrm{R}=0,0.185,0.308,0.615$, and 1.231$)$ for each set of data. The data sets for $9 \mathrm{~mm}$ of lift for the axial velocities contained 3 radial traverses $(\mathrm{z} / \mathrm{R}=$ 
$0.308,0.615$, and 1.231 ). The data sets for $9 \mathrm{~mm}$ of lift for swirl velocities contained 4 radial traverses $(\mathrm{z} / \mathrm{R}=0,0308,0.615$, and 1.231). Radial distances between data points were $3.2 \mathrm{~mm}(1 / 8$ inch).

Sample sizes for LDA measurement points were $8 \mathrm{kpts}$. The sample time varied depending upon density of seed particles and clarity of optical access. The sample times typically ranged from 10 seconds to 60 seconds, giving data rates around 800 to 100 samples/sec. This variation of data rates was partially caused by inconsistent flow seeding with the theatrical smoke. Another reason for the variation of data rates was the poor signal to noise ratio at various locations across the cylinder. The poor signal to noise ratios were caused by reflections of the laser beams off the cylinder wall. This was noticeable at locations near the wall and just past the center of the cylinder where the two beams were reflected off the cylinder wall at angles that returned near the probe volume. 


\section{Chapter 5: Presentation and Discussion of Results}

\subsection{Presentation of CTA Results}

Constant temperature anemometry (CTA) data has been acquired along radial traverses at $\mathrm{z} / \mathrm{R}=0,0.185,0.308,0.615$ and 1.231 for a valve lift of $4 \mathrm{~mm}$. The CTA axial/radial mean velocity measurements for the straight intake with $4 \mathrm{~mm}$ of lift show a conical jet after the valve (Figure 5.1). The jet impacts the cylinder wall at $25.4 \mathrm{~mm}$ (1 inch; $z / R=0.615)$ above the cylinder head. After contacting the wall, the jet continues along the wall. In the center of the cylinder, directly above the valve, a small velocity profile value can be observed. However, the direction of this flow cannot be determined due to the limitations of CTA equipment. The measured velocities in the jet range from approximately $14 \mathrm{~m} / \mathrm{s}$ very close to the valve to $10 \mathrm{~m} / \mathrm{s}$ just before reaching the cylinder wall. The flow velocities along the wall are approximately $8 \mathrm{~m} / \mathrm{s}$. The flow in the center of the cylinder has velocities ranging from 2 to $4 \mathrm{~m} / \mathrm{s}$, while velocities in the remaining locations of the cylinder are about $2 \mathrm{~m} / \mathrm{s}$. As seen in Figure 5.2, the standard deviations of the velocities are approximately $1 \mathrm{~m} / \mathrm{s}$ throughout the cylinder, except in the conical jet where the standard deviations are approximately $2.5 \mathrm{~m} / \mathrm{s}$. Asymmetries in the mean and standard deviation profiles are believed to be due to a slight asymmetry in the location of the valve.

Radial traverse locations were $\mathrm{z} / \mathrm{R}=0,0.308,0.615$ and 1.231 for the CTA data at a valve lift of $9 \mathrm{~mm}$. The CTA axial/radial mean velocity measurements for the straight intake with $9 \mathrm{~mm}$ of lift also show a conical jet after the valve (Figure 5.3). The jet 
impacts the cylinder wall at $25.4 \mathrm{~mm}(1 \mathrm{inch} ; \mathrm{z} / \mathrm{R}=0.615)$ above the cylinder head. After contacting the wall, the jet continues along the wall. Again, in the center of the cylinder, directly above the valve, a small velocity profile value can be observed. The velocities in the jet are approximately $8 \mathrm{~m} / \mathrm{s}$. The velocity of the flow along the wall is approximately $5 \mathrm{~m} / \mathrm{s}$. In the center of the cylinder, the velocities are near $3 \mathrm{~m} / \mathrm{s}$ and the velocities in the remaining parts of the cylinder are approximately $2 \mathrm{~m} / \mathrm{s}$. As seen in Figure 5.4, the standard deviation of the mean velocities for the $9 \mathrm{~mm}$ lift case are near 1 $\mathrm{m} / \mathrm{s}$ except in the jet where the standard deviations are between 2 and $3 \mathrm{~m} / \mathrm{s}$.

The CTA axial/radial mean velocity measurements for the swirl intake with $4 \mathrm{~mm}$ of lift form a conical jet after the valve (Figure 5.5). The jet impacts the cylinder wall at $25.4 \mathrm{~mm}(1 \mathrm{inch} ; \mathrm{z} / \mathrm{R}=0.615)$ above the cylinder head. Then the flow continues along the cylinder wall. As for the straight intake cases, a slight velocity profile value can be seen in the center of the cylinder above the valve. The velocities in the jet range from 12 $\mathrm{m} / \mathrm{s}$ near the valve to $8 \mathrm{~m} / \mathrm{s}$ farther away from the valve. Along the cylinder wall, the velocities are between 5 and $6 \mathrm{~m} / \mathrm{s}$. In the center of the cylinder, the velocities are near 3 $\mathrm{m} / \mathrm{s}$. In Figure 5.6, the standard deviations of the velocities for the swirl intake, $4 \mathrm{~mm}$ lift case, can be seen to be $1 \mathrm{~m} / \mathrm{s}$ except in the jet where the standard deviations are approximately 2 to $2.5 \mathrm{~m} / \mathrm{s}$.

The CTA axial/swirl mean velocity measurements for the swirl intake with $4 \mathrm{~mm}$ of lift form a conical jet after the valve (Figure 5.7). The jet impacts the cylinder wall at $25.4 \mathrm{~mm}(1$ inch; $\mathrm{z} / \mathrm{R}=0.615)$ above the cylinder head. Then the flow continues along the cylinder wall. As with the straight intake cases, a slight velocity profile value can be seen in the center of the cylinder above the valve. The velocities in the jet range from 12 
$\mathrm{m} / \mathrm{s}$ near the valve to $6 \mathrm{~m} / \mathrm{s}$ farther away from the valve. Along the cylinder wall, the velocities are approximately $6 \mathrm{~m} / \mathrm{s}$. In the center of the cylinder, the velocities are $2 \mathrm{~m} / \mathrm{s}$. In Figure 5.8, the standard deviations of the velocities for the swirl intake, $4 \mathrm{~mm}$ lift case, can be seen to be $1 \mathrm{~m} / \mathrm{s}$ except in the jet where the standard deviations are approximately $2.5 \mathrm{~m} / \mathrm{s}$.

The graphs of the CTA axial/radial and axial/swirl for $4 \mathrm{~mm}$ of valve lift show similar trends and values for both the mean velocities and standard deviations when compared to each other. This indicates that the axial velocity is the dominant flow.

The CTA axial/radial mean velocity measurements for the swirl intake with $9 \mathrm{~mm}$ of lift form a conical jet after the valve (Figure 5.9). The jet impacts the cylinder wall at $25.4 \mathrm{~mm}(1 \mathrm{inch} ; \mathrm{z} / \mathrm{R}=0.615)$ above the cylinder head. Then the flow continues along the cylinder wall. As in the previous cases, a slight velocity profile value can be seen in the center of the cylinder above the valve. The velocities in the jet range from 5 to $8 \mathrm{~m} / \mathrm{s}$. Along the cylinder wall, the velocities are approximately $5 \mathrm{~m} / \mathrm{s}$. In the center of the cylinder, the velocities are $2 \mathrm{~m} / \mathrm{s}$. In Figure 5.10, the standard deviations of the velocities for the swirl intake, $9 \mathrm{~mm}$ lift case, can be seen to be $1 \mathrm{~m} / \mathrm{s}$ except in the jet where the standard deviations are approximately $2.5 \mathrm{~m} / \mathrm{s}$.

The CTA axial/swirl mean velocity measurements for the swirl intake with $9 \mathrm{~mm}$ of lift form a conical jet after the valve (Figure 5.11). The jet impacts the cylinder wall at $25.4 \mathrm{~mm}(1 \mathrm{inch} ; \mathrm{z} / \mathrm{R}=0.615)$ above the cylinder head. Then the flow continues along the cylinder wall. As for the previous cases, a slight velocity profile value can be seen in the center of the cylinder above the valve. The velocities in the jet range from 5 to $7 \mathrm{~m} / \mathrm{s}$. Along the cylinder wall, the velocities are approximately $5 \mathrm{~m} / \mathrm{s}$. In the center of the 
cylinder, the velocities are $2 \mathrm{~m} / \mathrm{s}$. In Figure 5.12, the standard deviations of the velocities for the swirl intake, $9 \mathrm{~mm}$ lift case, can be seen to be $1 \mathrm{~m} / \mathrm{s}$ except in the jet where the standard deviations are approximately $2 \mathrm{~m} / \mathrm{s}$.

The graphs of the CTA axial/radial and axial/swirl for $9 \mathrm{~mm}$ of valve lift show similar trends and values for both the mean velocities and standard deviations when compared to each other. As with the case for $4 \mathrm{~mm}$ of valve lift, this indicates that the axial velocity is the dominant flow.

\subsection{Presentation of LDA Results}

Radial traverse locations were $\mathrm{z} / \mathrm{R}=0,0.185,0.308,0.615$ and 1.231 for the LDA data at a valve lift of $4 \mathrm{~mm}$, same as for the CTA results. The Laser Doppler Anemometry (LDA) axial mean velocity measurements for the straight intake with $4 \mathrm{~mm}$ of lift again indicate a conical jet after the valve (Figure 5.13). The jet impacts the wall at $25.4 \mathrm{~mm}(1 \mathrm{inch} ; \mathrm{z} / \mathrm{R}=0.615)$ above the cylinder head. Then the flow continues along the cylinder wall. As in the previous cases of CTA measurements, a slight velocity profile value can be seen in the center of the cylinder above the valve. Where the CTA can only show the velocity magnitude, the LDA can correctly show both velocity magnitude and direction, and above the valve, the LDA shows a flow down into the cylinder (negative values). The velocities in the jet range from 6 to $8 \mathrm{~m} / \mathrm{s}$. Along the cylinder wall, the velocities are approximately $5 \mathrm{~m} / \mathrm{s}$. In the center of the cylinder, the velocities are approximately $2 \mathrm{~m} / \mathrm{s}$ into the cylinder. In Figure 5.14, the standard deviations of the velocity for the straight intake, $4 \mathrm{~mm}$ lift case, can be seen to be $1 \mathrm{~m} / \mathrm{s}$ throughout the cylinder except in the jet where the standard deviations are $2.5 \mathrm{~m} / \mathrm{s}$. 
The LDA swirl mean velocity measurements for the straight intake with $4 \mathrm{~mm}$ of lift are all approximately $0 \mathrm{~m} / \mathrm{s}$ (Figure 5.15). The straight intake was not designed to create a flow in the swirl direction, only flow in the axial and radial directions. In Figure 5.16, the standard deviations of the velocity for the straight intake, $4 \mathrm{~mm}$ lift case, can be seen to be near $1 \mathrm{~m} / \mathrm{s}$ throughout the cylinder with a slight increase in the jet.

LDA data has been acquired along radial traverses at $\mathrm{z} / \mathrm{R}=0,0.308,0.615$ and 1.231 for a valve lift of $9 \mathrm{~mm}$. The LDA axial mean velocity measurements for the straight intake with $9 \mathrm{~mm}$ of lift form a conical jet after the valve (Figure 5.17). The jet impacts the wall at $25.4 \mathrm{~mm}(1 \mathrm{inch} ; \mathrm{z} / \mathrm{R}=0.615)$ above the cylinder head. As for the previous case of LDA axial measurements, a flow into the cylinder can be seen in the center of the cylinder above the valve. The velocities in the jet are approximately $7 \mathrm{~m} / \mathrm{s}$. Along the cylinder wall, the velocities are approximately $5 \mathrm{~m} / \mathrm{s}$. In the center of the cylinder, the velocities are approximately $2 \mathrm{~m} / \mathrm{s}$ into the cylinder (negative values). In Figure 5.18, the standard deviations of the velocity for the straight intake, $9 \mathrm{~mm}$ lift case, can be seen to be $1 \mathrm{~m} / \mathrm{s}$ except in the jet where the standard deviations are $2 \mathrm{~m} / \mathrm{s}$.

The LDA swirl mean velocity measurements for the straight intake with $9 \mathrm{~mm}$ of lift are all approximately $0 \mathrm{~m} / \mathrm{s}$ (Figure 5.19). The straight intake was designed to have flow in the axial and radial directions and was not designed to create a flow in the swirl direction. In Figure 5.20, the standard deviations of the velocity for the straight intake, 9 $\mathrm{mm}$ lift case, can be seen to be near $1 \mathrm{~m} / \mathrm{s}$ throughout the cylinder with a slight increase in the jet.

The LDA axial mean velocity measurements for the swirl intake with $4 \mathrm{~mm}$ of lift form a conical jet after the valve (Figure 5.21). The jet impacts the wall at $25.4 \mathrm{~mm}$ (1 
inch; $\mathrm{z} / \mathrm{R}=0.615$ ) above the cylinder head. As with the previous cases of LDA axial measurements, a flow into the cylinder can be seen in the center of the cylinder above the valve. The velocities in the jet are approximately $5 \mathrm{~m} / \mathrm{s}$. Along the cylinder wall, the velocities are approximately $5 \mathrm{~m} / \mathrm{s}$. In the center of the cylinder, the velocities are approximately $2 \mathrm{~m} / \mathrm{s}$ into the cylinder (negative values). In Figure 5.22, the standard deviations of the velocity for swirl intake, $4 \mathrm{~mm}$ case, can be seen to be $1 \mathrm{~m} / \mathrm{s}$ except in the jet where the standard deviations are $2.5 \mathrm{~m} / \mathrm{s}$.

The LDA swirl mean velocity measurements for the swirl intake with $4 \mathrm{~mm}$ of lift show a solid body rotation of the flow (Figure 5.23). The velocities range from approximately $\pm 2 \mathrm{~m} / \mathrm{s}$ near the cylinder wall linearly to $0 \mathrm{~m} / \mathrm{s}$ in the center of the cylinder. A small swirl jet can be seen as the flow passes the valve before it dissipates into solid body rotation; here the maximum swirl jet velocity is near $5 \mathrm{~m} / \mathrm{s}$. In Figure 5.24 , the standard deviations of the velocity for the swirl intake, $4 \mathrm{~mm}$ lift case, can be seen to be $1 \mathrm{~m} / \mathrm{s}$ throughout the cylinder with a slight increase to about $2 \mathrm{~m} / \mathrm{s}$ in the jet.

The LDA axial mean velocity measurements for the swirl intake with $9 \mathrm{~mm}$ of lift form a conical jet after the valve (Figure 5.25). The jet impacts the wall at $25.4 \mathrm{~mm}$ (1 inch; $z / R=0.615$ ) above the cylinder head. As in the previous cases of LDA axial measurements, a flow into the cylinder can be seen in the center of the cylinder above the valve. The velocities in the jet are approximately $3 \mathrm{~m} / \mathrm{s}$. Along the cylinder wall, the velocities are approximately $2 \mathrm{~m} / \mathrm{s}$. In the center of the cylinder, the velocities are approximately $1 \mathrm{~m} / \mathrm{s}$ into the cylinder (negative values). In Figure 5.26, the standard deviations of the velocity for swirl intake, $4 \mathrm{~mm}$ case, can be seen to be $1 \mathrm{~m} / \mathrm{s}$ except in the jet where the standard deviations are $2 \mathrm{~m} / \mathrm{s}$. 
The LDA swirl mean velocity measurements for the swirl intake with $4 \mathrm{~mm}$ of lift again show a solid body rotation of the flow (Figure 5.27). The velocities range from approximately $\pm 2 \mathrm{~m} / \mathrm{s}$ near the cylinder wall linearly to $0 \mathrm{~m} / \mathrm{s}$ in the center of the cylinder. A small swirl jet can be seen as the flow passes the valve before it dissipates into solid body rotation, here the maximum swirl jet velocity is again near $5 \mathrm{~m} / \mathrm{s}$. In Figure 5.28, the standard deviations of the velocity for the swirl intake, $4 \mathrm{~mm}$ lift case, can be seen to be $1 \mathrm{~m} / \mathrm{s}$ throughout the cylinder with a slight increase in the jet.

Comparing the axial mean velocities with the results in Stier and Koochesfahani (1998) show similar flow patterns. In both studies, a conical jet can be seen after the valve. The jet impacts the wall at about $25.4 \mathrm{~mm}(1 \mathrm{inch})$ above the cylinder head and continues up the cylinder wall for both studies. A returning flow into the cylinder above the valve can also be seen in both studies. In Stier and Koochesfahani a vortex region in the corner of the cylinder between the cylinder head and cylinder wall is easily seen in the data. In this study, evidence of that vortex region is seen in the negative LDA velocities for the lower traverse measurements in that corner.

\subsection{Comparison of LDA to CTA Data}

A conical jet forming at the valve and impacting the cylinder wall at approximately $25.4 \mathrm{~mm}(1 \mathrm{inch} ; \mathrm{z} / \mathrm{R}=0.615)$ above the cylinder head can be seen for all LDA and CTA measurements. A lower velocity flow can be seen for all LDA and CTA measurements above the valve in the center of the cylinder. Both LDA and CTA measurements, for each case, show somewhat similar trends at each radial position for each axial location. However, the most basic difference between the LDA and CTA results is that the LDA data indicates a downward flow above the valve. 
Above the valve, the LDA axial mean velocity measurements for the straight intake with $4 \mathrm{~mm}$ of lift shows a negative velocity, or a flow into the cylinder, while CTA axial/radial mean velocity measurements only show a positive velocity (Figure 5.29). Differences in the values between LDA and CTA measurements can be explained by the limitations of CTA equipment. CTA can only measure the magnitude of the flow velocity and not the flow direction, thus CTA measurements are always positive. LDA, when fitted with a Bragg cell, can detect flow direction. In the conical jet, the CTA measurements show higher velocities than the LDA measurements. LDA can only measure one component of the flow velocity, axial in this case, while CTA responds somewhat to all velocities perpendicular to the wire of the probe, axial and radial in this case.

As seen for $4 \mathrm{~mm}$ of lift, the LDA axial mean velocity measurements for the straight intake with $9 \mathrm{~mm}$ of lift show similar trends to the CTA axial/radial mean velocity measurements (Figure 5.30). Again, the differences between LDA and CTA measurements above the valve can be explained by the limitation of CTA equipment being unable to detect flow reversals. Also, the difference in the conical jet can be explained by the LDA only measuring one component of velocity, axial in this case, and CTA being sensitive to two components of velocity, axial and radial in this case.

The LDA axial mean velocities show similar trends as the CTA axial/radial mean velocities for the swirl intake with $4 \mathrm{~mm}$ of valve lift (Figure 5.31). The differences between LDA and CTA measurements above the valve can again be explained by the limitation of CTA equipment being unable to properly respond to the flow reversals. Also, the differences in the conical jet can again be explained by the LDA only 
measuring one component of velocity, axial in this case, and CTA being sensitive to two components of velocity, axial and radial in this case.

The LDA swirl mean velocities show similar trends as the CTA axial/swirl mean velocities for the swirl intake with $4 \mathrm{~mm}$ of valve lift (Figure 5.32), at least in the jet region near to the valve. As before, the differences between LDA and CTA measurements throughout the cylinder can be attributed to the LDA only measuring one component of velocity, swirl in this case, and the CTA measuring two components of velocity, axial and swirl in this case. The negative velocities for the LDA measurements on the right side of the figure can be explained by the orientation of the LDA system and direction of the flow. The LDA system measures velocities as positive when crossing the probe volume in one direction, as the left side of the figure. After crossing the center of the cylinder, the swirl flow is moving in the opposite direction relative to the probe volume and is detected as a negative flow velocity. The LDA swirl velocity measurements clearly indicate a nearly solid body rotation motion in the cylinder above the jet region.

Near the valve, the LDA axial mean velocities show similar trends as the CTA axial/radial mean velocities for the swirl intake with $9 \mathrm{~mm}$ of valve lift (Figure 5.33). The differences between LDA and CTA measurements above the valve can again be explained by the limitation of CTA equipment only able to measure the magnitude of the velocity, where the LDA results clearly indicate flow reversal above the valve. Also, the differences in the conical jet can again be explained by the LDA only measuring one component of velocity, axial in this case, and CTA measuring two components of velocity, axial and radial in this case. 
Near the valve, the LDA swirl mean velocities show similar trends as the CTA axial/swirl mean velocities for the swirl intake with $9 \mathrm{~mm}$ of valve lift (Figure 5.34). As before, the differences between LDA and CTA measurements throughout the cylinder can be attributed to the LDA only measuring one component of velocity, swirl in this case, and the CTA measuring two components of velocity, axial and swirl in this case. The negative velocities for the LDA measurements on the right side of the figure can again be explained by the orientation of the LDA system and direction of the flow. As for the $4 \mathrm{~mm}$ valve lift case, the LDA results indicate a solid body rotation in the upper portion of the cylinder, as well as indicating that the conical jet is asymmetric.

The comparison of standard deviation of axial velocity for LDA measurements to standard deviation of axial/radial velocity for CTA measurements for the straight intake with $4 \mathrm{~mm}$ of lift shows similar results (Figure 5.35). Throughout most of the cylinder, the standard deviations between LDA and CTA measurements match very well. Only in the conical jet do some of the standard deviations differ significantly. Similarly, the standard deviations for the straight intake with $9 \mathrm{~mm}$ of lift match very well between LDA and CTA except for in the conical jet (Figure 5.36).

The standard deviations of axial velocities for LDA measurements for the swirl intake with $4 \mathrm{~mm}$ of lift are very similar to the standard deviations of axial/radial velocities for CTA measurements (Figure 5.37). Throughout most of the cylinder, the standard deviations between LDA and CTA measurements match very well except in the conical jet. This same trend can also be seen in the comparison between the standard deviations of swirl velocities for LDA measurements and the standard deviations of 
axial/swirl velocities of CTA measurements for swirl intake with $4 \mathrm{~mm}$ of valve lift (Figure 5.38).

The standard deviations of axial velocities for LDA measurements for the swirl intake with $9 \mathrm{~mm}$ of valve lift are very similar to the standard deviations of axial/radial velocities for CTA measurements (Figure 5.39). Throughout most of the cylinder, the standard deviations between LDA and CTA measurements match very well except in the conical jet. This same trend can be seen in the comparison between the standard deviations of swirl velocities for LDA measurements and the standard deviations of axial/swirl velocities of CTA measurements for the swirl intake with $9 \mathrm{~mm}$ of valve lift (Figure 5.40).

\subsection{LDA Absolute Instantaneous Velocity Compared with CTA}

The CTA equipment can only measure the magnitude of the flow velocity while the LDA, with a Bragg cell, can properly measure both flow velocity and direction of the flow. In an effort to simulate the CTA response, the absolute value of each instantaneous LDA velocity measurement has been used to calculate mean velocity and standard deviation of velocity. By taking the absolute value of the instantaneous LDA data, only the magnitude of the velocity is available, like the CTA measurements.

After computing statistics using the absolute values of the LDA instantaneous velocity data, the LDA axial mean velocities for the straight intake with $4 \mathrm{~mm}$ of valve lift matches the CTA axial/radial mean velocities very well throughout most of the cylinder (Figure 5.41). The only areas with discrepancy between LDA and CTA velocities are in the conical jet. This can be explained by the LDA only measuring one component of velocity, axial in this case, and CTA being sensitive to two components of 
velocity, axial and radial in this case. These same trends can be seen when comparing absolute instantaneous LDA axial mean velocities for the straight intake with $9 \mathrm{~mm}$ of valve lift to the CTA axial/radial mean velocities (Figure 5.42).

As seen with the straight intake, the absolute instantaneous LDA axial mean velocities for the swirl intake with $4 \mathrm{~mm}$ of valve lift match very well with the CTA axial/radial mean velocities throughout most of the cylinder (Figure 5.43). The only areas where the LDA and CTA do not agree are again in the conical jet. The absolute instantaneous LDA swirl mean velocities for the swirl intake with $4 \mathrm{~mm}$ of valve lift do not agree very well with the CTA axial/swirl mean velocities (Figure 5.44). The velocities are somewhat close throughout most of the cylinder with the larger differences occurring in the conical jet. The differences between LDA and CTA velocities can again be explained by the LDA only measuring one component of velocity, swirl in this case, and the CTA measuring two components of velocity, axial and swirl in this case.

As seen with the previous cases which measured axial velocities, the absolute instantaneous LDA axial mean velocities for the swirl intake with $9 \mathrm{~mm}$ of valve lift match very well with the CTA axial/radial mean velocities throughout most of the cylinder (Figure 5.45). The only areas where the LDA and CTA do not agree are again in the conical jet. The absolute instantaneous LDA swirl mean velocities for the swirl intake with $9 \mathrm{~mm}$ of valve lift do not agree very well with the CTA axial/swirl mean velocities (Figure 5.46). The velocities are somewhat close throughout most of the cylinder with the larger differences occurring in the conical jet. The differences between the LDA and CTA velocities can again be explained by the LDA only measuring one 
component of velocity, swirl in this case, and the CTA measuring two components of velocity, axial and swirl in this case.

The comparison of absolute instantaneous standard deviation of axial velocity for LDA measurements to standard deviation of axial/radial velocity for CTA measurements for the straight intake with $4 \mathrm{~mm}$ of lift shows similar results (Figure 5.47). Throughout most of the cylinder, the standard deviations between LDA and CTA measurements match very well. Only in the conical jet do some of the standard deviations differ significantly. Similarly, the absolute instantaneous standard deviations for the straight intake with $9 \mathrm{~mm}$ of lift match very well between LDA and CTA except for in the conical jet (Figure 5.48).

The absolute instantaneous standard deviations of axial velocities for LDA measurements for the swirl intake with $4 \mathrm{~mm}$ of lift are very similar to the standard deviations of axial/radial velocities for CTA measurements (Figure 5.49). Throughout most of the cylinder, the standard deviations between LDA and CTA measurements match very well except in the conical jet. This same trend can also be seen in the comparison between the absolute instantaneous standard deviations of swirl velocities for LDA measurements and the standard deviations of axial/swirl velocities of CTA measurements for swirl intake with $4 \mathrm{~mm}$ of valve lift (Figure 5.50), although agreement here is not as good as with the axial velocity results.

The absolute instantaneous standard deviations of axial velocities for LDA measurements for the swirl intake with $9 \mathrm{~mm}$ of valve lift are very similar to the standard deviations of axial/radial velocities for CTA measurements (Figure 5.51). Throughout most of the cylinder, the standard deviations between LDA and CTA measurements 
match very well except in the conical jet. This same trend can be seen in the comparison between the absolute instantaneous standard deviations of swirl velocities for LDA measurements and the standard deviations of axial/swirl velocities of CTA measurements for the swirl intake with $9 \mathrm{~mm}$ of valve lift (Figure 5.52).

\subsection{Integral Time Scales and Integral Length Scales for CTA Data}

The integral time scales and integral length scales were calculated for the CTA data for both swirl and straight intakes with valve lifts of $4 \mathrm{~mm}$ and $9 \mathrm{~mm}$. The time and length scales were calculated for 5 radial locations $(r / R=-0.909,-0.697,-0.015,0.667$, and 0.969 for the straight intake and $r / R=-0.918,-0.681,0,0.681$, and 0.955 for the swirl intake) at each axial position. Some of these results have been presented in Ayala and Bailey (2000).

The integral time scales and integral length scales for the CTA data were calculated using the autocorrelation coefficient, $\mathrm{R}_{\mathrm{uu}}$.

$$
R_{u u}(x)=\frac{\frac{1}{(N-x+1)} \sum_{i=1}^{(N-x+1)}\left(u_{f l u c t, i} * u_{f l u c t,(i+x-1)}\right)}{\left(u_{R M S}\right)^{2}}
$$

For the calculation of the autocorrelation coefficient, $\mathrm{N}$ is the number of instantaneous velocity samples, $\mathrm{x}$ is the time distance (in number of samples) between velocities compared, and $\mathrm{u}_{\mathrm{fluct}}$ is the difference between the instantaneous velocity and the mean velocity. The integral time scale, $\Lambda_{\tau}$, was then calculated by integrating the autocorrelation coefficient.

$$
\Lambda_{\tau}=\int_{0}^{\tau} R_{u u}(\tau) d \tau
$$


For the calculation of the integral time scale, $\tau$ is the time difference (in seconds) between velocities compared. By integrating, the integral time scale is equal to the area under the autocorrelation coefficient curve. Generally, only the first positive area under the curve is used, assuming the negative areas will cancel the remaining positive areas. The integral length scale, $\Lambda$, was then calculated from the integral time scale.

$$
\Lambda=u_{R M S} * \Lambda_{\tau}
$$

The integral time scales for the straight intake with $4 \mathrm{~mm}$ of lift show a decrease as the flow passes the valve, then an increase after the valve (Figure 5.53). The measurement points at the outer radial positions $(r / R=-0.909$ and 0.969$)$ have time scales that match each other relatively well at all axial locations. The measurement points at radial locations just outside of the valve radius $(r / R=-0.697$ and 0.667$)$ have time scales that match each other relatively well at axial locations at and below the valve, and then differentiate above the valve. The measurement points in the center of the cylinder $(\mathrm{r} / \mathrm{R}=$ -0.015) have a time scale of $7 \mathrm{~ms}$ just above the valve and $6 \mathrm{~ms}$ at the other axial locations.

As seen for the $4 \mathrm{~mm}$ valve lift, the integral time scales for the straight intake with $9 \mathrm{~mm}$ of lift show a decrease as the flow passes the valve, then an increase after the valve (Figure 5.54). The measurement points at the outer radial positions $(\mathrm{r} / \mathrm{R}=-0.909$ and 0.969) have time scales that match each other relatively well at all axial locations. The measurement points at radial locations just outside of the valve radius $(r / R=-0.697$ and 0.667) have time scales that match each other relatively well at axial locations at and below the valve, and then differ significantly above the valve. The measurement points 
in the center of the cylinder $(\mathrm{r} / \mathrm{R}=-0.015)$ have a time scale of $8 \mathrm{~ms}$ just above the valve and $6 \mathrm{~ms}$ and $7 \mathrm{~ms}$ at the other axial locations.

As seen for the straight intake, the integral time scales for the swirl intake with 4 $\mathrm{mm}$ of lift show a decrease as the flow passes the valve, then an increase after the valve (Figure 5.55). For the swirl intake, two velocity measurements were recorded for each position, one with the CTA probe turned to measure axial and radial velocities and the other with the probe turned to measure axial and swirl velocities. The measurement points at the outer radial positions $(\mathrm{r} / \mathrm{R}=-0.918$ and 0.955$)$ have time scales that match each other relatively well at all axial locations and both probe positions. The measurement points at radial locations just outside of the valve radius $(\mathrm{r} / \mathrm{R}=-0.681$ and 0.681) have time scales that match each other relatively well at all axial locations and both probe positions. The measurement points in the center of the cylinder $(r / R=0)$ have time scales that match each other relatively well for both probe positions.

As seen for the $4 \mathrm{~mm}$ valve lift, the integral time scales for the swirl intake with 9 $\mathrm{mm}$ of lift show a decrease as the flow passes the valve, then an increase after the valve (Figure 5.56). The measurement points at the outer radial positions $(\mathrm{r} / \mathrm{R}=-0.918$ and 0.955) have time scales that match each other relatively well at the lower axial locations and slightly differentiate at the highest axial location. Both outer radial location matches relatively well for both probe positions. The measurement points at radial locations just outside of the valve radius $(\mathrm{r} / \mathrm{R}=-0.681$ and 0.681$)$ have time scales that match each other relatively well at the lower axial locations and differ slightly at the higher axial locations. The time scales for the axial/swirl measurements are slightly higher than the axial/radial measurements at the higher axial locations. The measurement points in the 
center of the cylinder $(r / R=0)$ have time scales that are relatively constant at each axial location, but with the axial/swirl velocities having a $3 \mathrm{~ms}$ larger time scale than the axial/radial velocities.

The integral length scales for the straight intake with $4 \mathrm{~mm}$ of lift show a decrease as the flow passes the valve, then an increase after the valve (Figure 5.57). The measurement points at the outer radial positions $(r / R=-0.909$ and 0.969$)$ have length scales that do not match each other relatively well at any axial location except the highest axial location, but are within $0.05 \Lambda / \mathrm{R}$ of each other. The measurement points at radial locations just outside of the valve radius $(r / R=-0.697$ and 0.667$)$ have length scales that are within $0.05 \Lambda / \mathrm{R}$ of each other at axial locations at and below the valve, and then differ significantly above the valve. The measurement points in the center of the cylinder $(\mathrm{r} / \mathrm{R}=-0.015)$ have a length scale near $0.1 \Lambda / \mathrm{R}$ at all axial locations.

As seen for the $4 \mathrm{~mm}$ valve lift, the integral length scales for the straight intake with $9 \mathrm{~mm}$ of lift show a decrease as the flow passes the valve, then an increase after the valve (Figure 5.58). The measurement points at the outer radial positions $(\mathrm{r} / \mathrm{R}=-0.909$ and 0.969) have time scales that do not match each other relatively well at the lower axial locations, but are within $0.05 \Lambda / \mathrm{R}$ of each other. The measurement points at radial locations just outside of the valve radius $(r / R=-0.697$ and 0.667$)$ have length scales that match each other relatively well at axial locations at and below the valve, and then differ significantly above the valve. The measurement points in the center of the cylinder $(\mathrm{r} / \mathrm{R}$ $=-0.015)$ have a length scale near $0.1 \Lambda / R$ at all axial locations.

As seen for the straight intake, the integral length scales for the swirl intake with 4 $\mathrm{mm}$ of lift show a decrease as the flow passes the valve, then an increase after the valve 
(Figure 5.59). For the swirl intake, two velocity measurements were recorded for each position, one with the CTA probe turned to measure axial and radial velocities and the other with the probe turned to measure axial and swirl velocities. The measurement points at the outer radial positions $(r / R=-0.918$ and 0.955$)$ have length scales that match each other relatively well at the higher axial locations and both probe positions and differ slightly at the lower axial locations. The measurement points at radial locations just outside of the valve radius $(r / R=-0.681$ and 0.681$)$ have length scales that match each other relatively well at all axial locations and both probe positions. The measurement points in the center of the cylinder $(r / R=0)$ have length scales that match each other relatively well for both probe positions.

As seen for the $4 \mathrm{~mm}$ valve lift, the integral length scales for the swirl intake with $9 \mathrm{~mm}$ of lift show a decrease as the flow passes the valve, then an increase after the valve (Figure 5.60). The measurement points at the outer radial positions $(\mathrm{r} / \mathrm{R}=-0.918$ and 0.955) have length scales that match each other relatively well at the lower axial locations and slightly differentiate at the highest axial location. Both outer radial location matches relatively well for both probe positions. The measurement points at radial locations just outside of the valve radius $(r / R=-0.681$ and 0.681$)$ have length scales that match each other relatively well at all axial locations when comparing both radial positions for the same probe position. The length scales for the axial/swirl measurements are slightly higher than the axial/radial measurements at the higher axial locations. The measurement points in the center of the cylinder $(r / R=0)$ have time scales that are relatively constant at each axial location, but with the axial/swirl velocities having a $0.05 \Lambda / \mathrm{R}$ larger length scale than the axial/radial velocities. 
Integral length and integral time scales were calculated for the CTA data and not the LDA data. Both the integral length and integral time scales were calculated using the autocorrelation coefficient. The autocorrelation coefficient was a function of the time between measurements in a time sample. The CTA data was sampled at a constant frequency and the time between measurements was known. LDA data was recorded as a seeding particle passed through the probe volume and was random, thus the time between measurements was unknown.

The integral time scale for each intake and valve lift was relatively constant along the centerline of the cylinder for all axial locations. The radial locations near the wall generally had the lowest time scales of about $2 \mathrm{~ms}$ for the straight intake and $1 \mathrm{~ms}$ for the swirl intake. The time scales are minimum at axial locations just past the valve for each intake at both valve lifts, for the radial locations located just outside of the valve and near the wall. These minimum time scales correspond to the positions in the jet and vortex in the corner of the cylinder. The time scales were generally constant along the axis above the valve for each radial location. The time scales for the swirl intake were generally somewhat lower than the time scales for the straight intake, at corresponding locations.

The integral length scales along the centerline for the straight intake were relatively constant at a value of about $10 \%$ of the cylinder radius. The length scales for the swirl intake along the centerline were between $10 \%$ and $15 \%$ of the cylinder radius. For all cases, the length scales were relatively constant along the axis above the valve for each radial location. The length scales for locations outside of the valve and near the wall were between $3 \%$ and $25 \%$ of the cylinder radius for the straight intake. The length scales for the swirl intake at radial locations outside of the valve and near the wall were 
between $3 \%$ and $7 \%$ of the cylinder radius. The length scales were minimum at an axial location just above the valve for radial locations just outside of the valve and near the wall. These minimum length scales correspond to the measurements taken in the jet. Again, the integral length scales were somewhat smaller for the swirl results than for the straight intake cases.

\subsection{Error Estimation}

\subsubsection{Velocity Error}

An estimate of the error for the LDA velocities was calculated using formulas from Bendat and Piersol (1966). Using an estimate of the signal bandwidth on the order of $10^{2}$ to $10^{4} \mathrm{~s}^{-1}$ and a sample time between 10 and 60 seconds, the standard error could be estimated. Using a normalizing factor on the order of 0.5 to 1 , the normalized standard error could be estimated. The normalized standard error was calculated to be as high as $3 \%$. Actual uncertainty is expected to be somewhat larger for some traverse locations, due to noise in the data due to the Bragg cell and reflections off of the cylinder.

\subsubsection{LDA Probe Volume Position Error}

Light is refracted as it passes through one medium to another; this is also true for laser light. As the light is refracted, its path is altered. In the case for LDA measurements, as the path of the two beams are changed, so is the position of the probe volume. The amount of translation of the probe volume from the expected position caused by the laser beams passing through the acrylic cylinder was calculated by using a formula from Durst et al. (1981).

Measuring the axial velocities in the cylinder placed the two laser beams on a flat plane of the cylinder. At any point across the diameter of the cylinder, the probe volume 
was displaced about $1 \mathrm{~mm}$ away from the LDA optics. This is about a $1 \%$ error relative to the diameter of the cylinder.

Measuring the swirl velocities in the cylinder placed the two laser beams on a curved arc of the cylinder. As the probe volume traversed across the cylinder, the laser beams contacted the cylinder at different angles due to the curvature of the cylinder. This caused the amount of translation to be different at every point across the cylinder. The amount of translation was calculated at the two measurement points closest to the cylinder wall (far and near) and the center of the cylinder. For each calculation, the cylinder was assumed to be flat in the vicinity of the point of contact where the laser beams passed. At both outer locations, the probe volume moved about $1 \mathrm{~mm}$ towards the center of the cylinder. At the center of the cylinder, the probe volume did not move due to the laser beams passing perpendicular through the cylinder wall. This is about a maximum of a $1 \%$ error relative to the diameter of the cylinder. 


\section{Chapter 6: Conclusion}

The mean velocity figures for all cases show the presence of a conical jet after the valve. The conical jet flows past the valve and impacts the wall at approximately 25.4 mm (1 inch; $\mathrm{z} / \mathrm{R}=0.615)$ above the cylinder head. After impacting the wall, the flow continues up the cylinder wall and out of the test cylinder, with a weaker recirculating return flow above the valve.

The fast flow from under the valve pulls air from above the valve into the conical jet. This air is from the jet along the wall at the end of the test cylinder. Air from the jet at the end of the cylinder is pulled back into the cylinder through the center of the cylinder, creating a recirculating flow.

Comparing the CTA and LDA results provided similar trends. Major differences were in the area that the LDA showed negative flow velocities (flow down into the cylinder) above the valve. This can be explained by the CTA not being able to detect flow direction, but only the approximate magnitude of the velocity. To demonstrate this, the absolute values of the measured LDA instantaneous velocities were also used and compared to CTA results. Using the absolute values for the instantaneous LDA data and comparing to CTA provided results that matched reasonably well throughout all the measurement locations.

Many measurement locations may contain flow reversals, where the flow changes direction over time (both positive and negative velocity values in the same sample). These negative values must be used to correctly calculate the mean and standard deviation velocities (LDA data). The CTA cannot detect the direction (or negative values) and if flow reversals are present, these data cannot give the correct mean and 
standard deviations velocities. Also, the mean and standard deviation velocities calculated with absolute instantaneous LDA data cannot give correct calculations if flow reversals are present.

A laser light sheet, with theatrical smoke, was setup in the axial/radial plane and was used to visually inspect the flow pattern. The laser light sheet was used with the swirl intake with $4 \mathrm{~mm}$ of valve lift. This flow visualization confirmed the overall flow structure as a trapped, toroidal vortex with an upward flow along the cylinder wall and a weaker, turbulent down flow in the center of the cylinder.

The normalized standard error for the LDA measured velocities was calculated to be as high as $3 \%$. Actual uncertainty is expected to be somewhat larger, due to noise in the data due to the Bragg cell and reflections off of the cylinder wall at some locations. The error in the position of the LDA probe volume due to optical translation was $1 \%$ for the axial velocity measurements. For the swirl velocity measurements, the error was a maximum of $1 \%$ near the wall and decreasing along the radius to $0 \%$ at the center of the cylinder.

Comparison of the standard deviation results provided similar results between like cases for both CTA and LDA measurements. Even though the standard deviations were similar between CTA and LDA, only the LDA measurement technique gave truly useful results. This is a result of the LDA being able to properly sense flow reversals, which the CTA could not, and using the reversal velocities to properly calculate the mean velocities and standard deviations.

Axial/radial standard deviation results for the straight intake for the CTA were similar for both 4 and $9 \mathrm{~mm}$ of lift. The axial/radial standard deviation calculations were 
similar between 4 and $9 \mathrm{~mm}$ of lift for the swirl intake for the CTA. Likewise, the axial/swirl standard deviation results for the swirl intake for the CTA were similar between 4 and $9 \mathrm{~mm}$ of lift. Comparing the axial/radial standard deviation results for 4 $\mathrm{mm}$ of lift for both straight and swirl intakes showed similar results. The comparison for $9 \mathrm{~mm}$ of lift also showed similar results between the two intake geometries.

Standard deviation results were also compared for the LDA data. The standard deviations were similar between 4 and $9 \mathrm{~mm}$ of lift for each case: axial measurements for straight intake, swirl measurements for straight intake, axial measurements for swirl intake, and swirl measurements for swirl intake. The standard deviation calculations were also similar between straight and swirl intakes for each case: axial measurements for $4 \mathrm{~mm}$ of lift, swirl measurements for $4 \mathrm{~mm}$ of lift, axial measurements for $9 \mathrm{~mm}$ of lift, and swirl measurements for $9 \mathrm{~mm}$ of lift.

The integral time and length scales were both relatively constant for each case along the centerline. For the radial locations just outside of the valve and near the wall, the integral time and length scales were constant along the axis above the valve. Both the integral time and length scales were smaller for the swirl intake than for the straight intake. Both the integral time and length scales had minimums just above the valve, corresponding to the measurements in the jet. 


\section{Chapter 7: Recommendations}

In an attempt to better visualize and map the flow patterns, a smaller measurement grid spacing should be used in both the axial and radial directions with the LDA system. A system that would allow measurement of a whole plane at once, such as a particle image velocimetry (PIV) system, would provide better visualization and allow study of any large-scale or coherent structures in the flow.

A test cylinder with more realistic geometry (i.e., the intake valve off center) would produce more realistic results. Using a cylinder with moving intake valve and piston would further mimic true conditions in an internal combustion engine.

Improving the optical access and optical quality into the test cylinder would improve the data produced by increasing the signal to noise ratio. Using high quality optical glass for the cylinder wall would improve the clarity and reduce the diffusion of the laser beams. An anti-reflective coating would reduce the reflected beams into the probe volume and receiving optics.

Using a multiple component LDA system (2- or 3- component), would allow the measurement of two velocity components simultaneously.

Comparing the LDA data to computational fluid dynamic (CFD) simulations for the same conditions would validate both the CFD simulations and accuracy of the LDA data. 


\section{References}

- Auriemma, M., Corcione, F., Macchioni, R. and Valentino, G., 1998, "Interpretation of Air Motion in Reentrant Bowl in-Piston Engine by Estimating Reynolds Stresses," SAE International Congress and Exposition, Michigan.

- Ayala, A. and Bailey, G., 2000, "In-Cylinder Measurements of Intake-Generated Turbulence in a Steady Flow Rig," ASME 2000 Fall Technical Conference, Illinois.

- Bendat, J. and Piersol, A., 1966, Measurement and Analysis of Random Data, John Wiley and Sons, Inc., New York.

- Bicen, A., Vafidis, C. and Whitelaw, J., 1985, "Steady and Unsteady Airflow Through the Intake Valve of a Reciprocating Engine," Journal of Fluids Engineering, Vol. 107.

- Corcione, F. and Valentino, G., 1991, "Characterization of Fluid-Dynamic Behavior of Diesel Engines by LDA Technique," ASME Laser Anemometry Volume 1.

- Durst, F., Melling, A. and Whitelaw, J., 1981, Principles and Practice of LaserDoppler Anemometry, Academic Press, New York.

- Heywood, J., 1987, "Fluid Motion Within the Cylinder of Internal Combustion Engines - The 1986 Freeman Scholar Lecture," Journal of Fluids Engineering, Vol. 109.

- Stier, B. and Koochesfahani, M., 1998, "Whole Field MTV Measurements in a Steady Flow Rig Model of an IC Engine," SAE International Congress and Exposition, Michigan. 


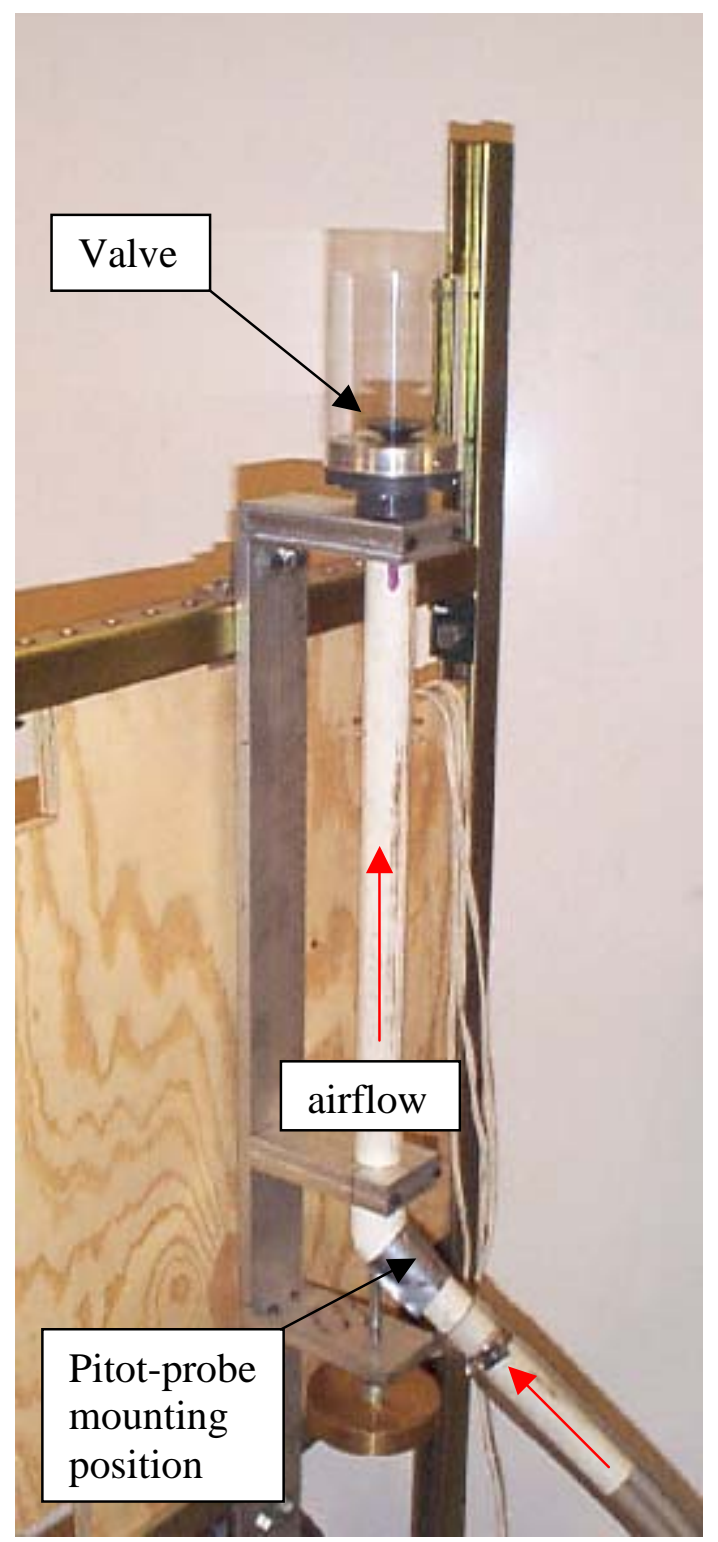

Figure 3.1: Straight intake test apparatus (close-up view)

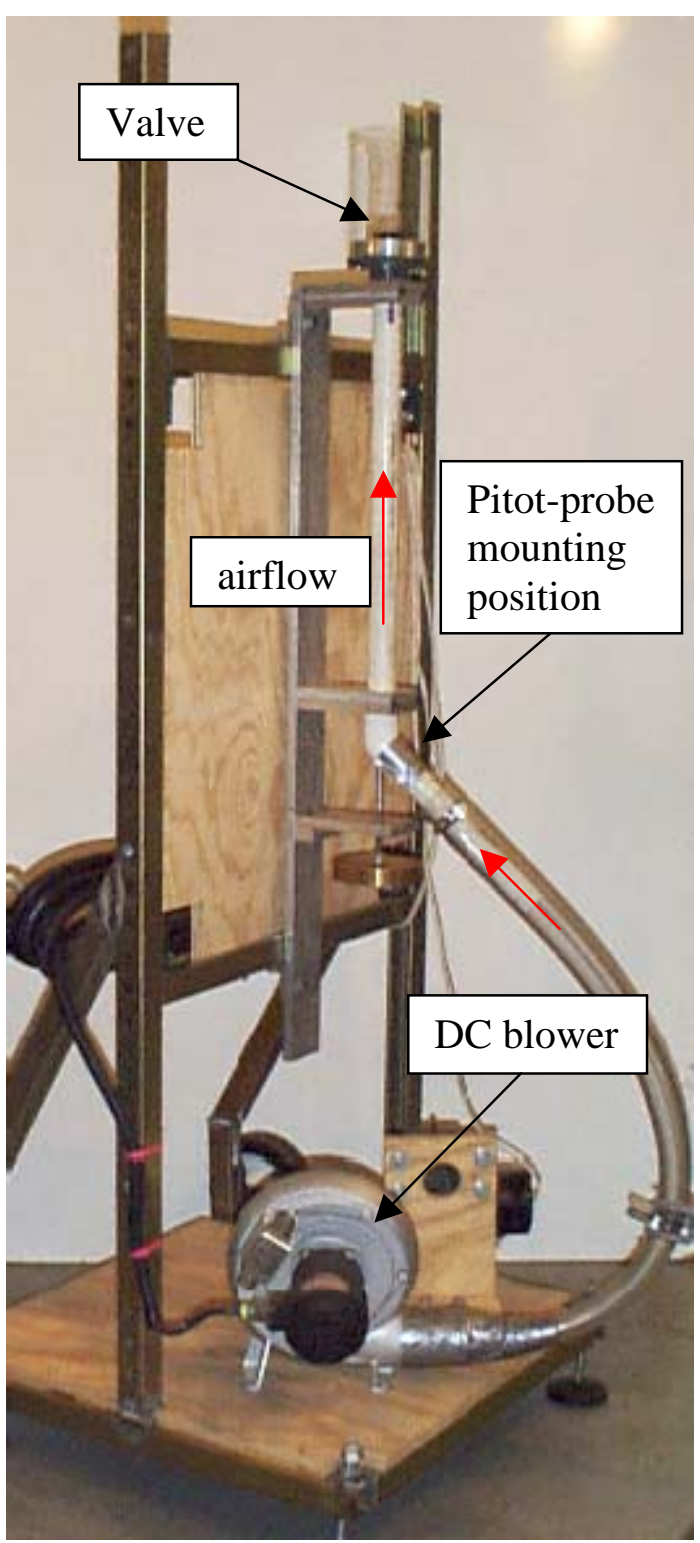

Figure 3.2: Straight intake test apparatus (full view) 


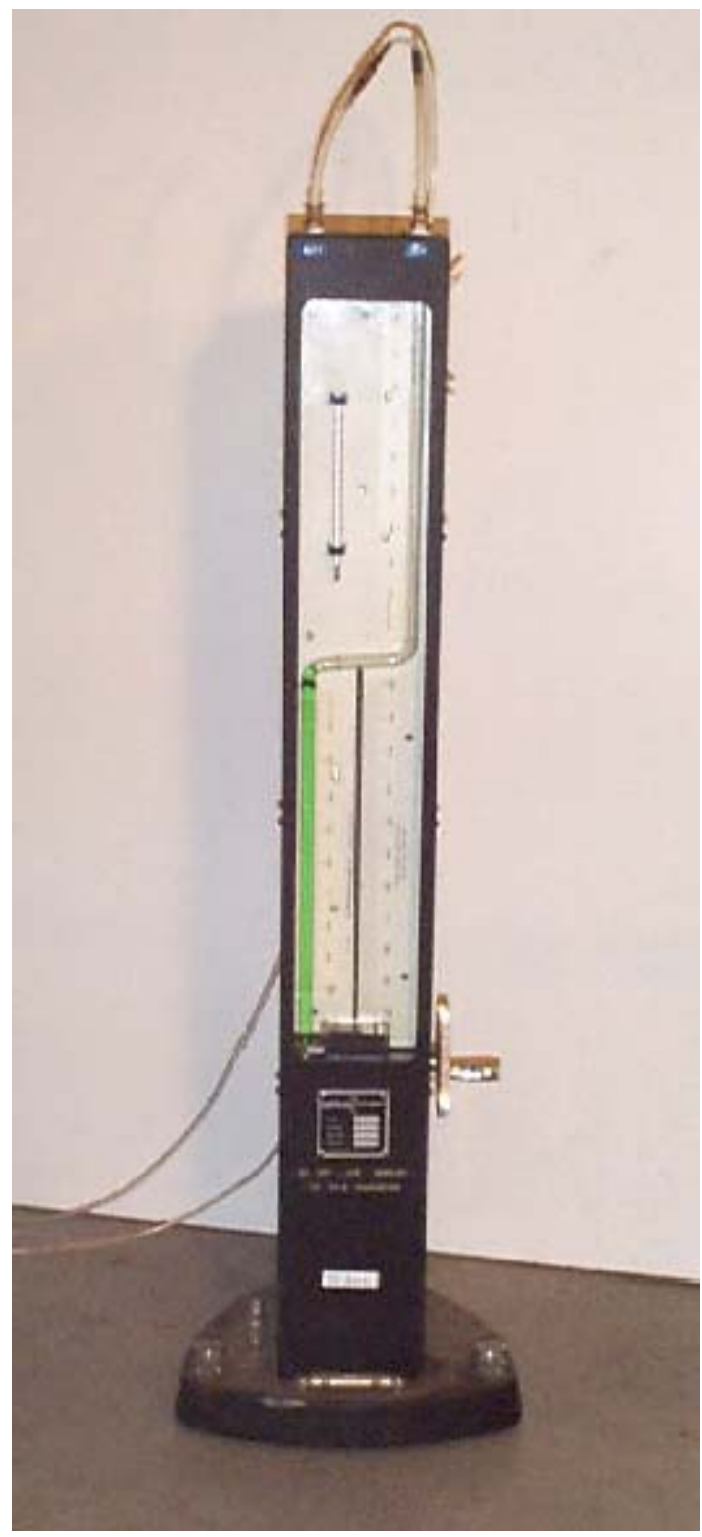

Figure 3.3: Micromanometer

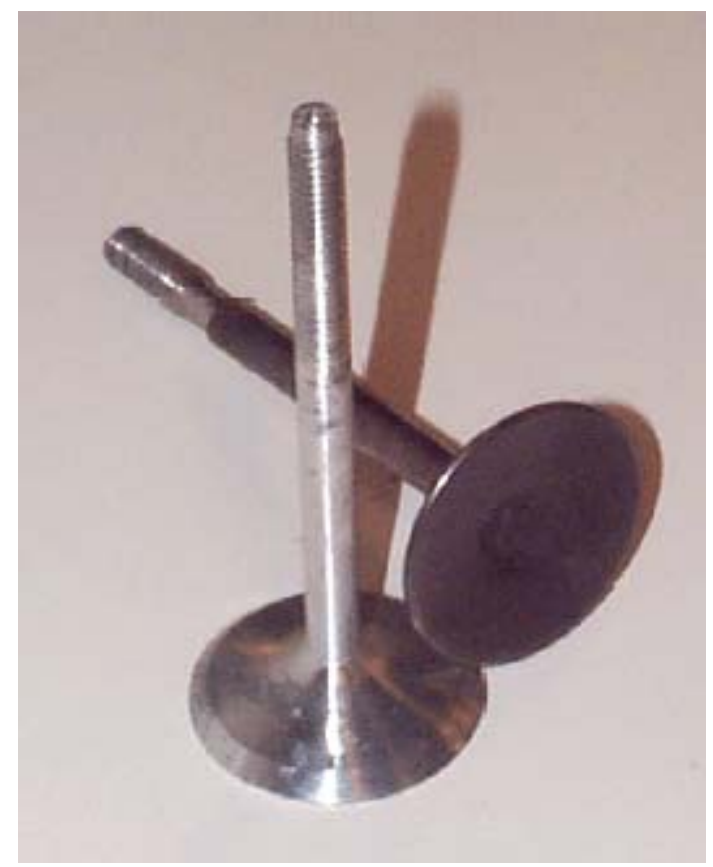

Figure 3.4: Intake valves 


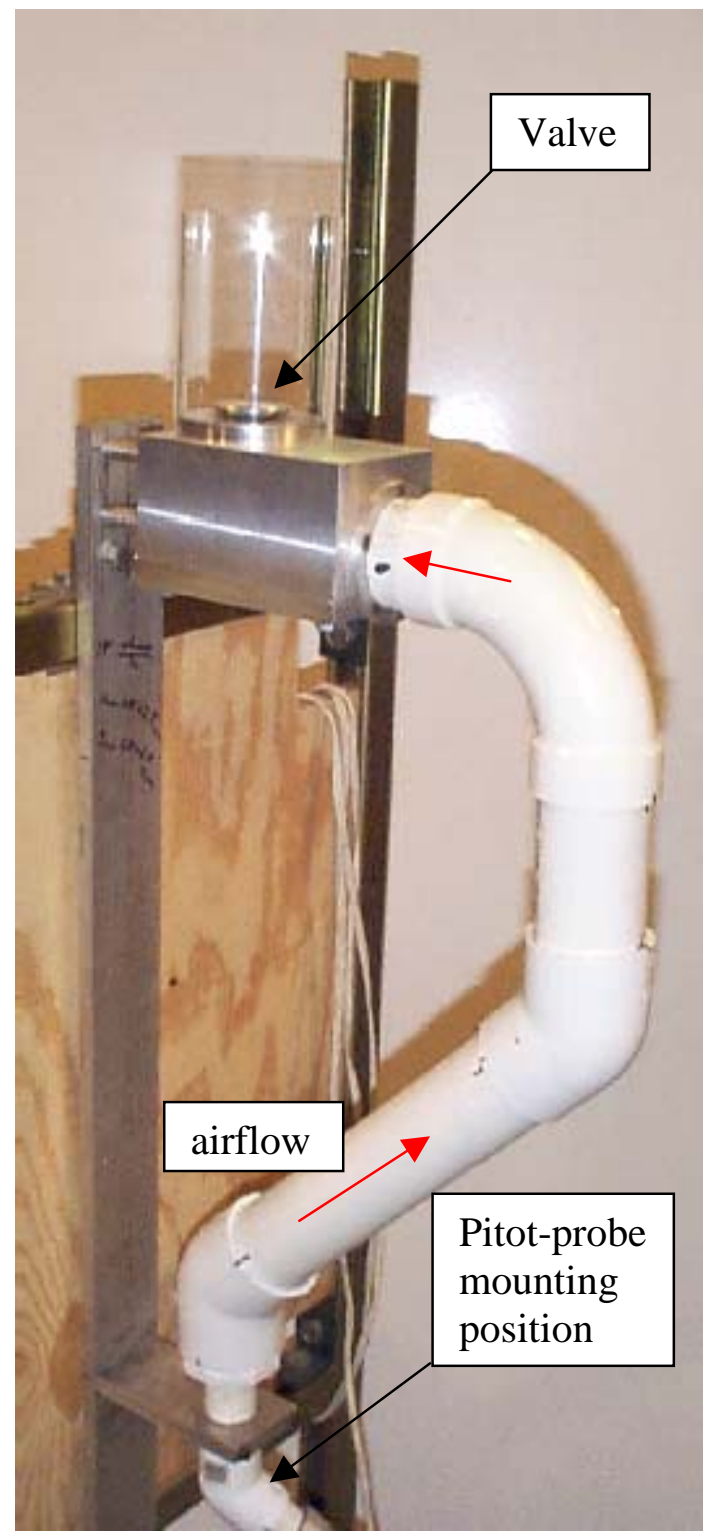

Figure 3.5: Swirl intake test apparatus (close-up view)

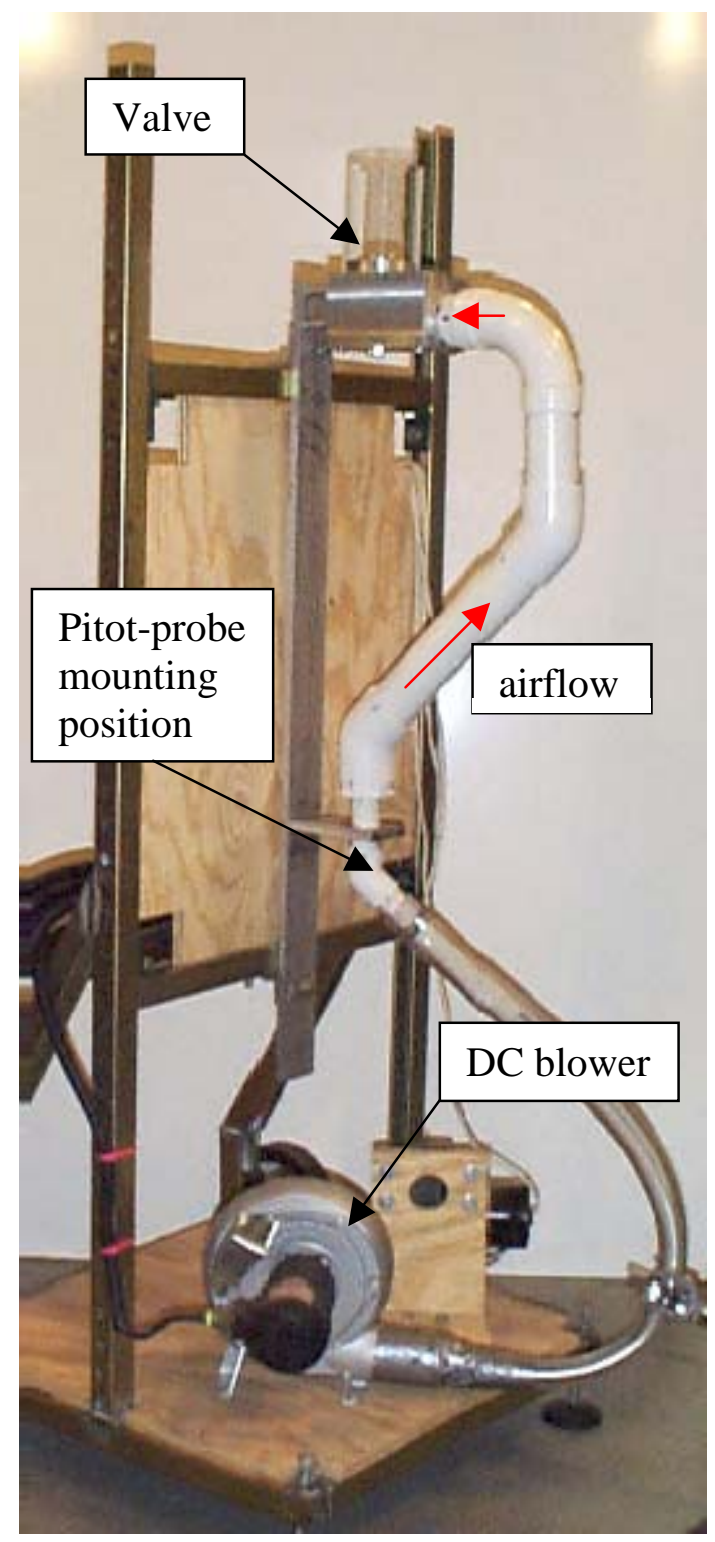

Figure 3.6: Swirl intake test apparatus (full view) 


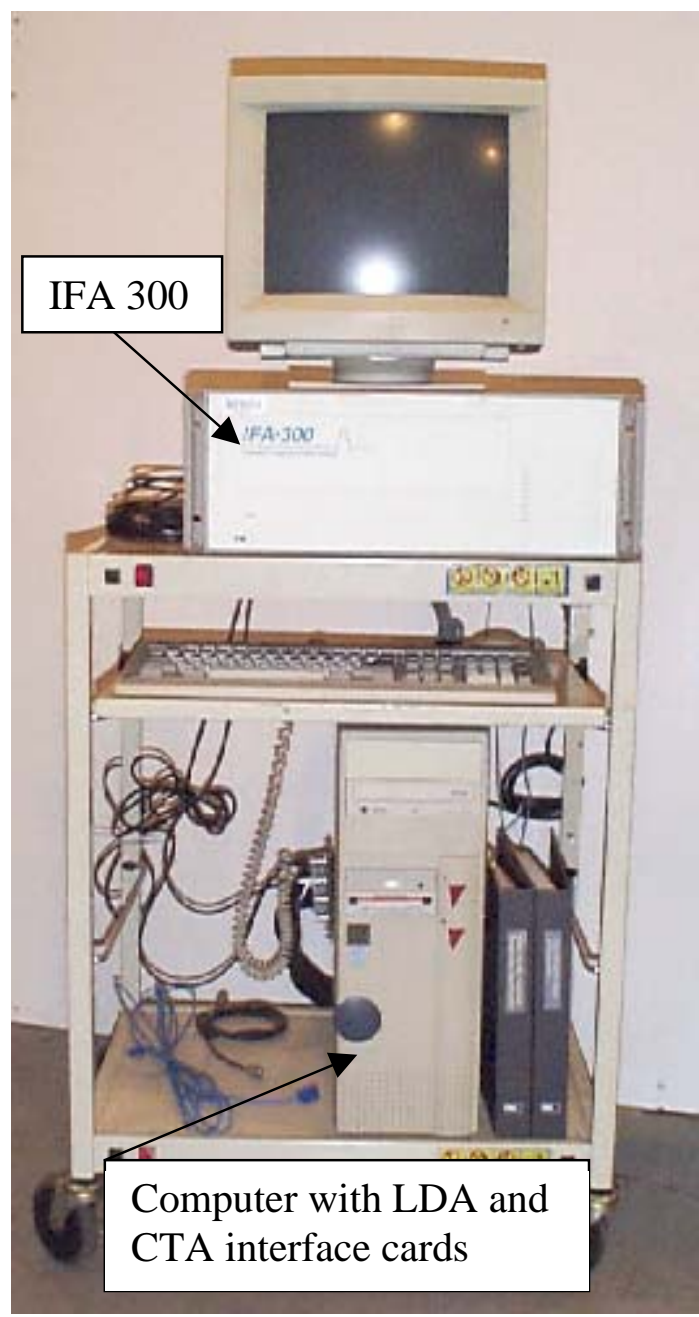

Figure 3.7: Data acquisition computer and IFA 300
CTA probe (in storage container)

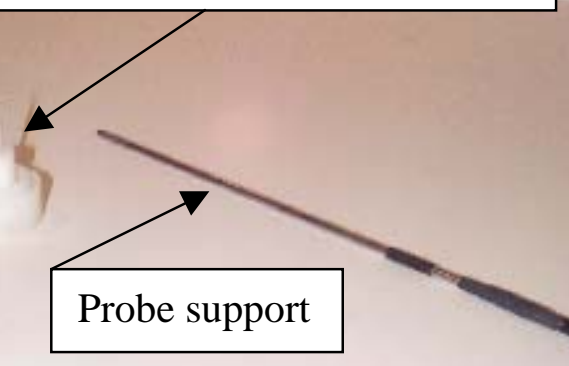

Figure 3.8: CTA probe and probe support

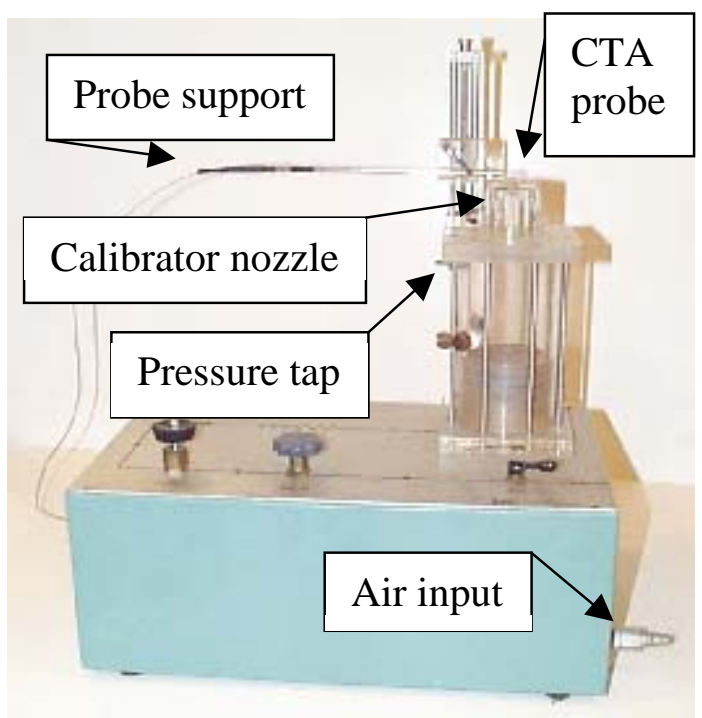

Figure 3.9: CTA calibrator 


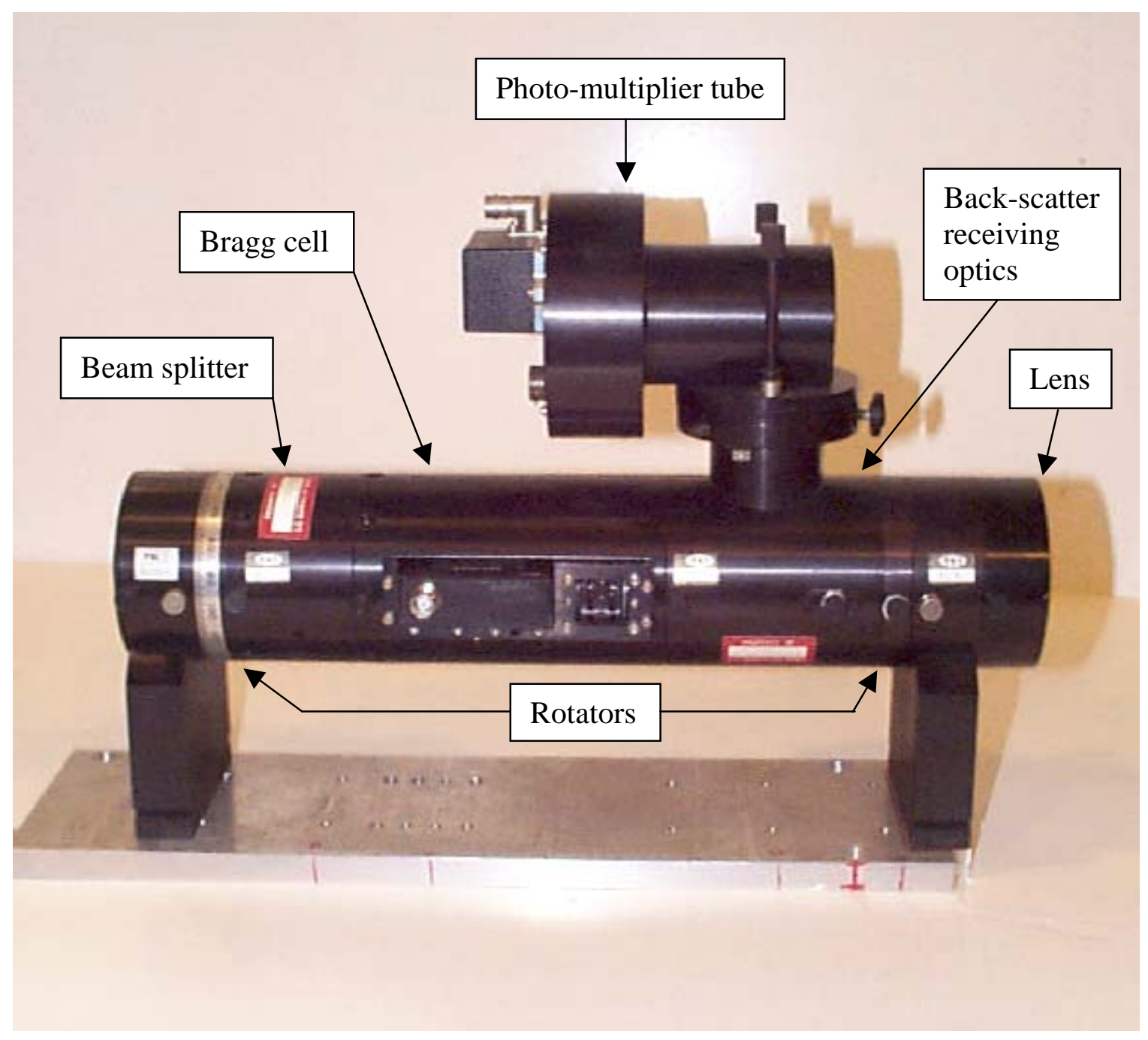

Figure 3.10: LDA optics 


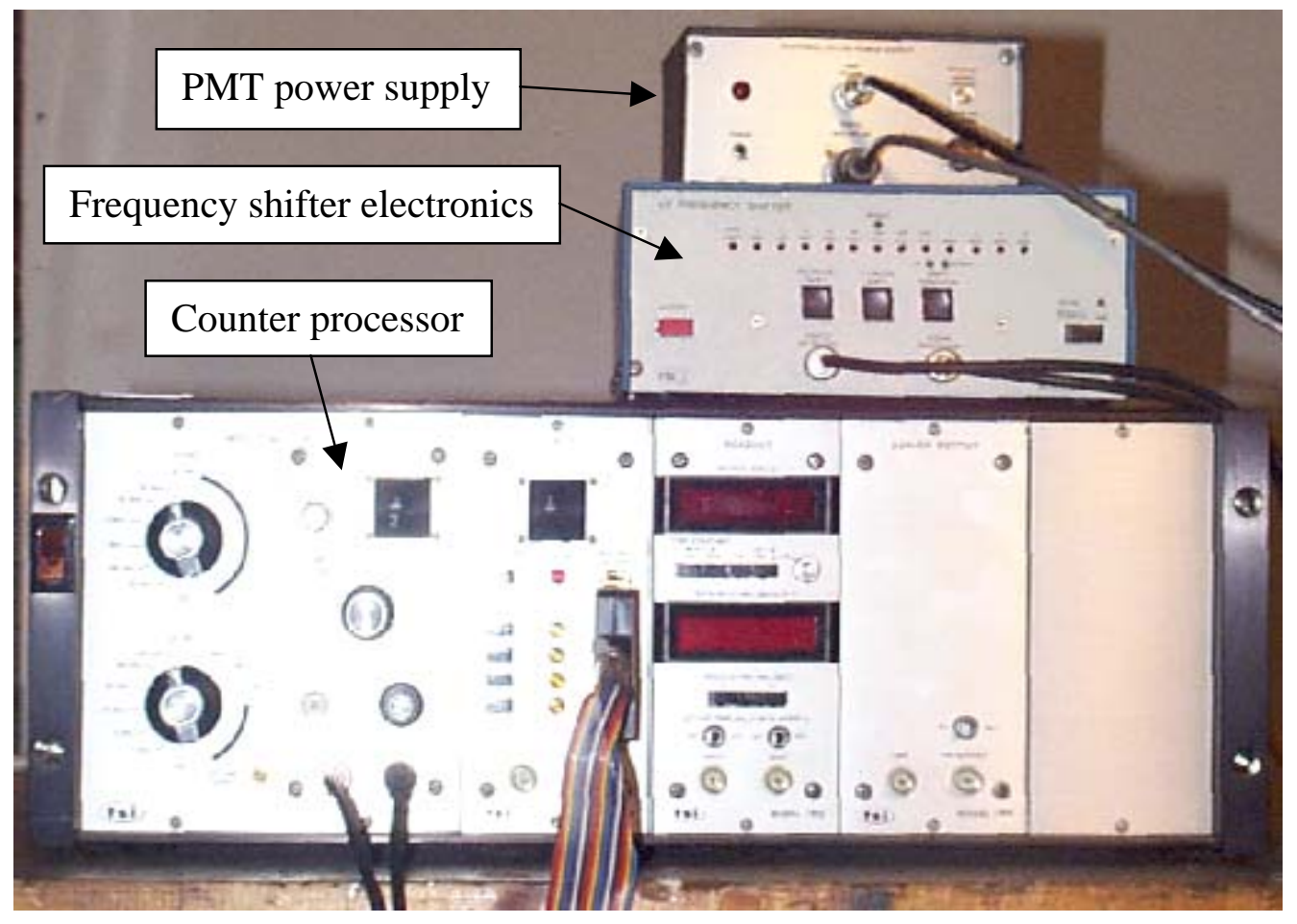

Figure 3.11: LDA electronics

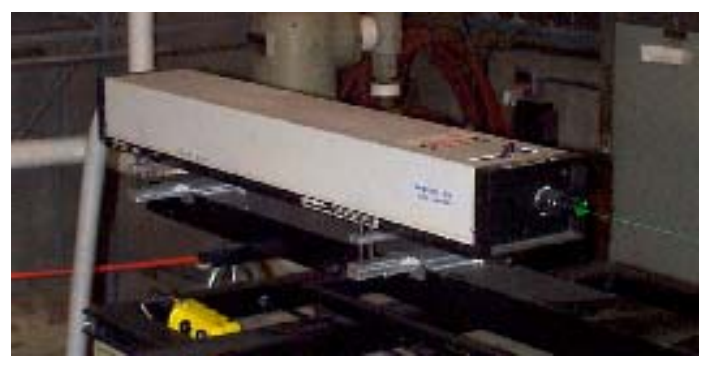

Figure 3.12: Argon-Ion laser

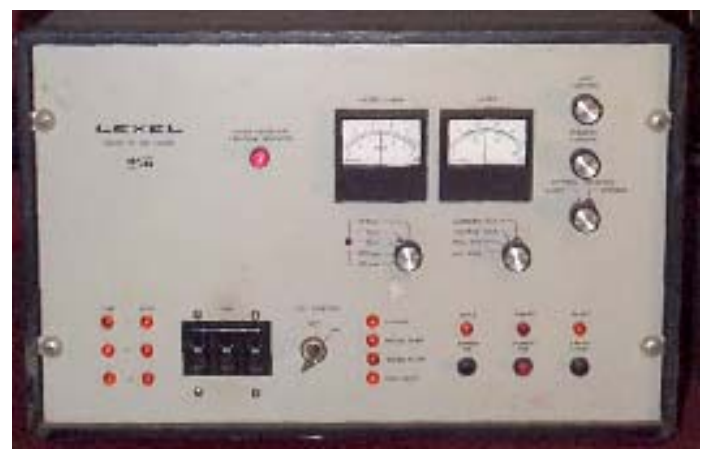

Figure 3.13: Laser power supply

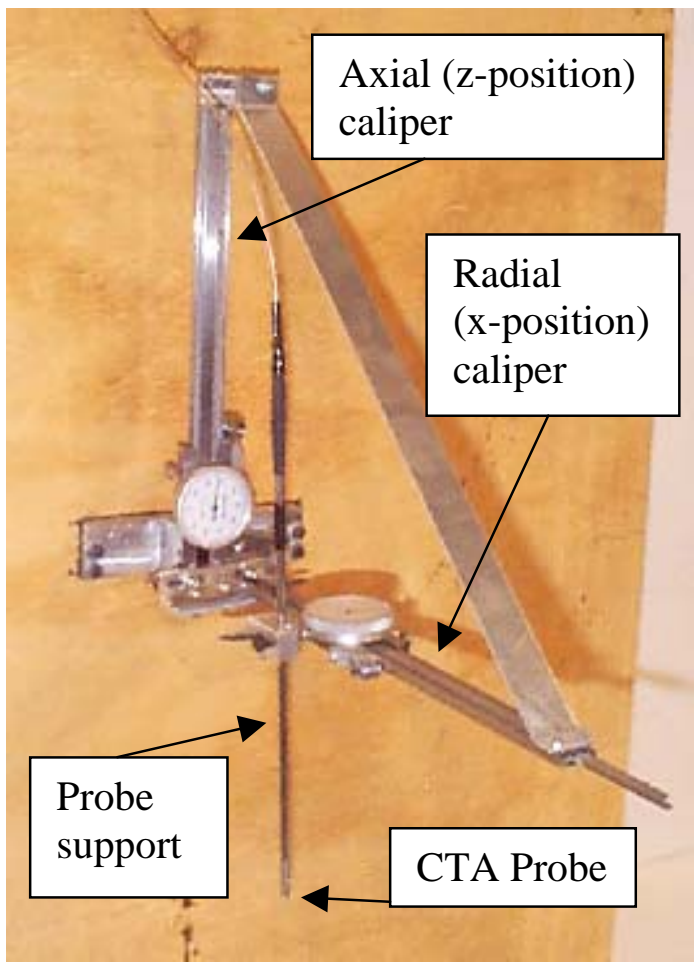

Figure 3.14: CTA X-Z traverse 


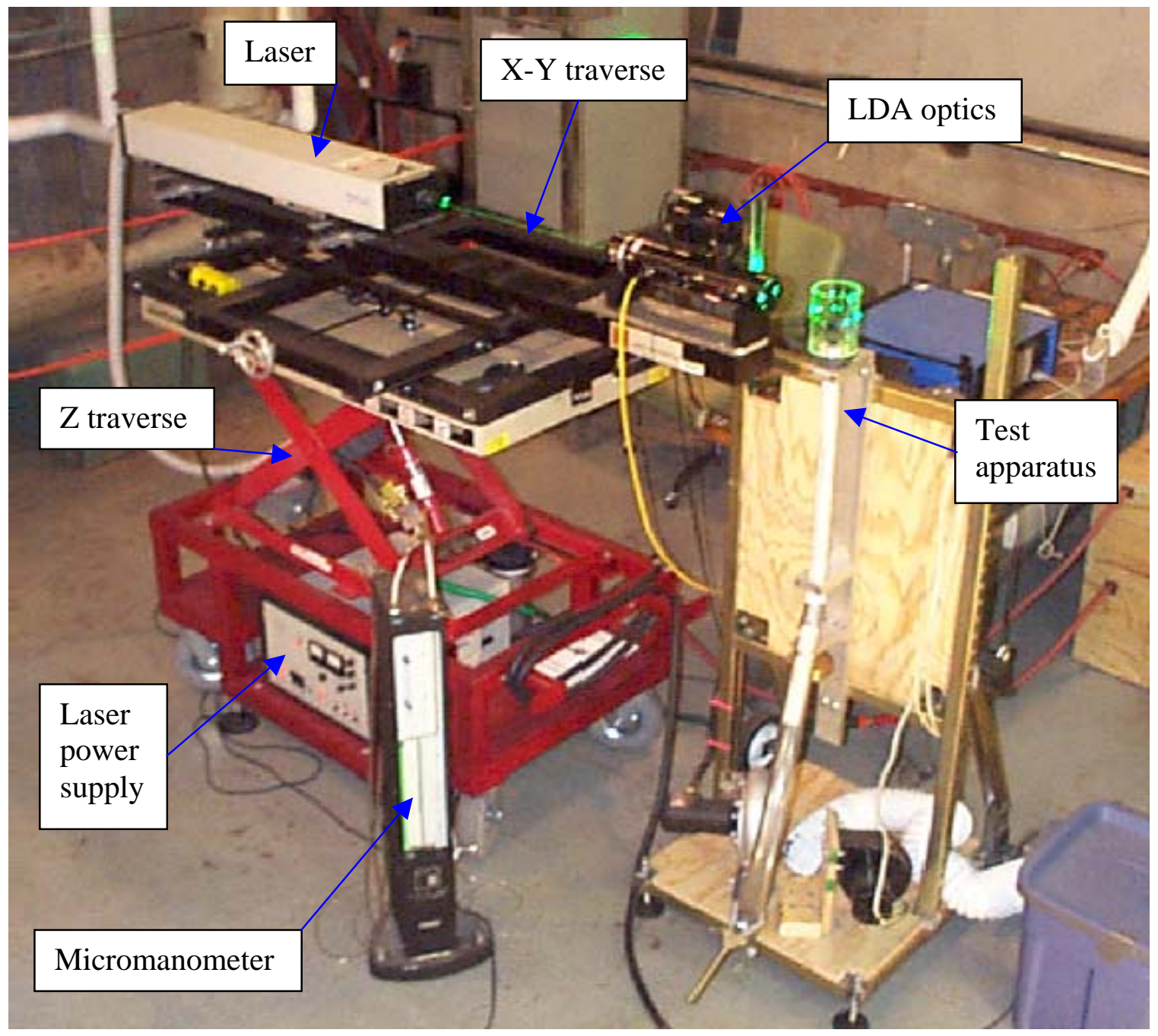

Figure 3.15: Complete LDA system with $\mathrm{X}-\mathrm{Y}-\mathrm{Z}$ traverse 


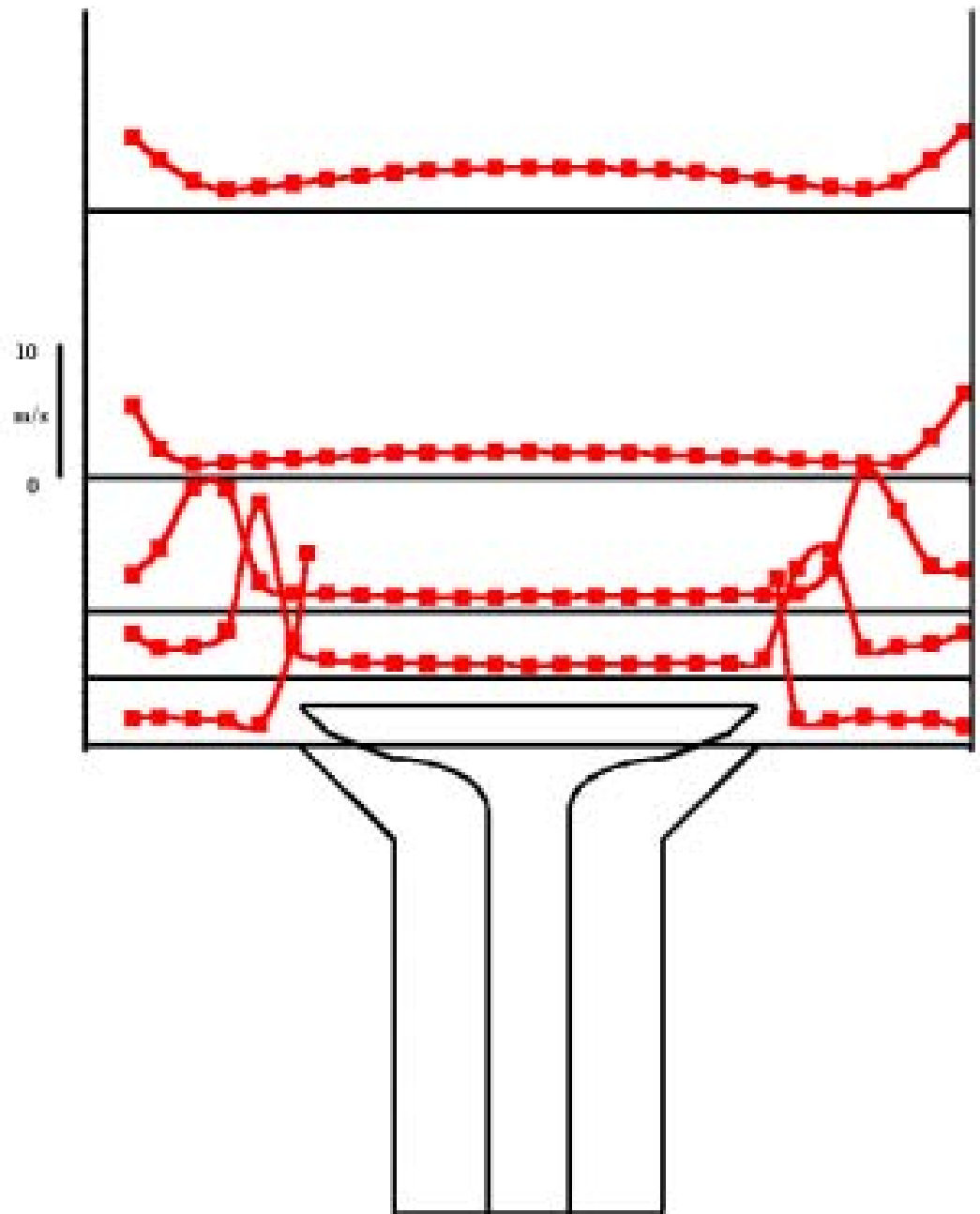

Figure 5.1: Axial/radial mean velocity measurements for $4 \mathrm{~mm}$ valve lift and straight intake using CTA.

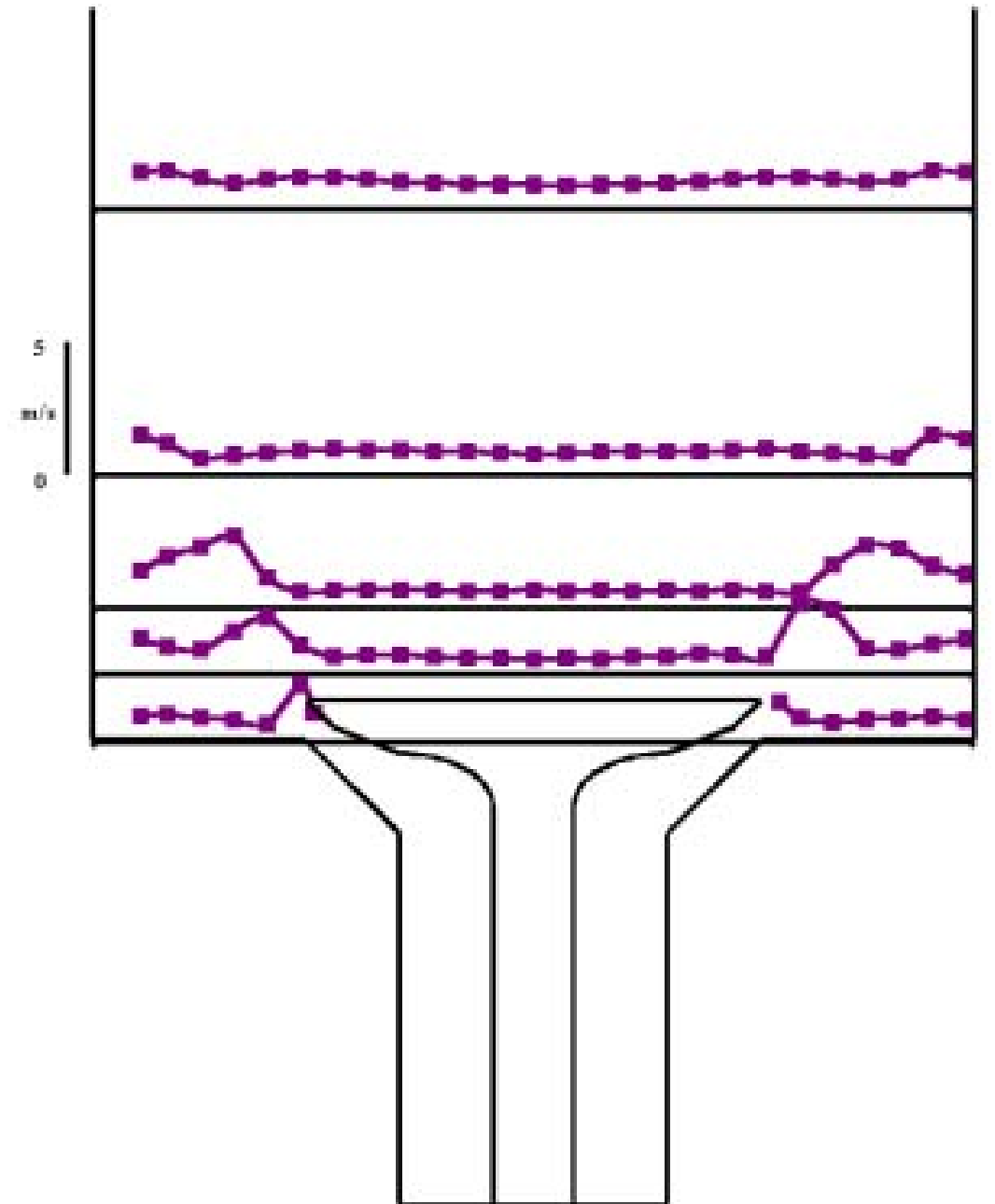

Figure 5.2: Axial/radial standard deviation measurements for 4 $\mathrm{mm}$ valve lift and straight intake using CTA. 


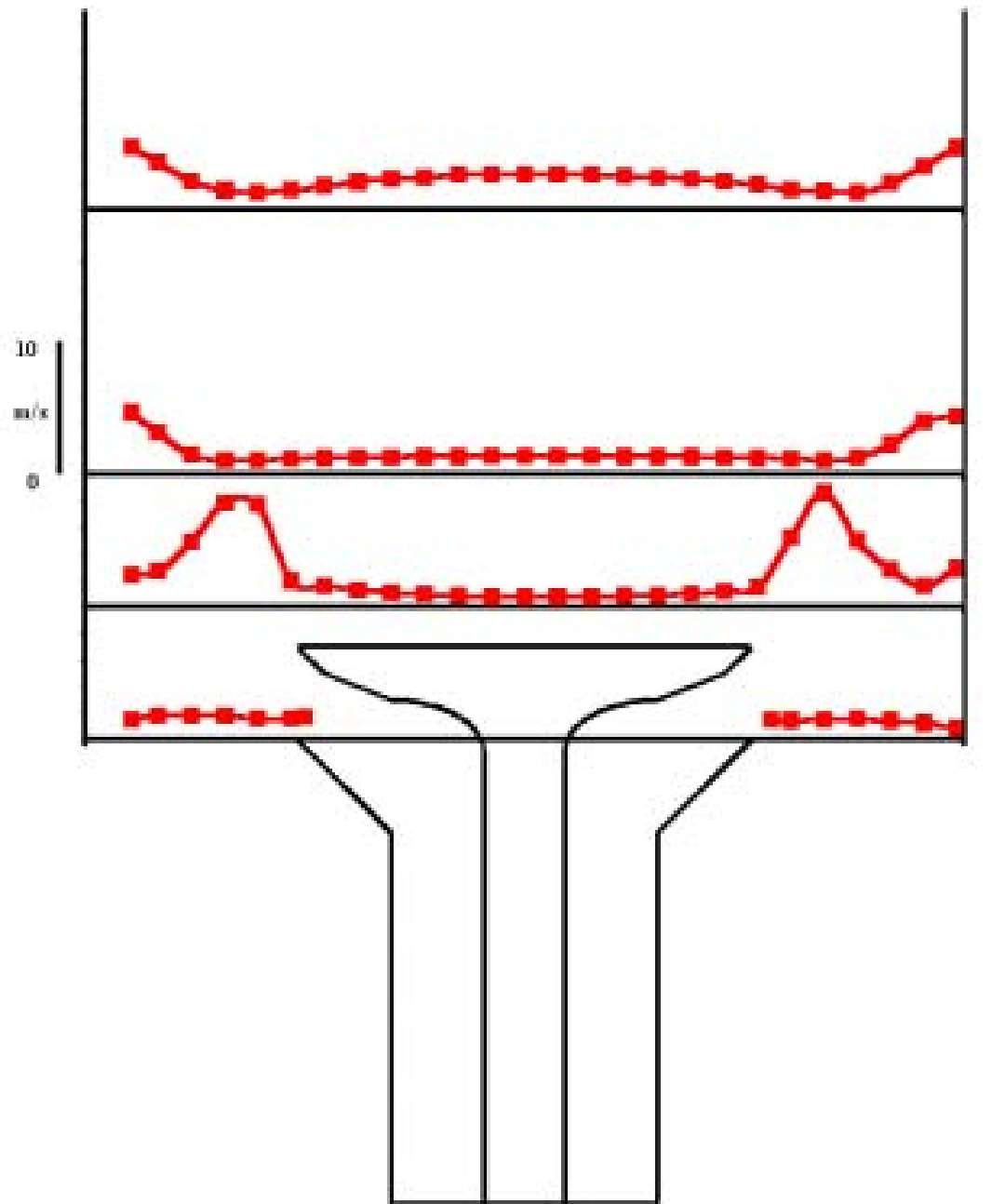

Figure 5.3: Axial/radial mean velocity measurements for $9 \mathrm{~mm}$ valve lift and straight intake using CTA.

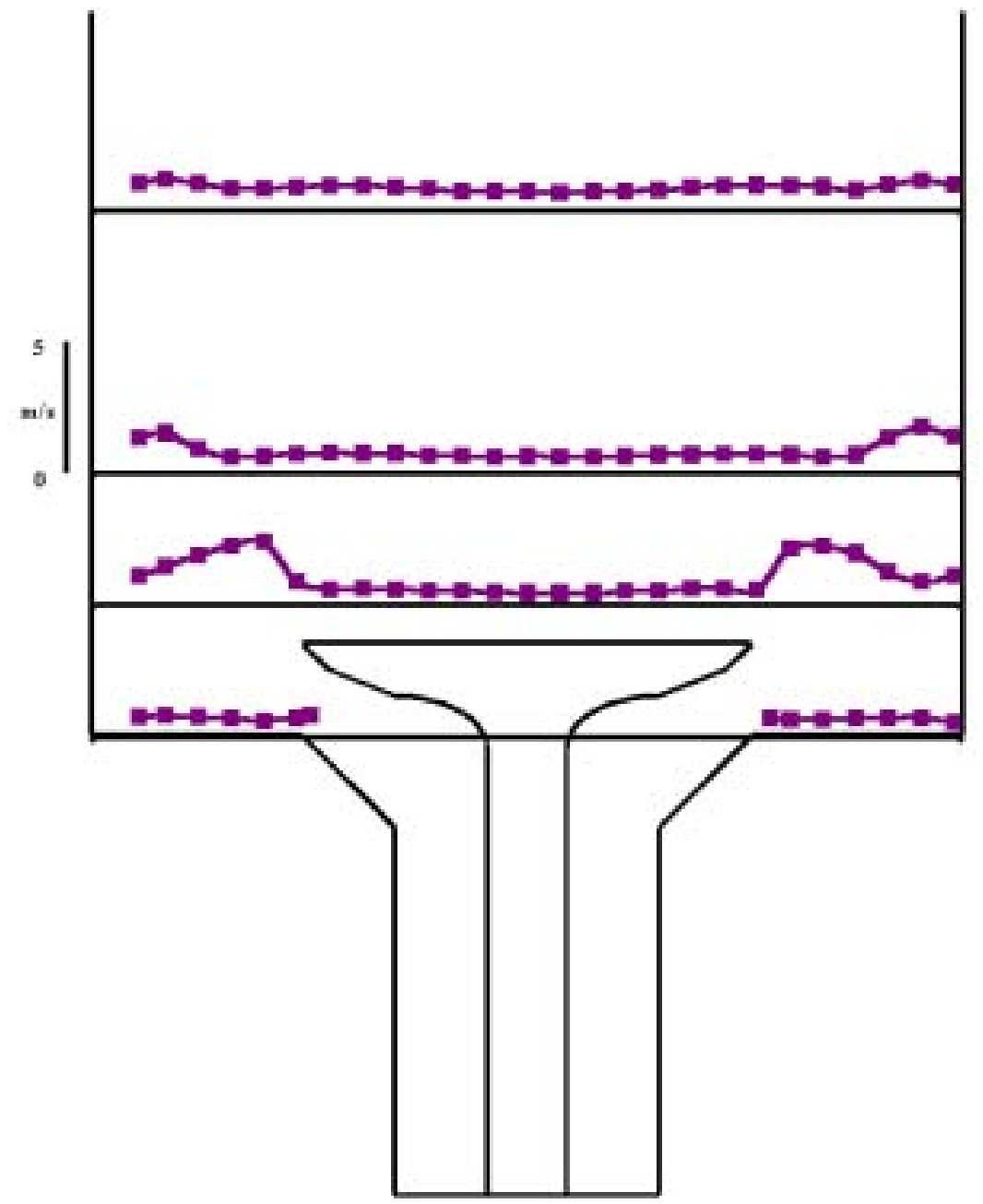

Figure 5.4: Axial/radial standard deviation measurements for 9 $\mathrm{mm}$ valve lift and straight intake using CTA. 


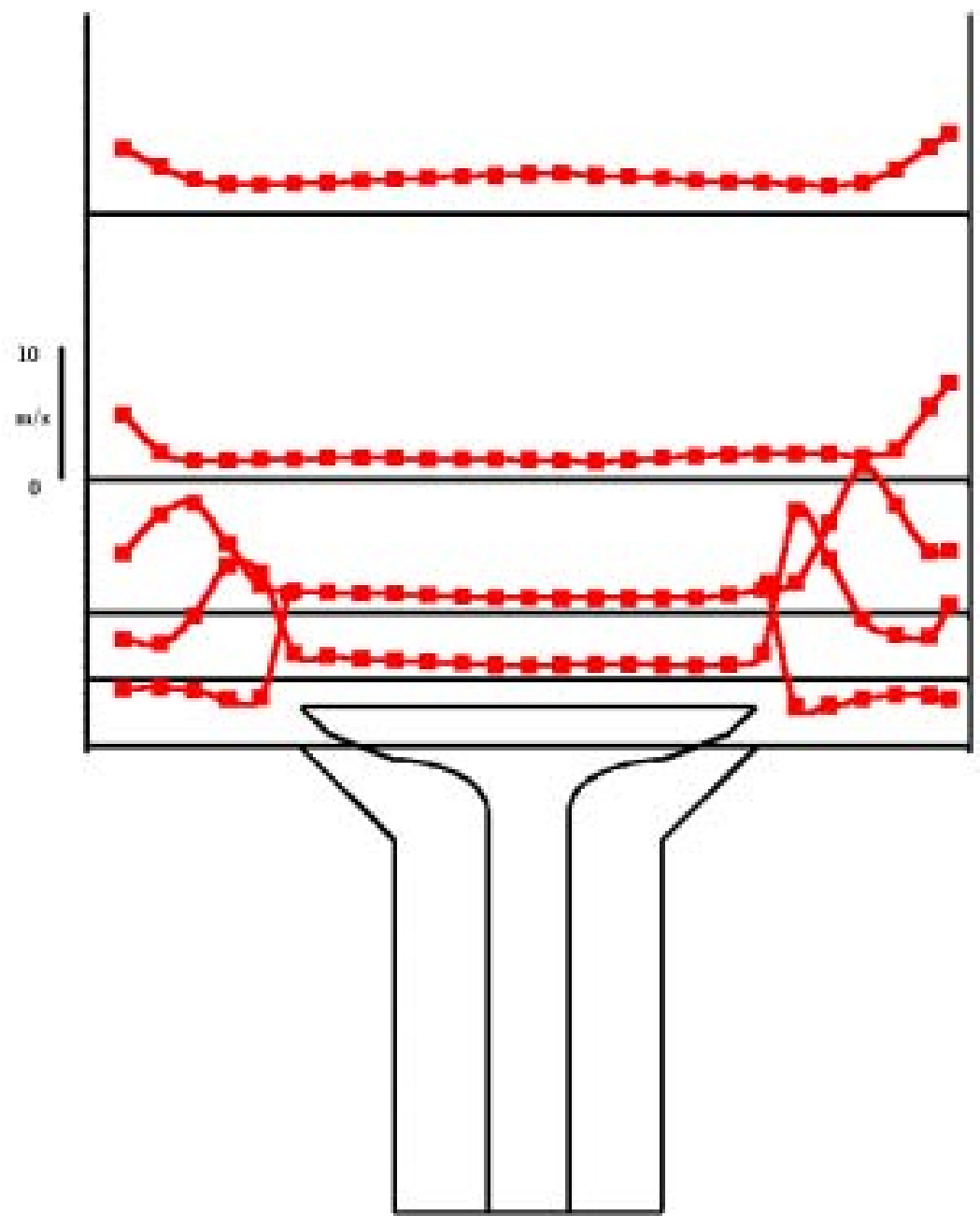

Figure 5.5: Axial/radial mean velocity measurements for $4 \mathrm{~mm}$ valve lift and swirl intake using CTA.

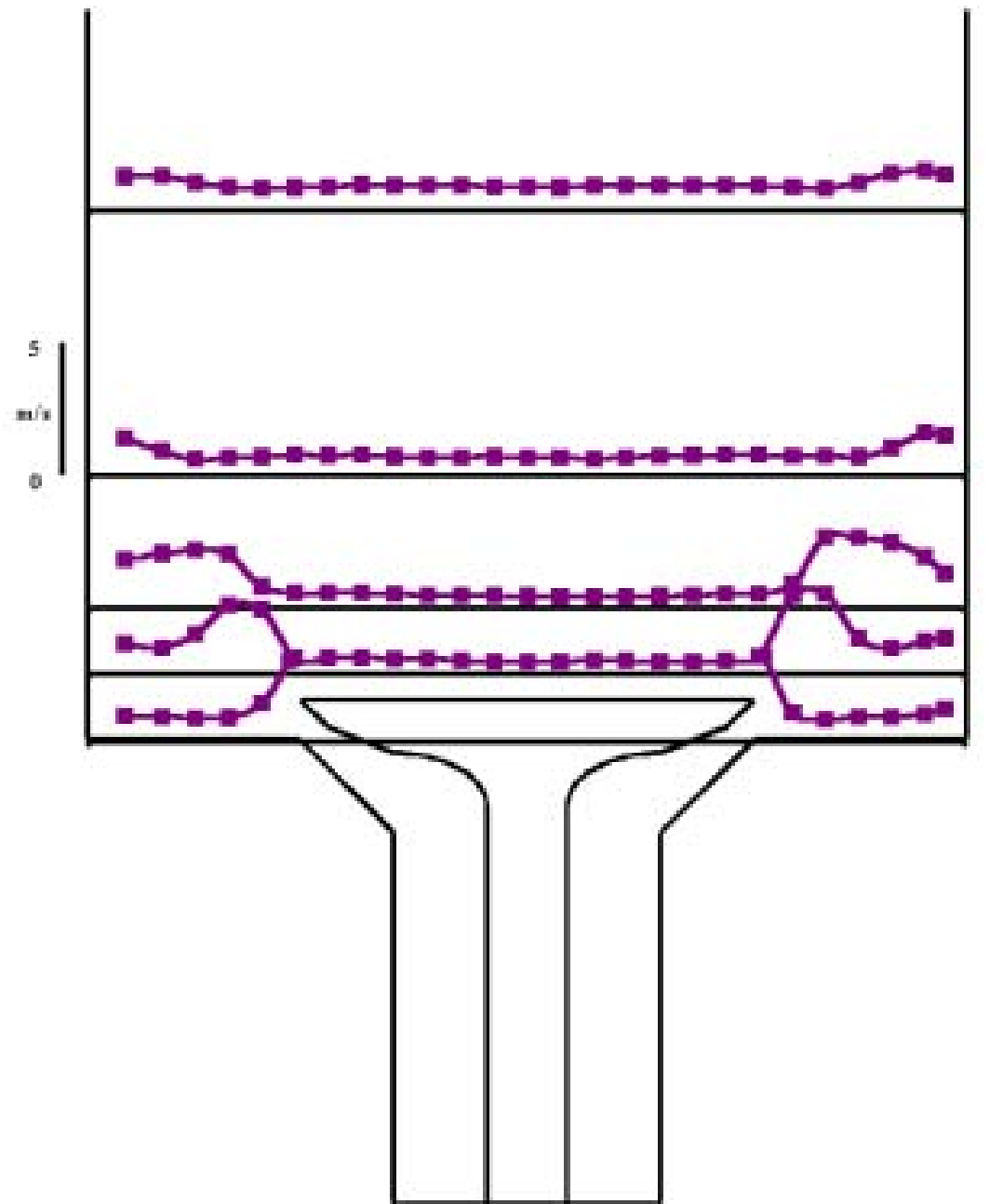

Figure 5.6: Axial/radial standard deviation measurements for 4 $\mathrm{mm}$ valve lift and swirl intake using CTA. 


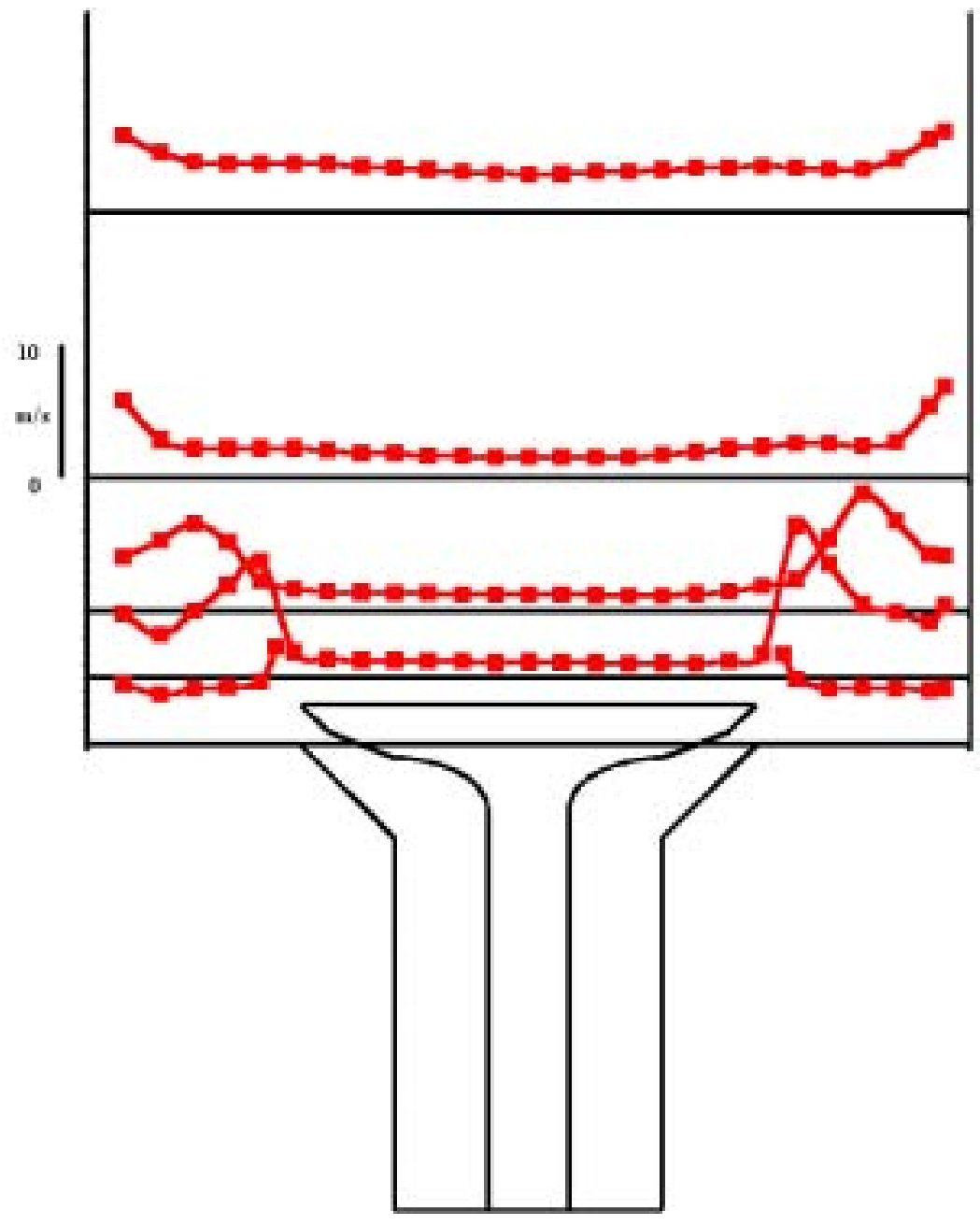

Figure 5.7: Axial/swirl mean velocity measurements for $4 \mathrm{~mm}$ valve lift and swirl intake using CTA.

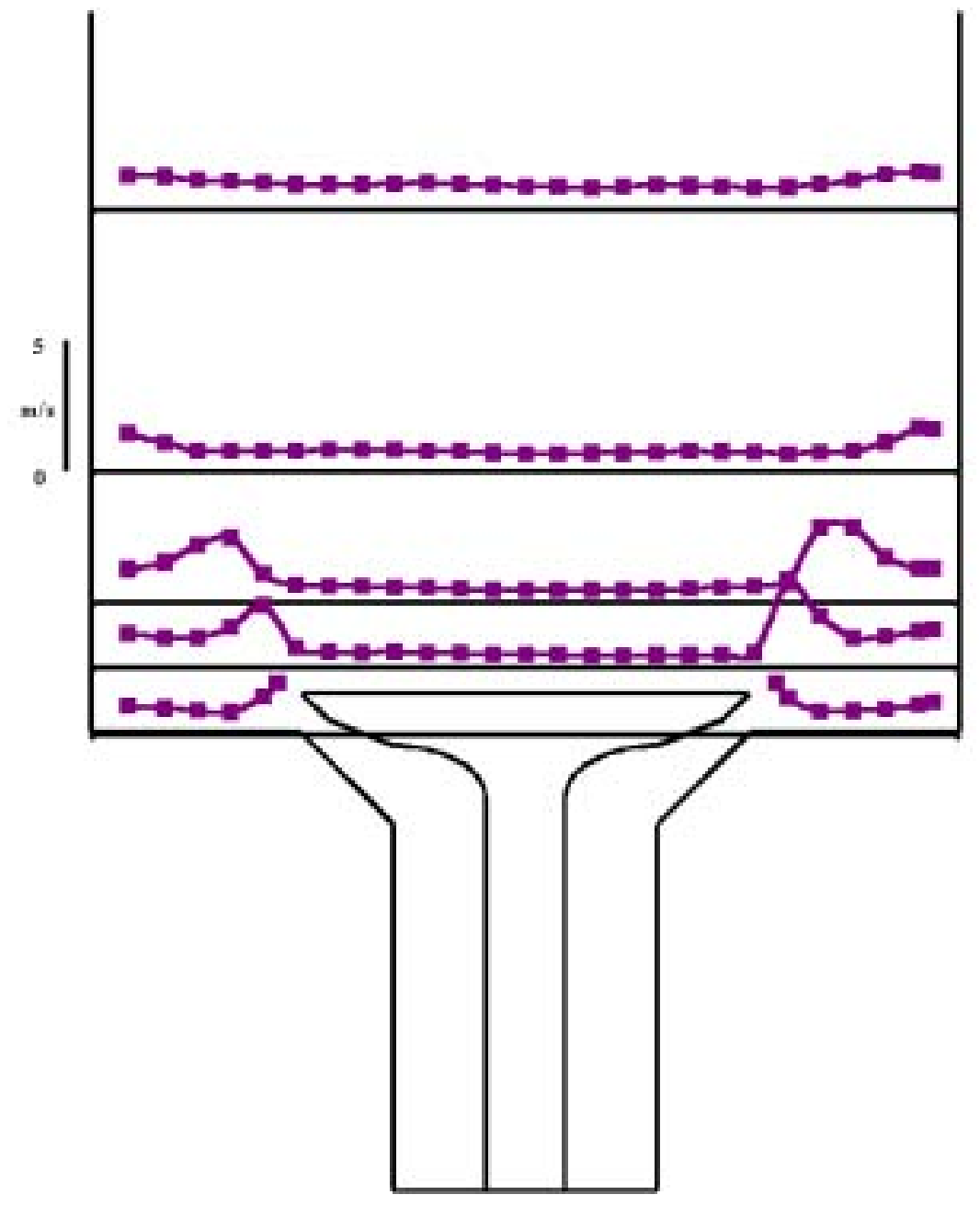

Figure 5.8: Axial/swirl standard deviation measurements for 4 $\mathrm{mm}$ valve lift and swirl intake using CTA. 


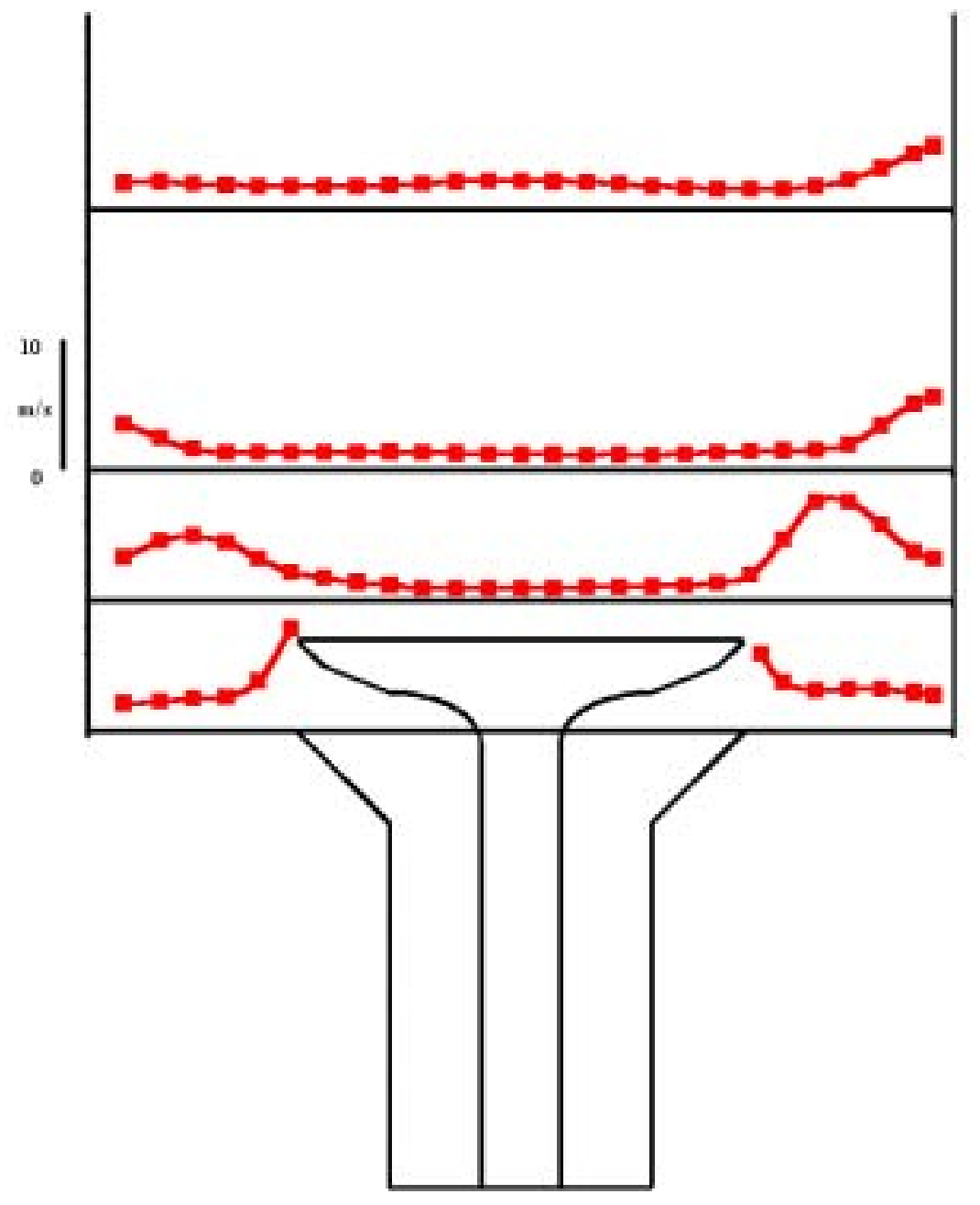

Figure 5.9: Axial/radial mean velocity measurements for $9 \mathrm{~mm}$ valve lift and swirl intake using CTA.

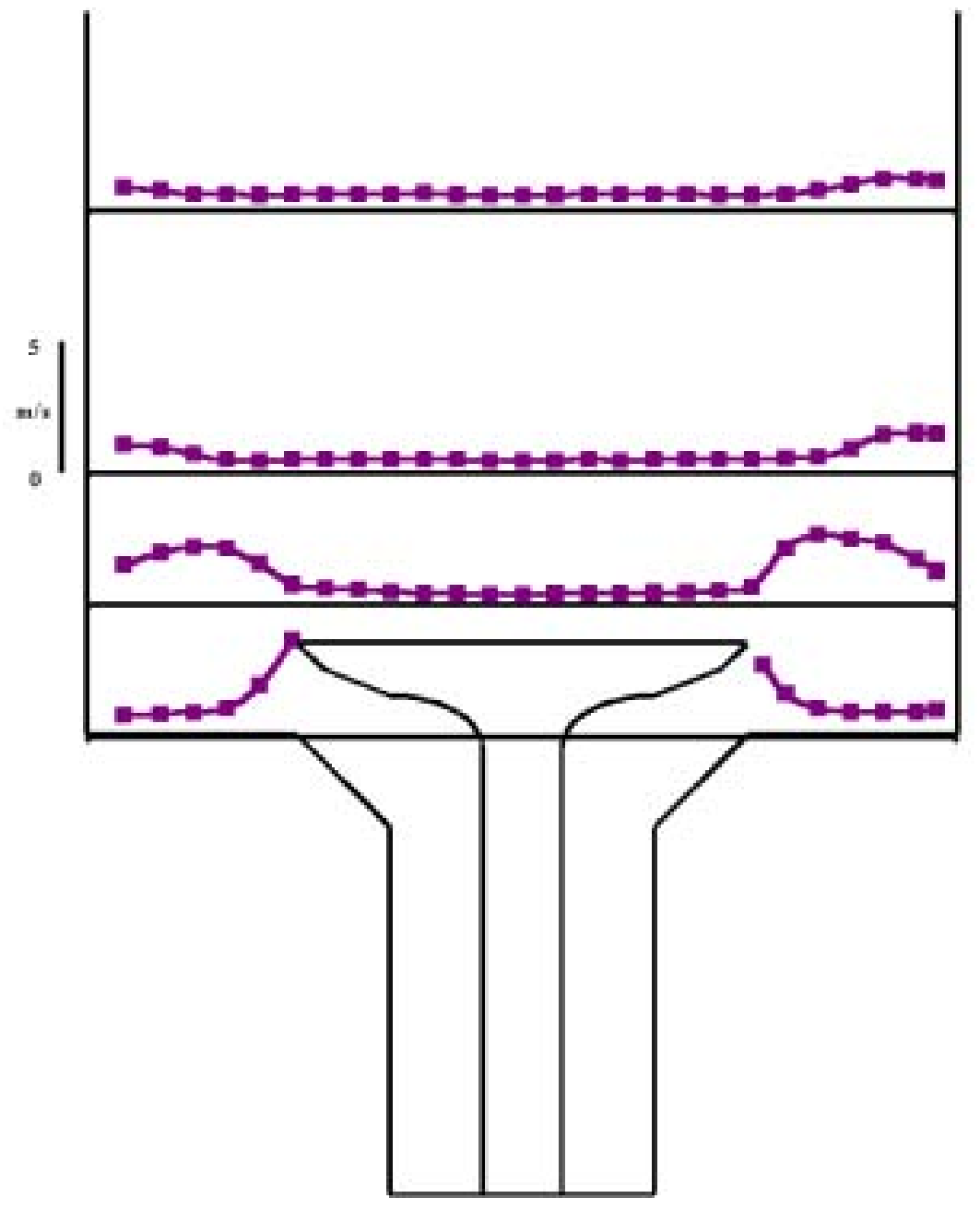

Figure 5.10: Axial/radial standard deviation measurements for $9 \mathrm{~mm}$ valve lift and swirl intake using CTA. 


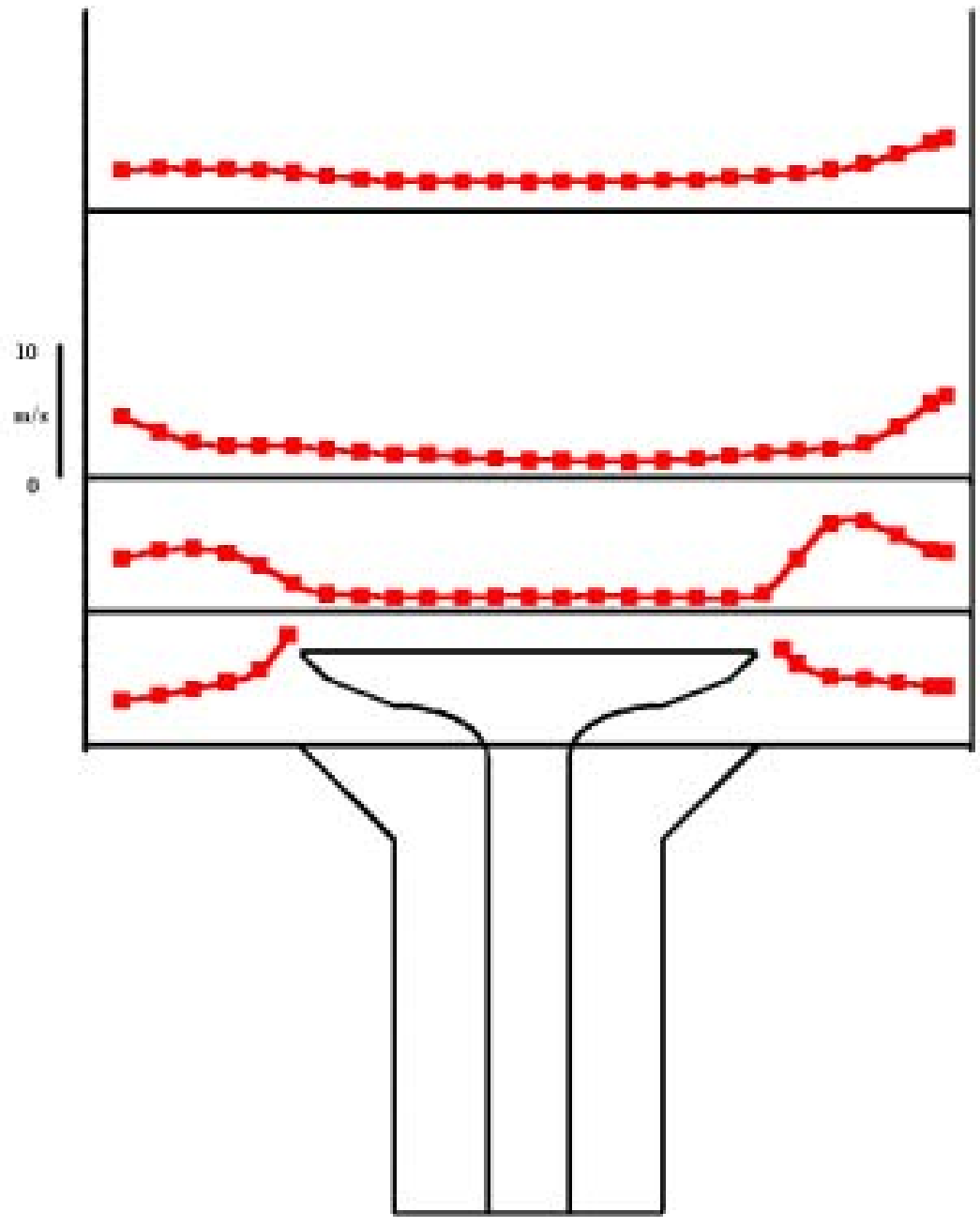

Figure 5.11: Axial/swirl mean velocity measurements for 9 $\mathrm{mm}$ valve lift and swirl intake using CTA.

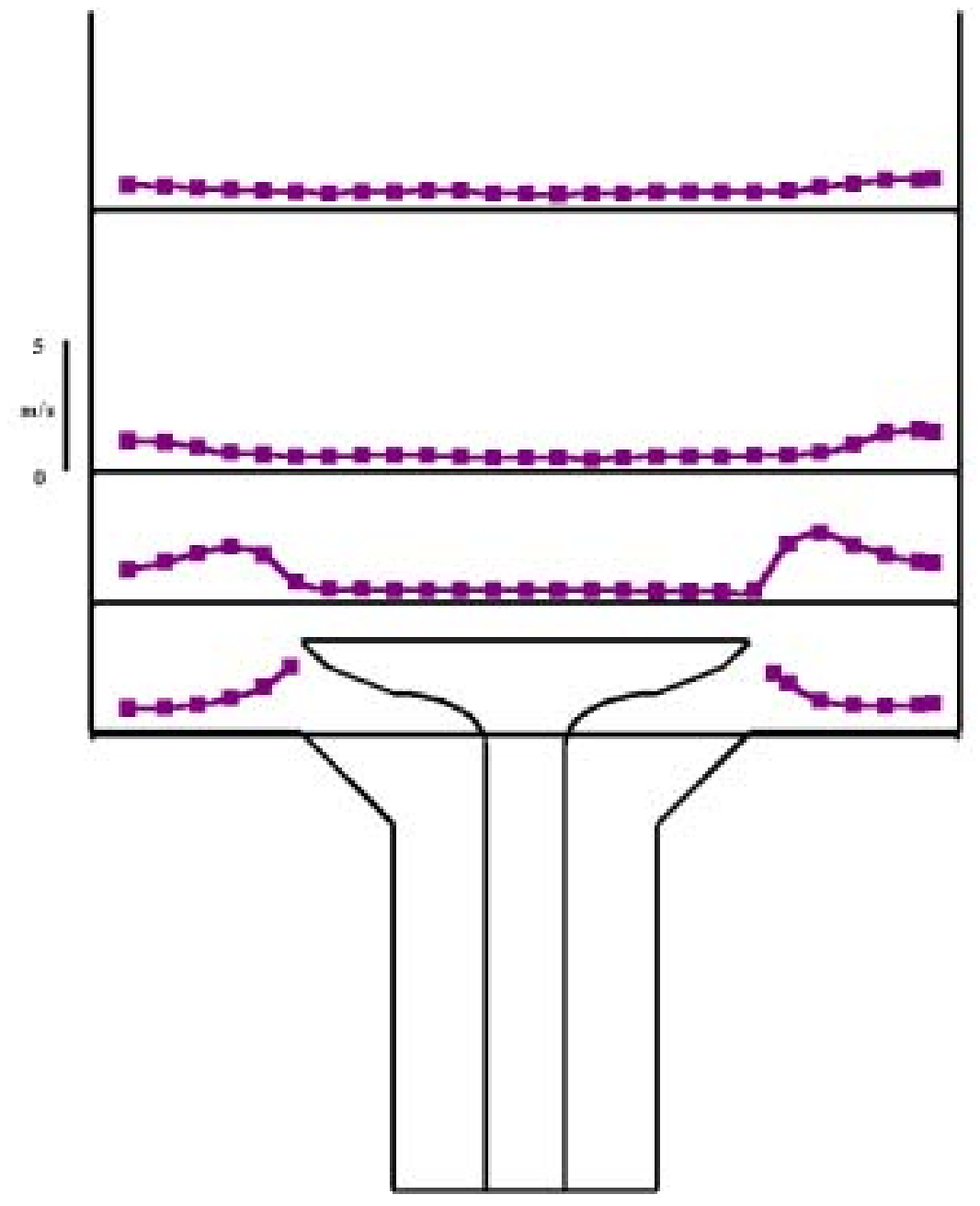

Figure 5.12: Axial/swirl standard deviation measurements for $9 \mathrm{~mm}$ valve lift and swirl intake using CTA. 


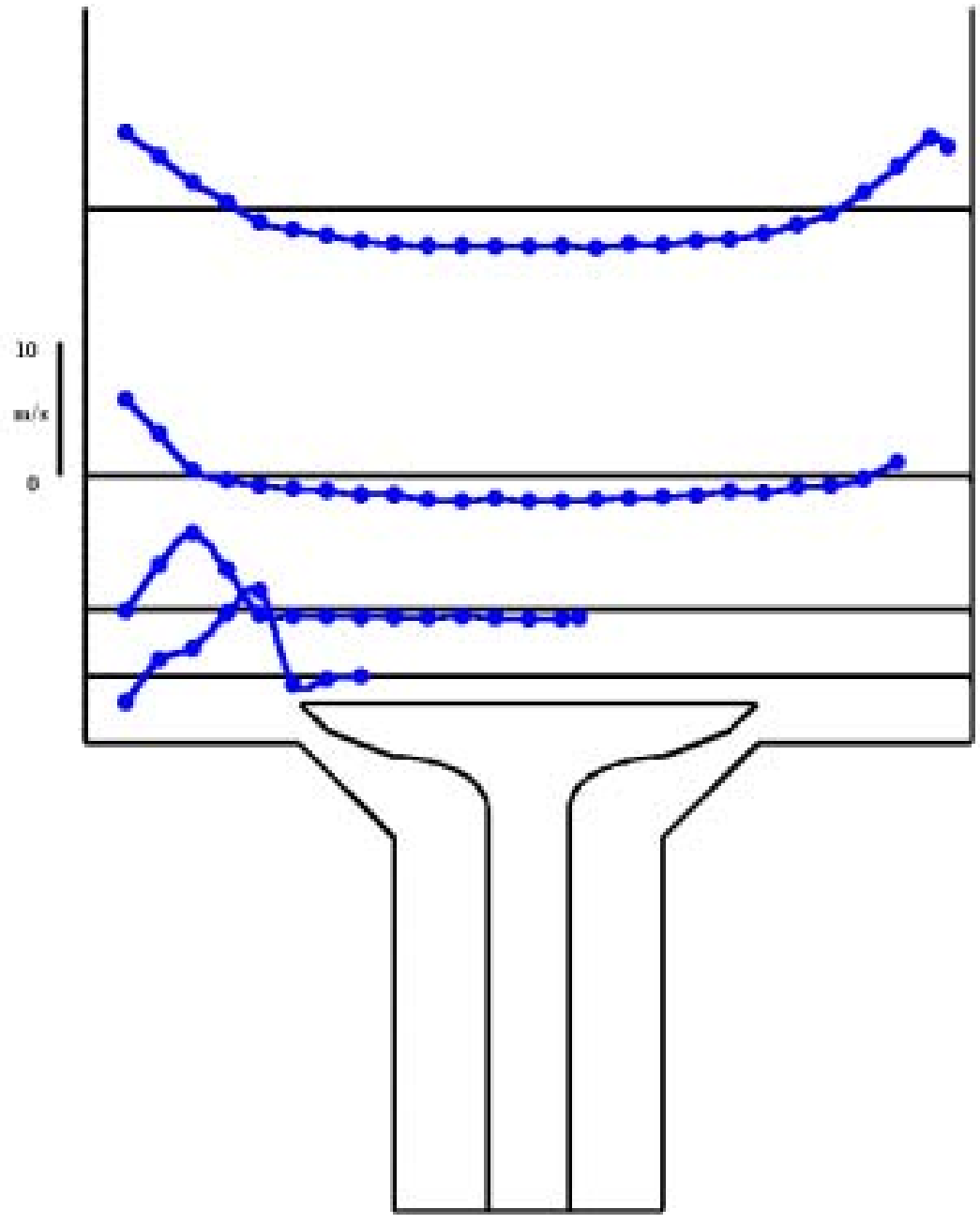

Figure 5.13: Axial mean velocity measurements for $4 \mathrm{~mm}$ valve lift and straight intake using LDA.

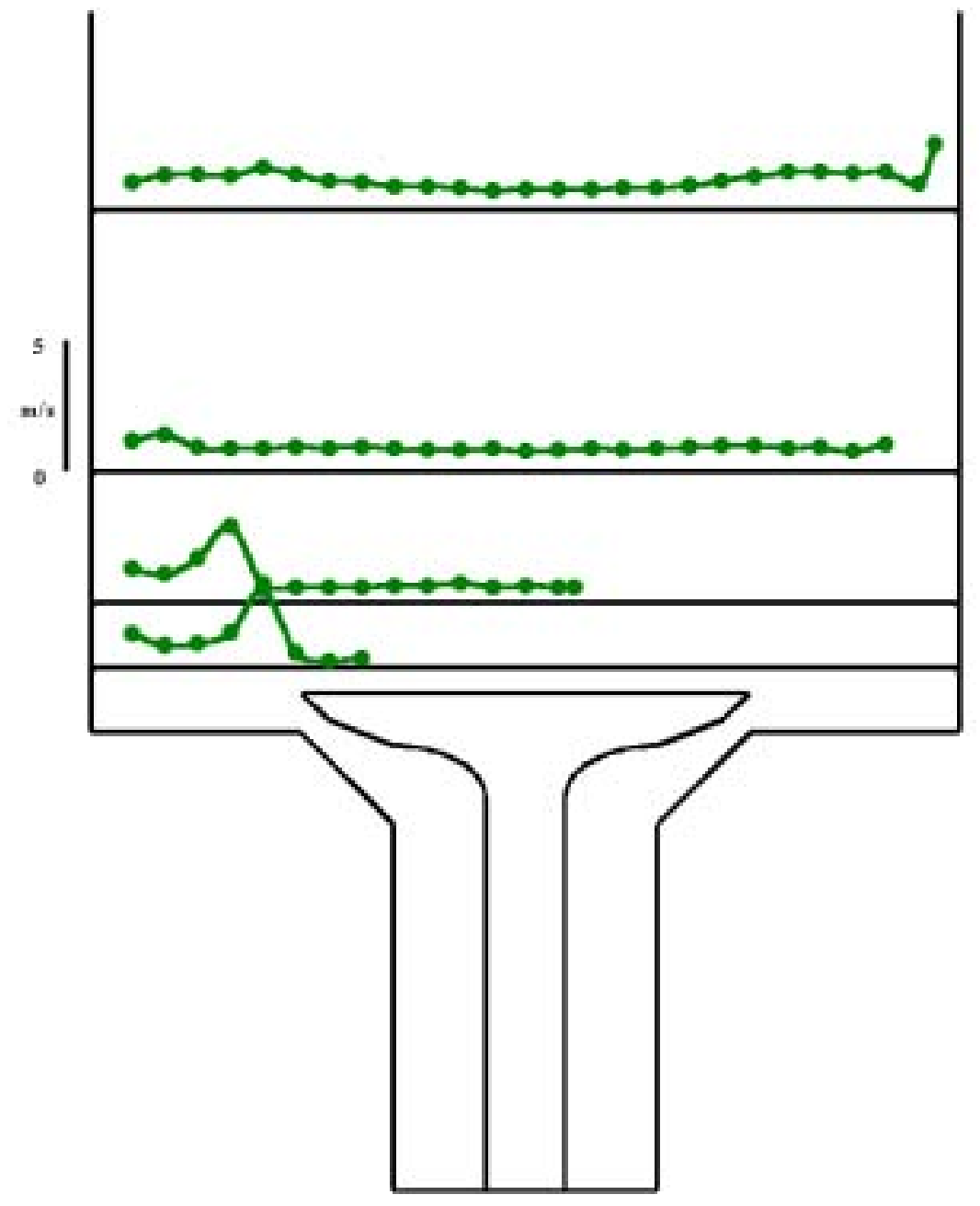

Figure 5.14: Axial standard deviation measurements for $4 \mathrm{~mm}$ valve lift and straight intake using LDA. 


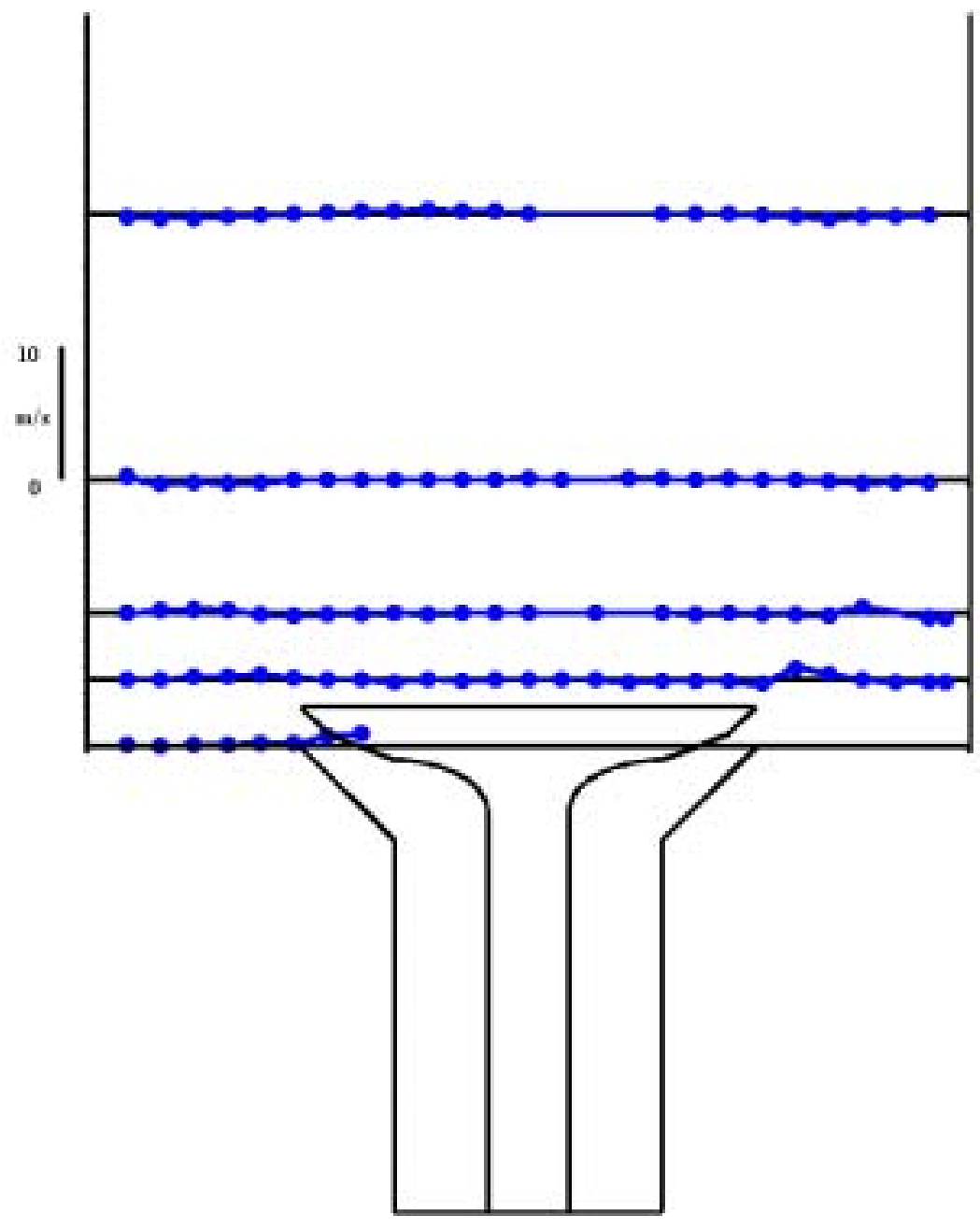

Figure 5.15: Swirl mean velocity measurements for $4 \mathrm{~mm}$ valve lift and straight intake using LDA.

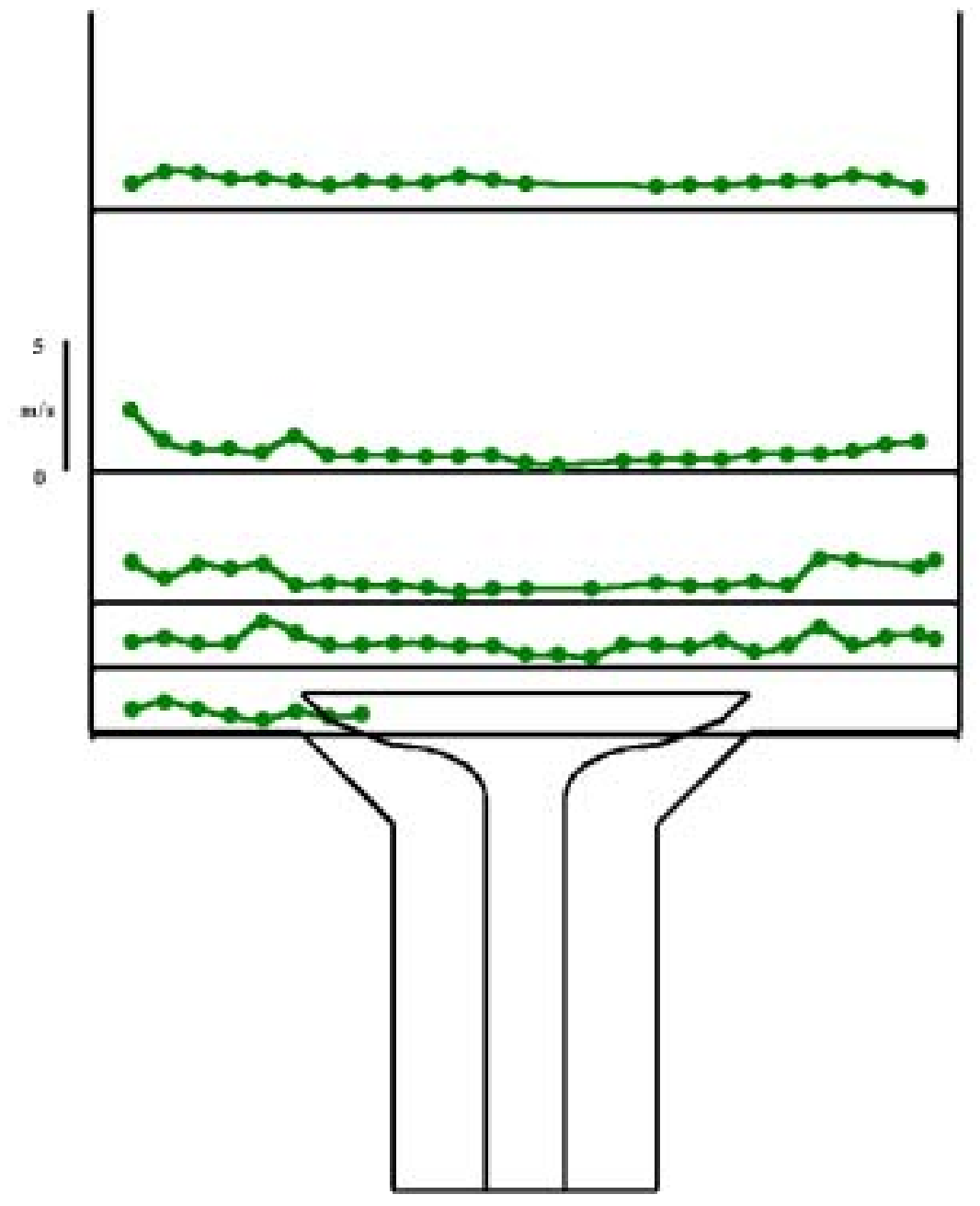

Figure 5.16: Swirl standard deviation measurements for $4 \mathrm{~mm}$ valve lift and straight intake using LDA. 


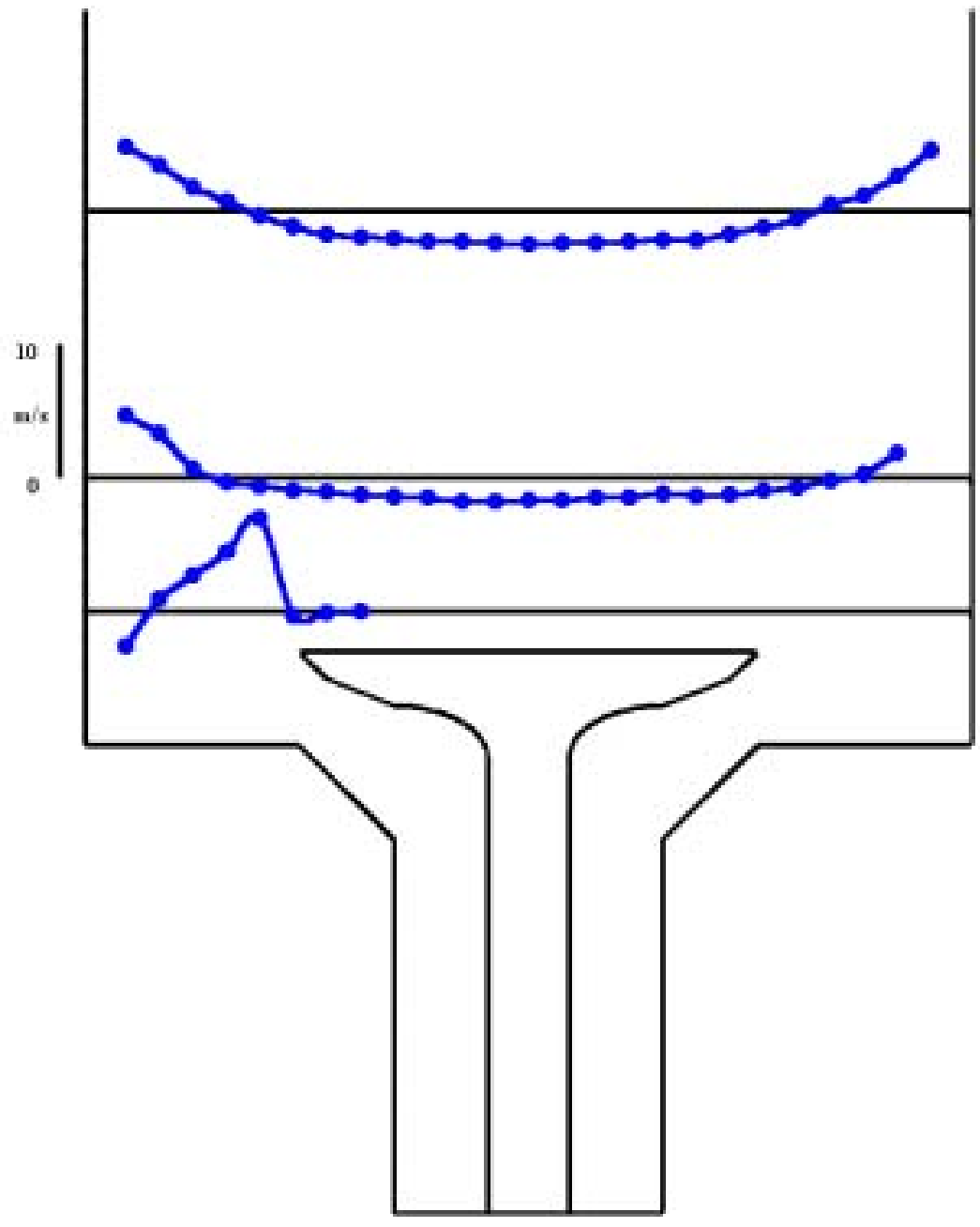

Figure 5.17: Axial mean velocity measurements for $9 \mathrm{~mm}$ valve lift and straight intake using LDA.

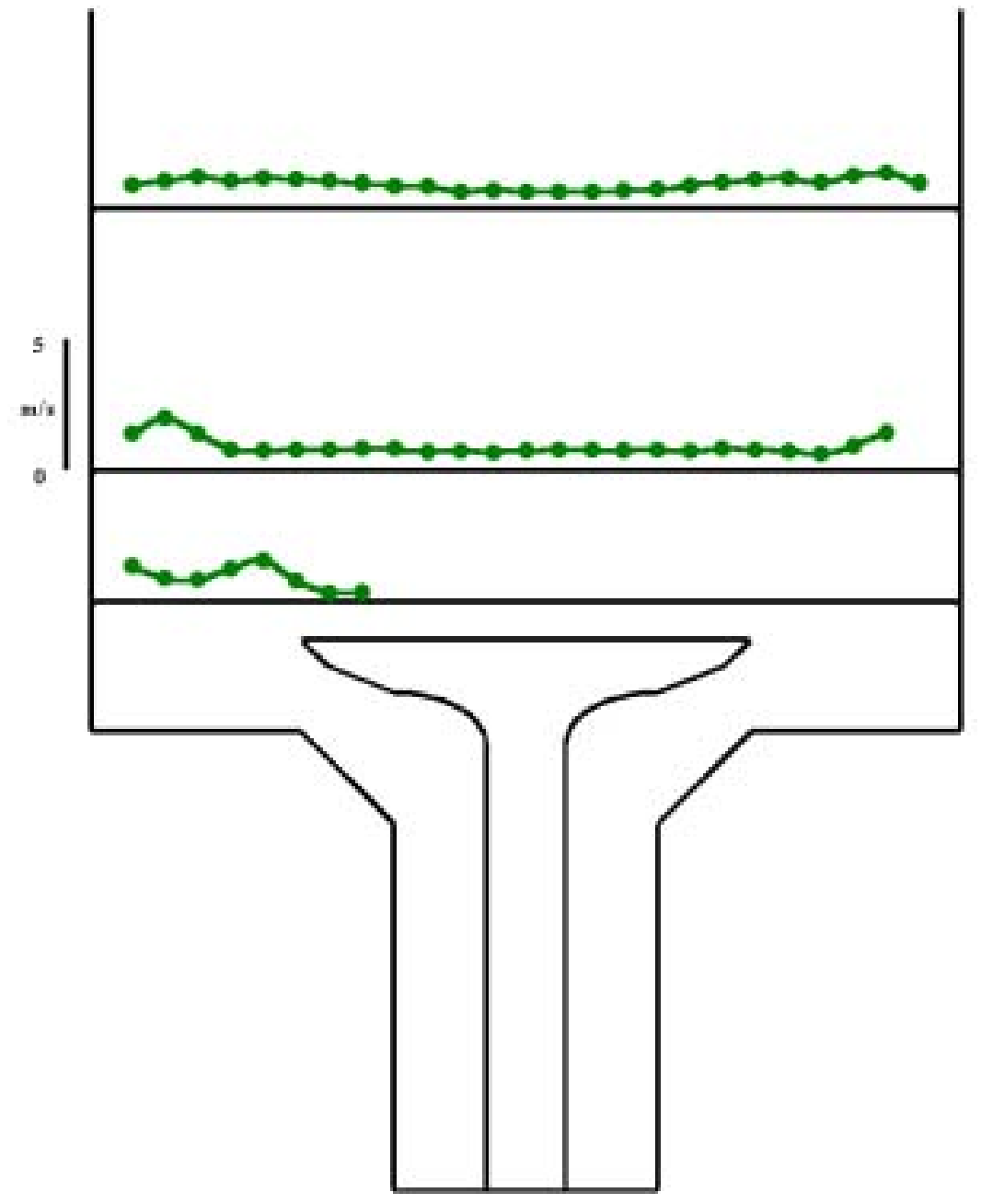

Figure 5.18: Axial standard deviation measurements for $9 \mathrm{~mm}$ valve lift and straight intake using LDA. 


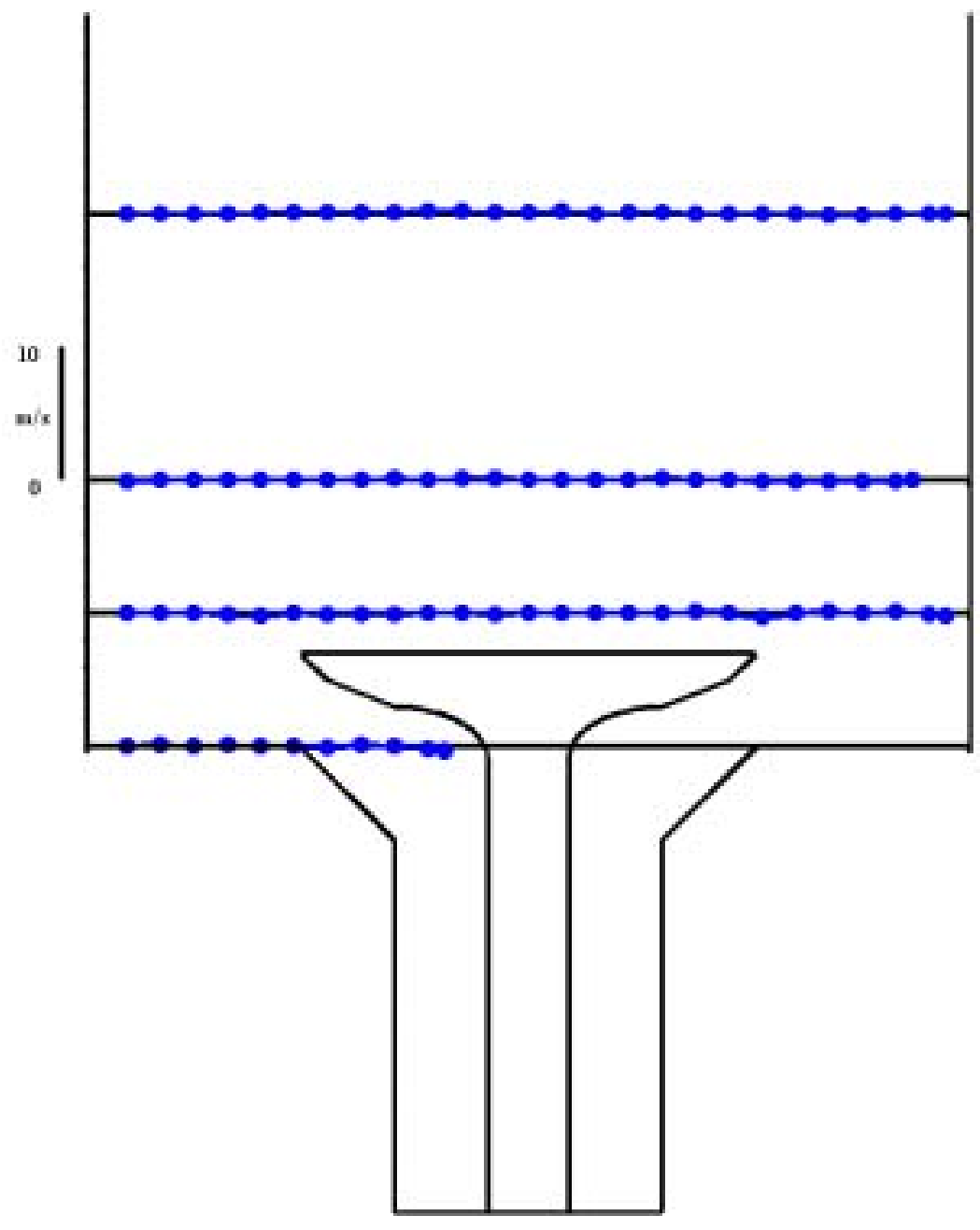

Figure 5.19: Swirl mean velocity measurements for $9 \mathrm{~mm}$ valve lift and straight intake using LDA.

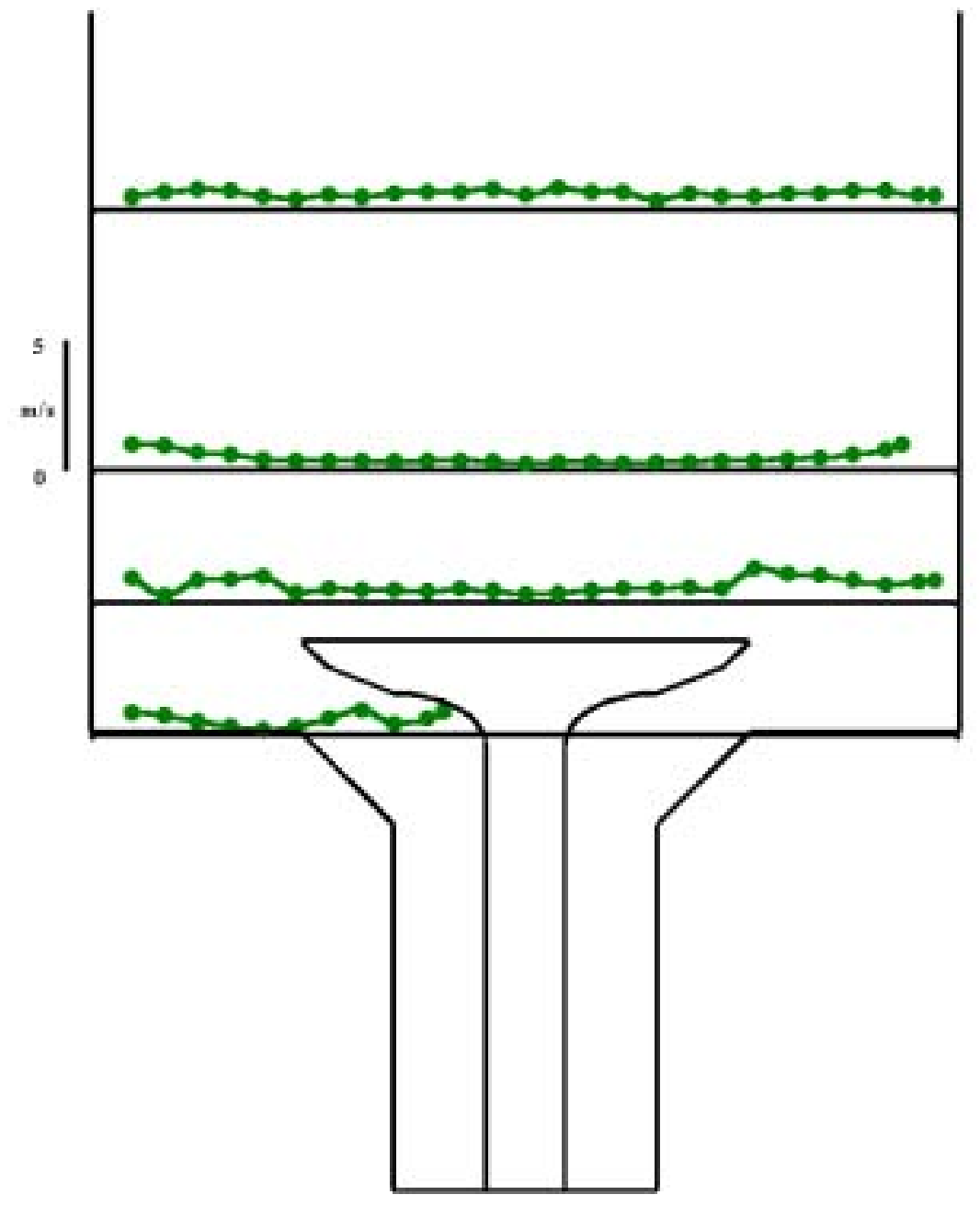

Figure 5.20: Swirl standard deviation measurements for $9 \mathrm{~mm}$ valve lift and straight intake using LDA. 


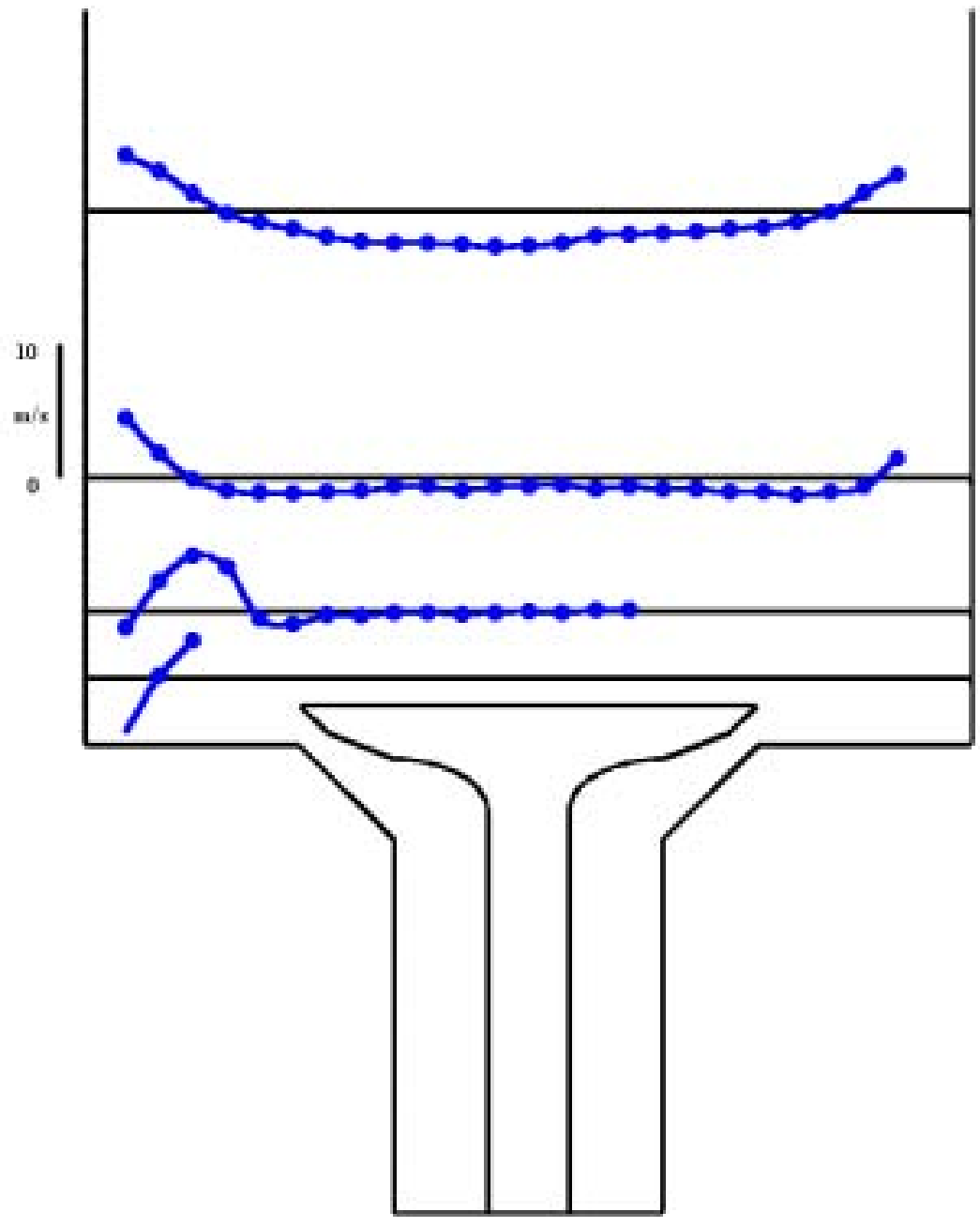

Figure 5.21: Axial mean velocity measurements for $4 \mathrm{~mm}$ valve lift and swirl intake using LDA.

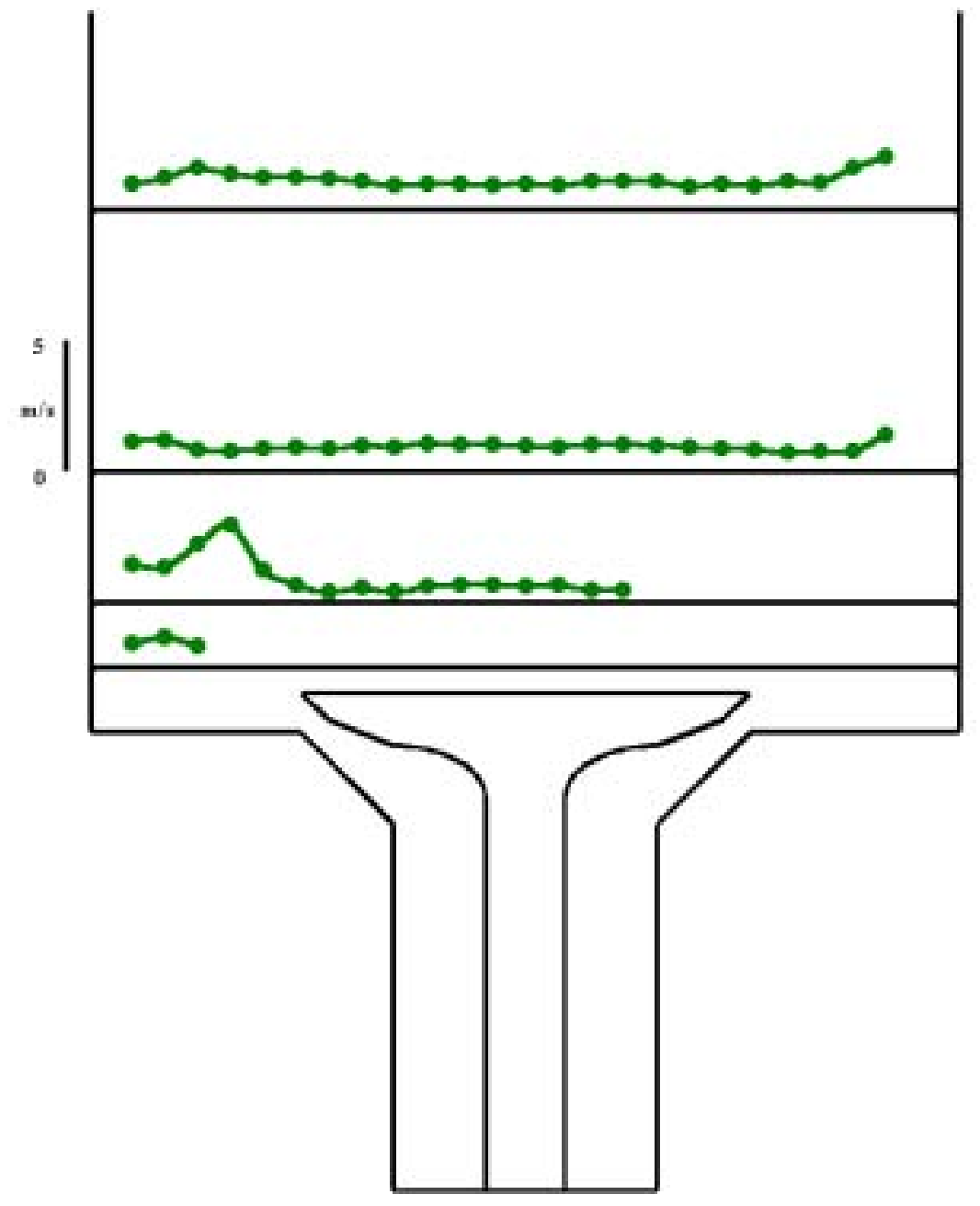

Figure 5.22: Axial standard deviation measurements for $4 \mathrm{~mm}$ valve lift and swirl intake using LDA. 


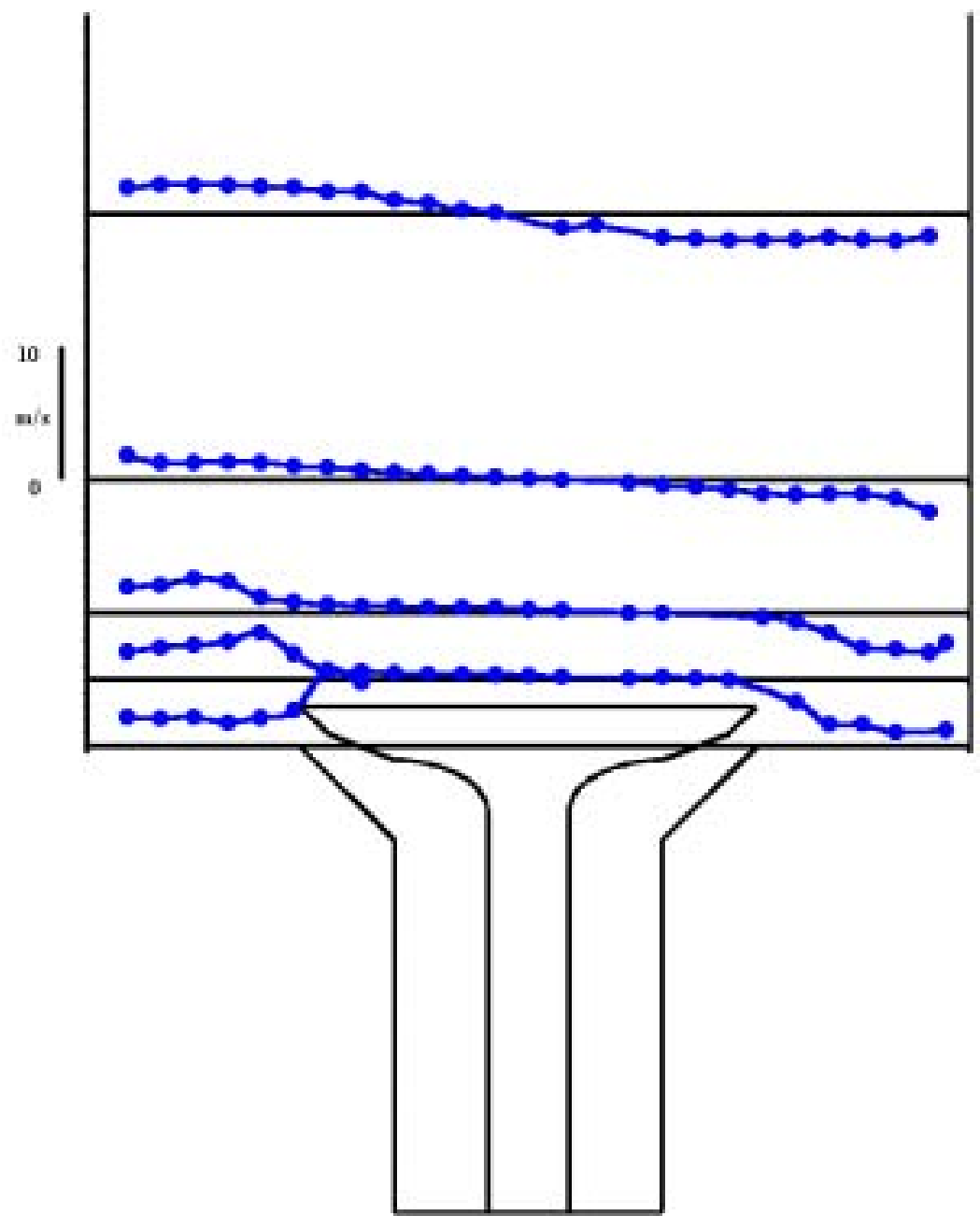

Figure 5.23: Swirl mean velocity measurements for $4 \mathrm{~mm}$ valve lift and swirl intake using LDA.

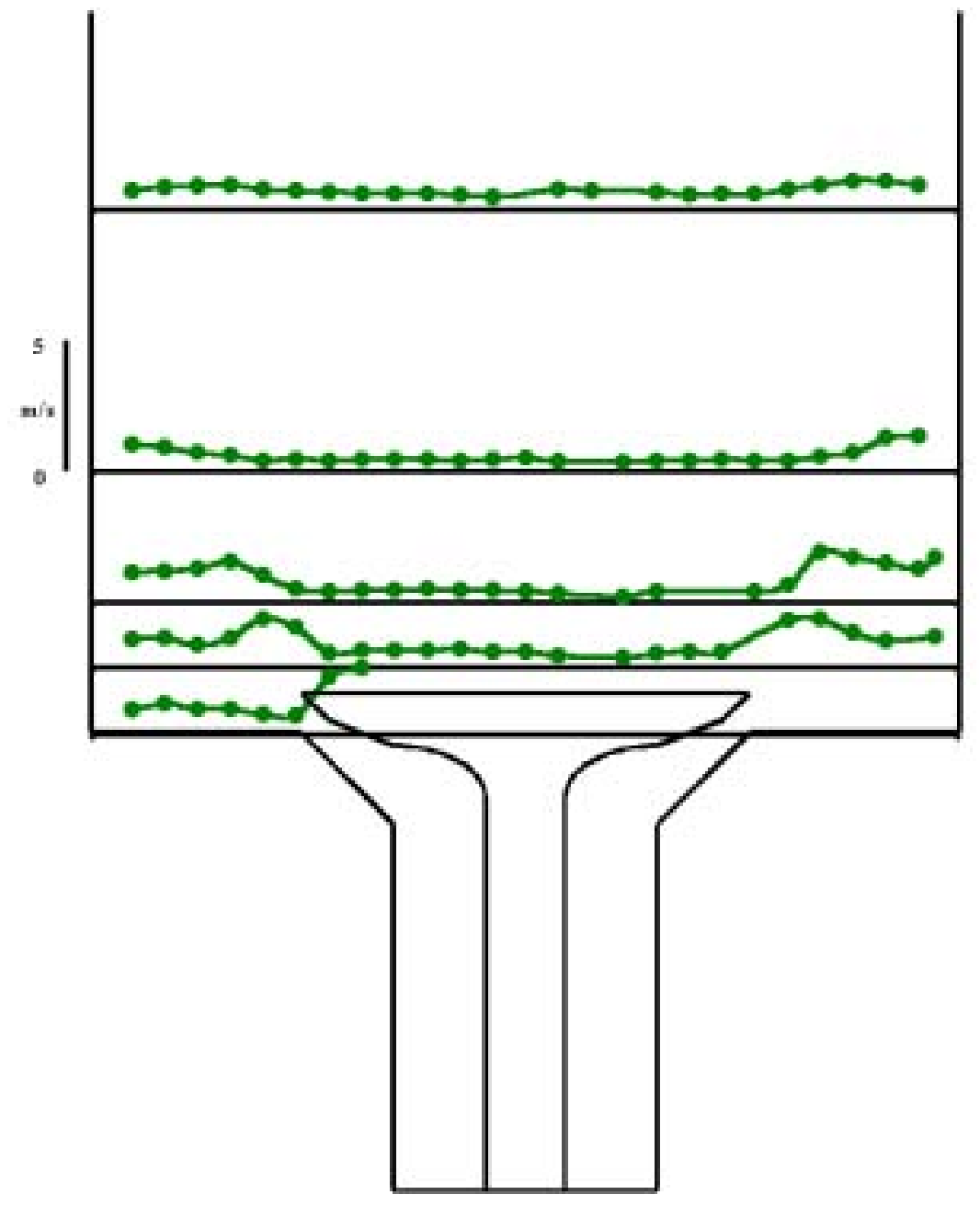

Figure 5.24: Swirl standard deviation measurements for $4 \mathrm{~mm}$ valve lift and swirl intake using LDA. 


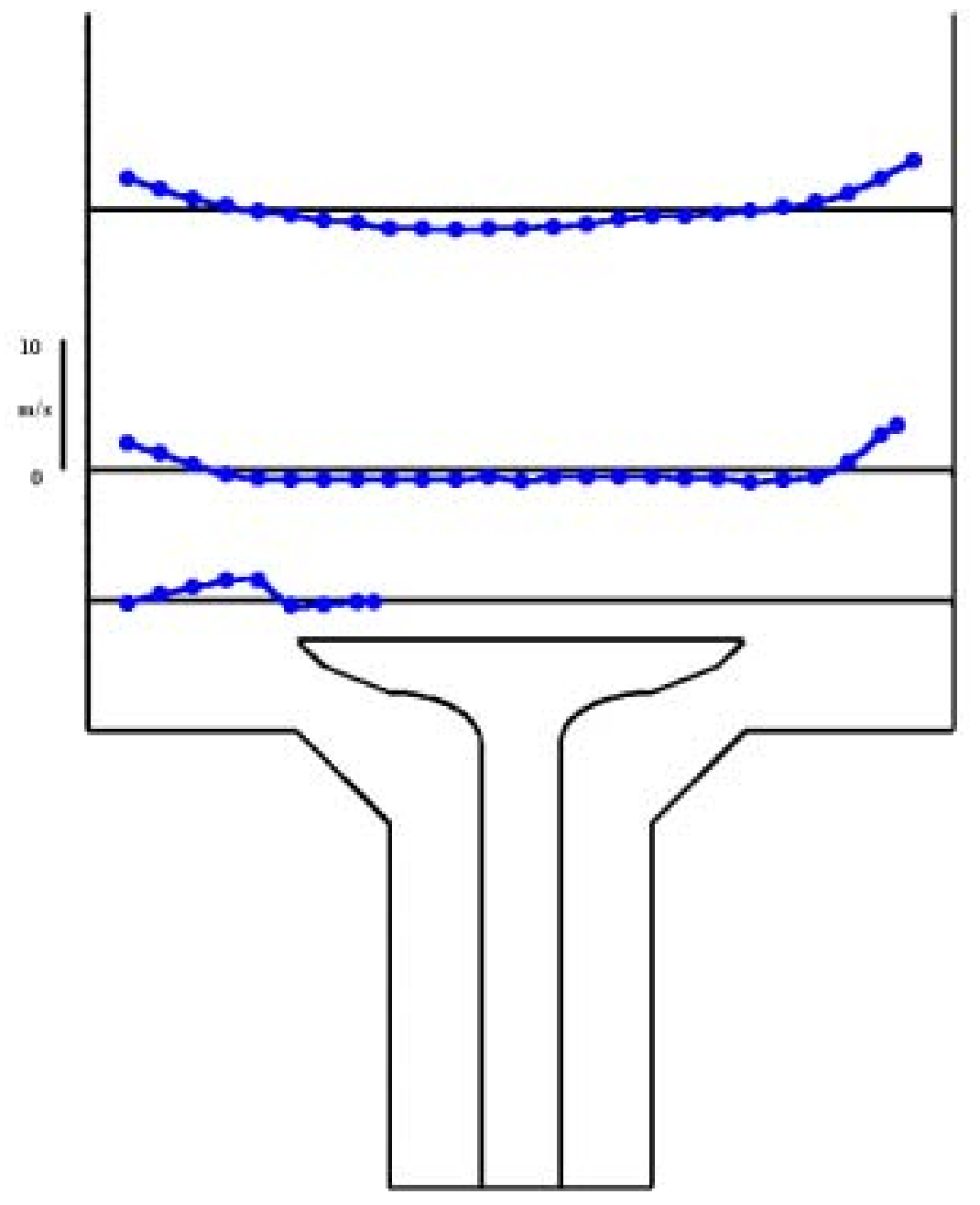

Figure 5.25: Axial mean velocity measurements for $9 \mathrm{~mm}$ valve lift and swirl intake using LDA.

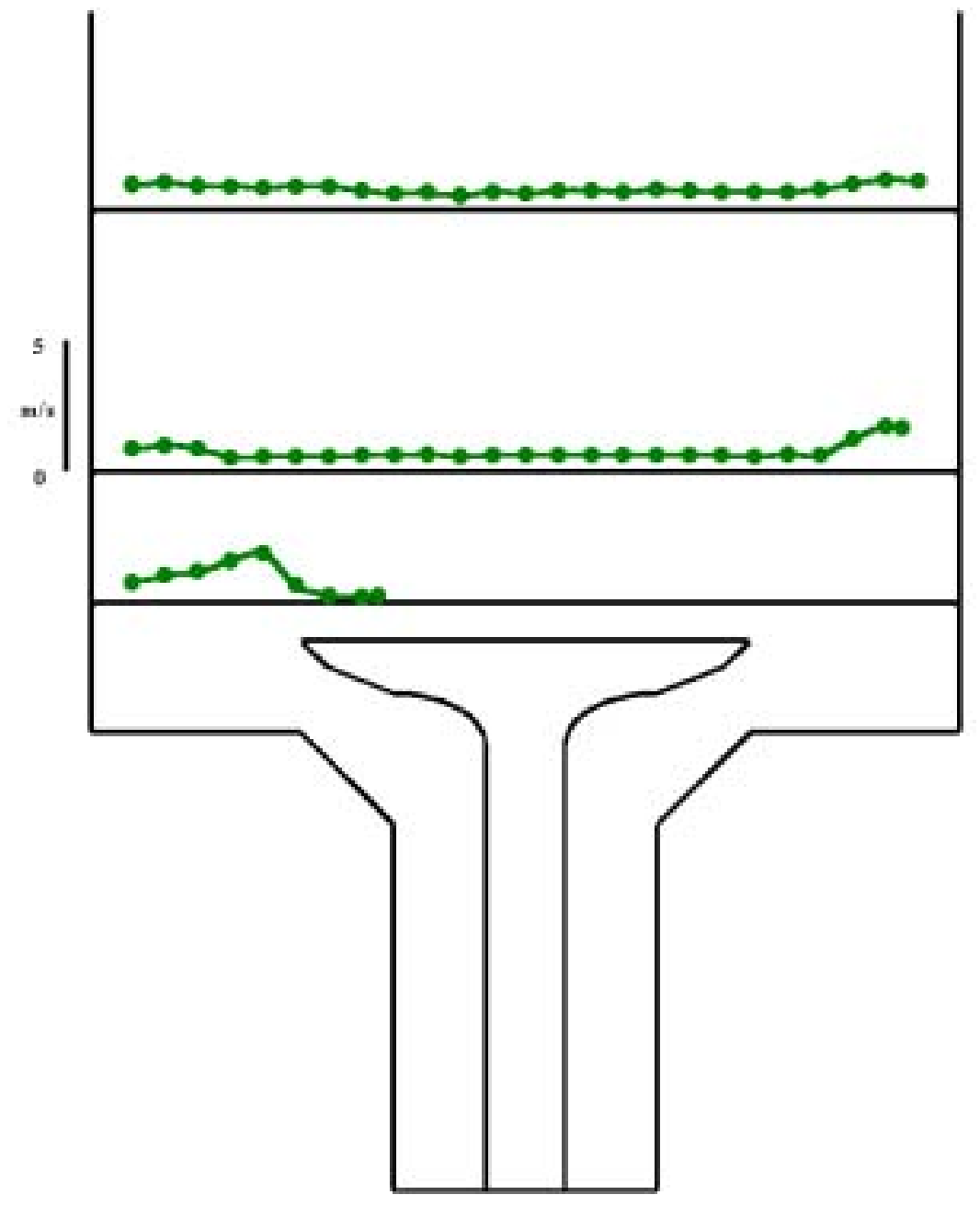

Figure 5.26: Axial standard deviation measurements for $9 \mathrm{~mm}$ valve lift and swirl intake using LDA. 


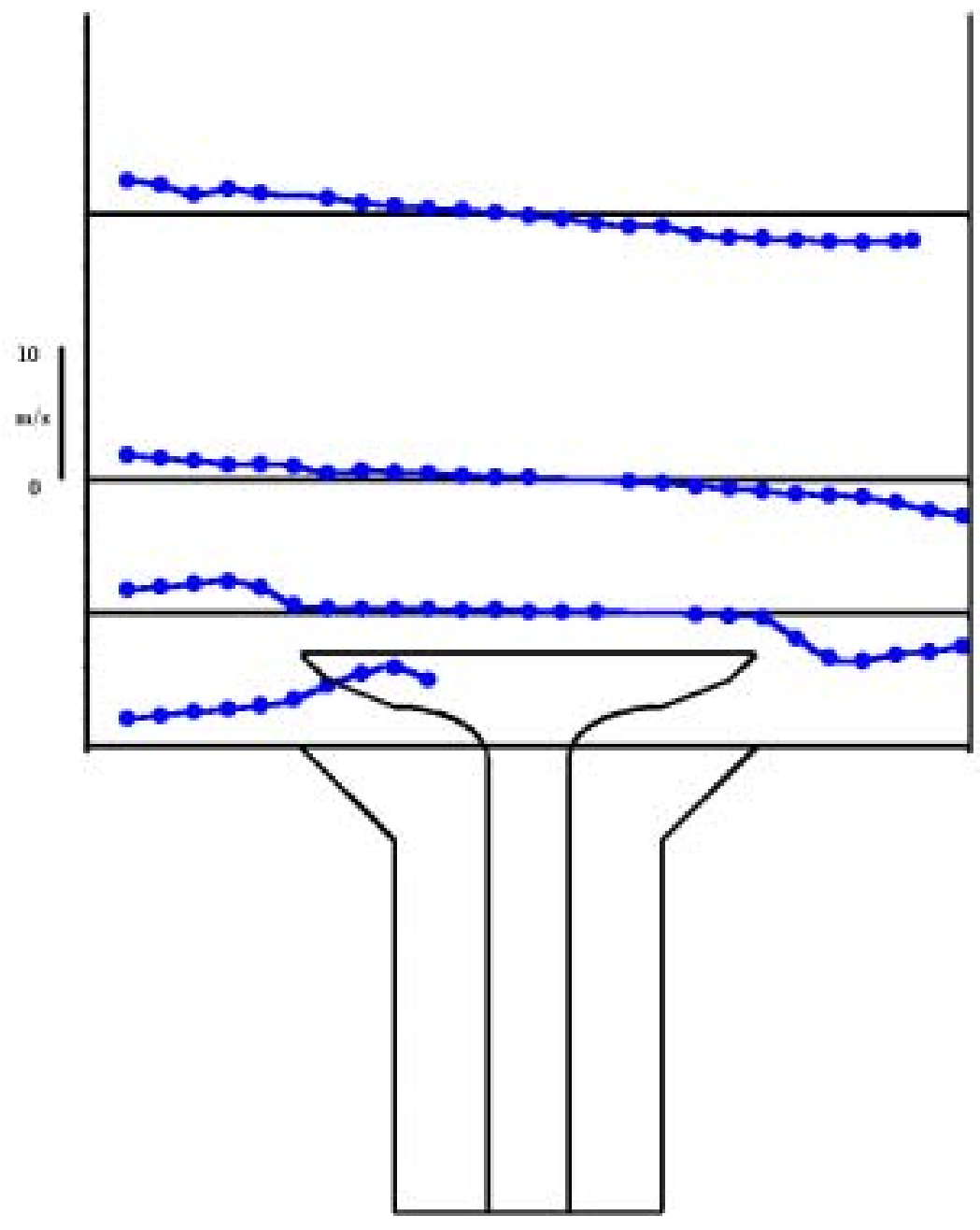

Figure 5.27: Swirl mean velocity measurements for $9 \mathrm{~mm}$ valve lift and swirl intake using LDA.

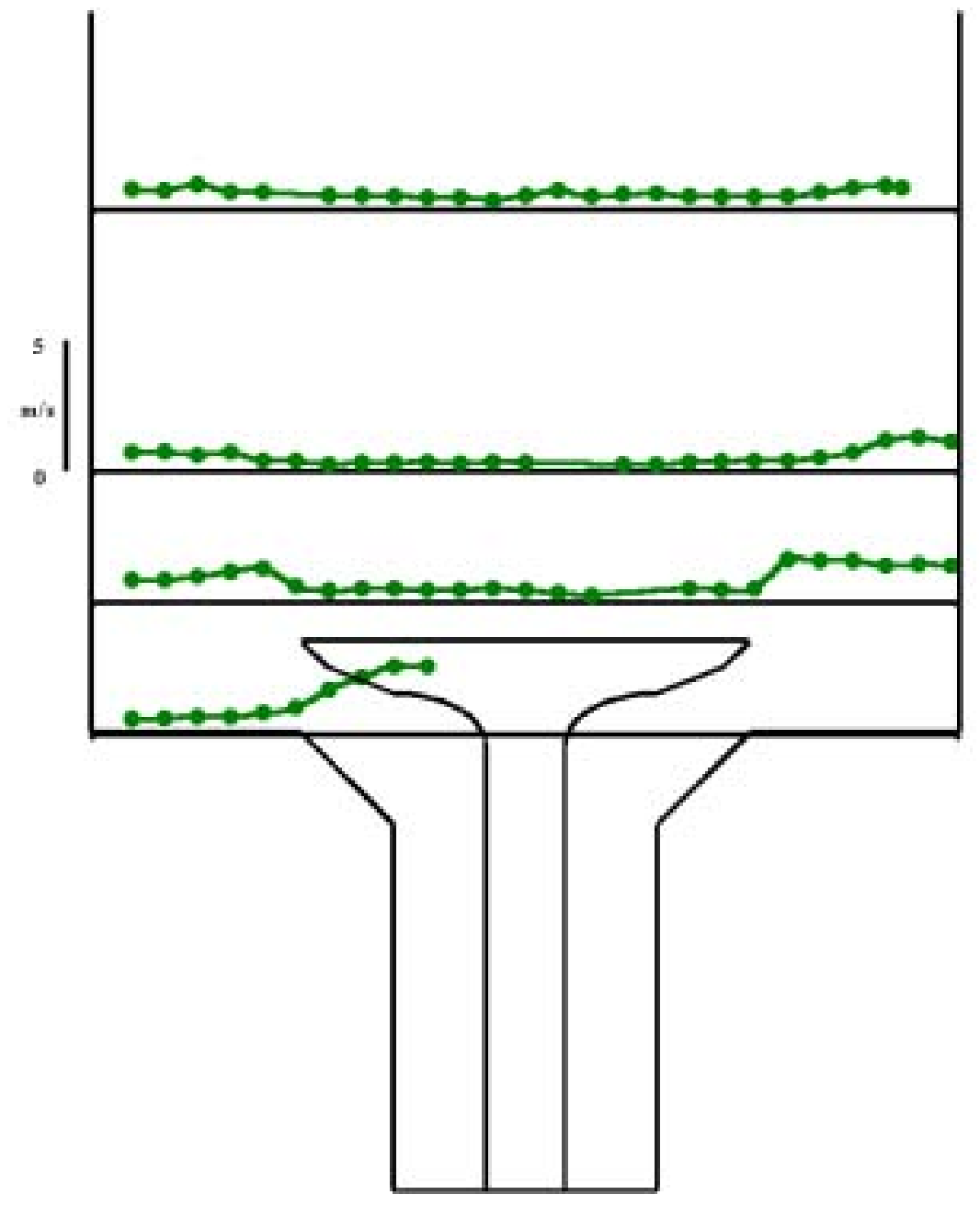

Figure 5.28: Swirl standard deviation measurements for $9 \mathrm{~mm}$ valve lift and swirl intake using LDA. 


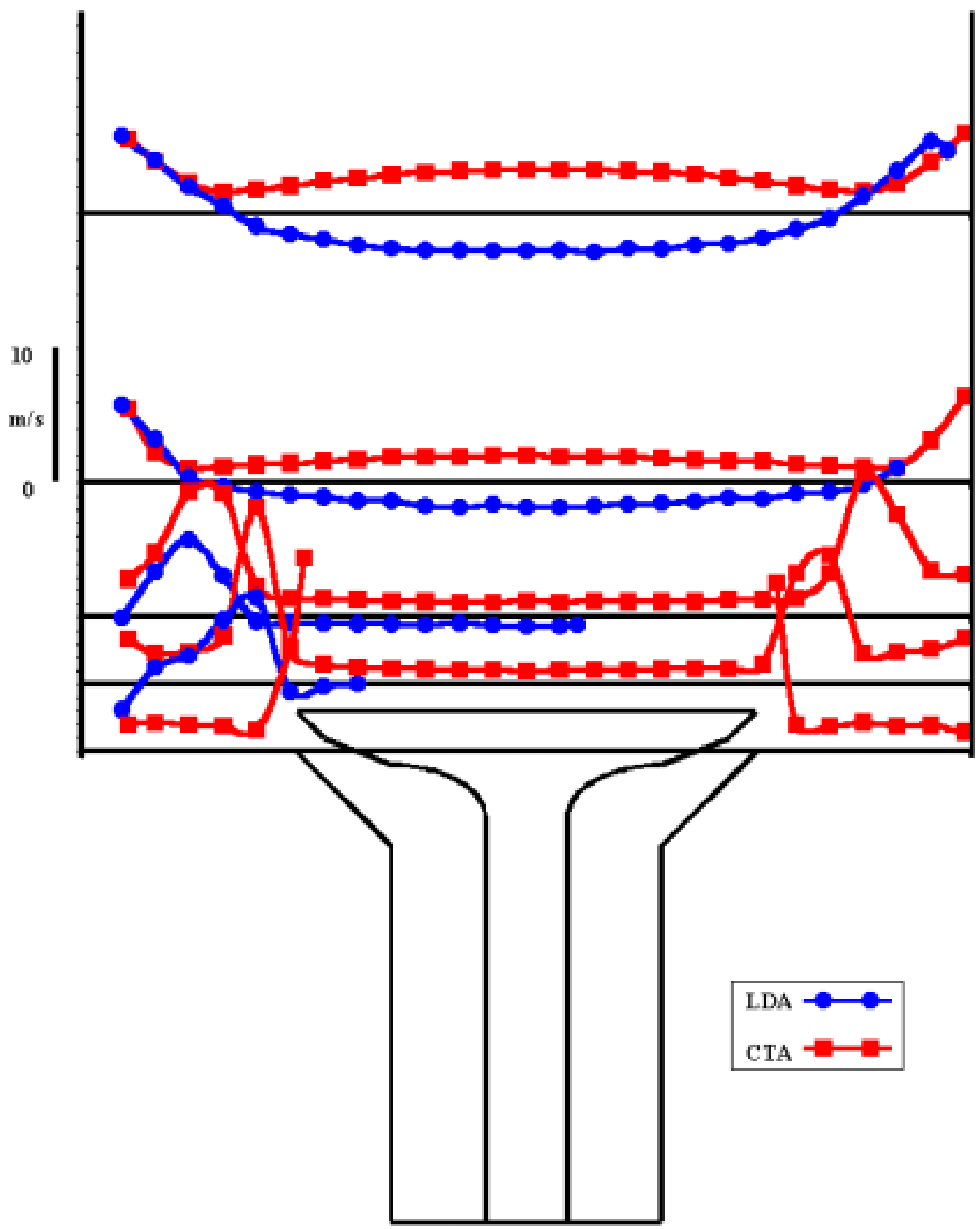

Figure 5.29: Comparison between LDA axial mean velocity and CTA axial/radial mean velocity measurements with $4 \mathrm{~mm}$ valve lift and straight intake. 


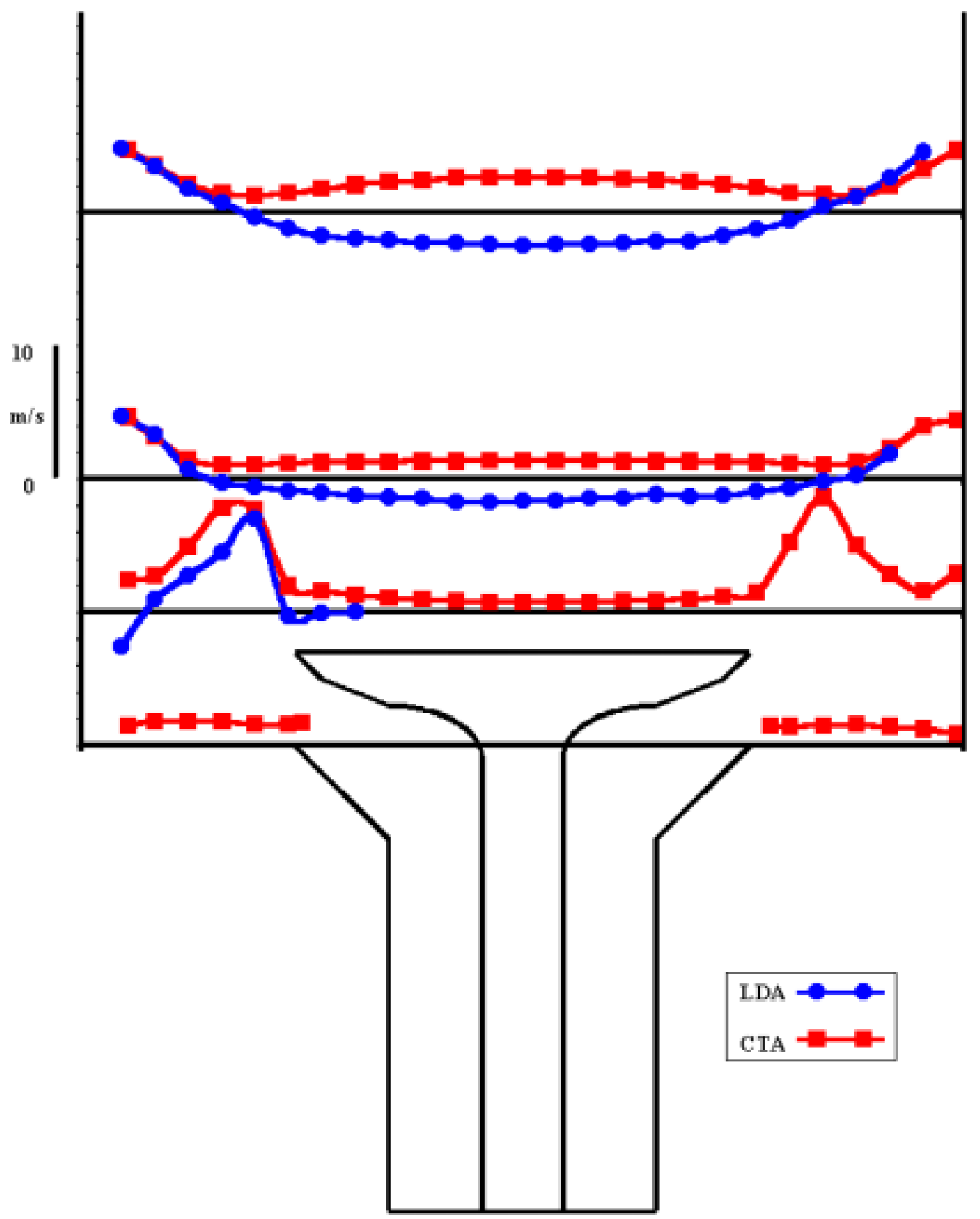

Figure 5.30: Comparison between LDA axial mean velocity and CTA axial/radial mean velocity measurements with $9 \mathrm{~mm}$ valve lift and straight intake. 


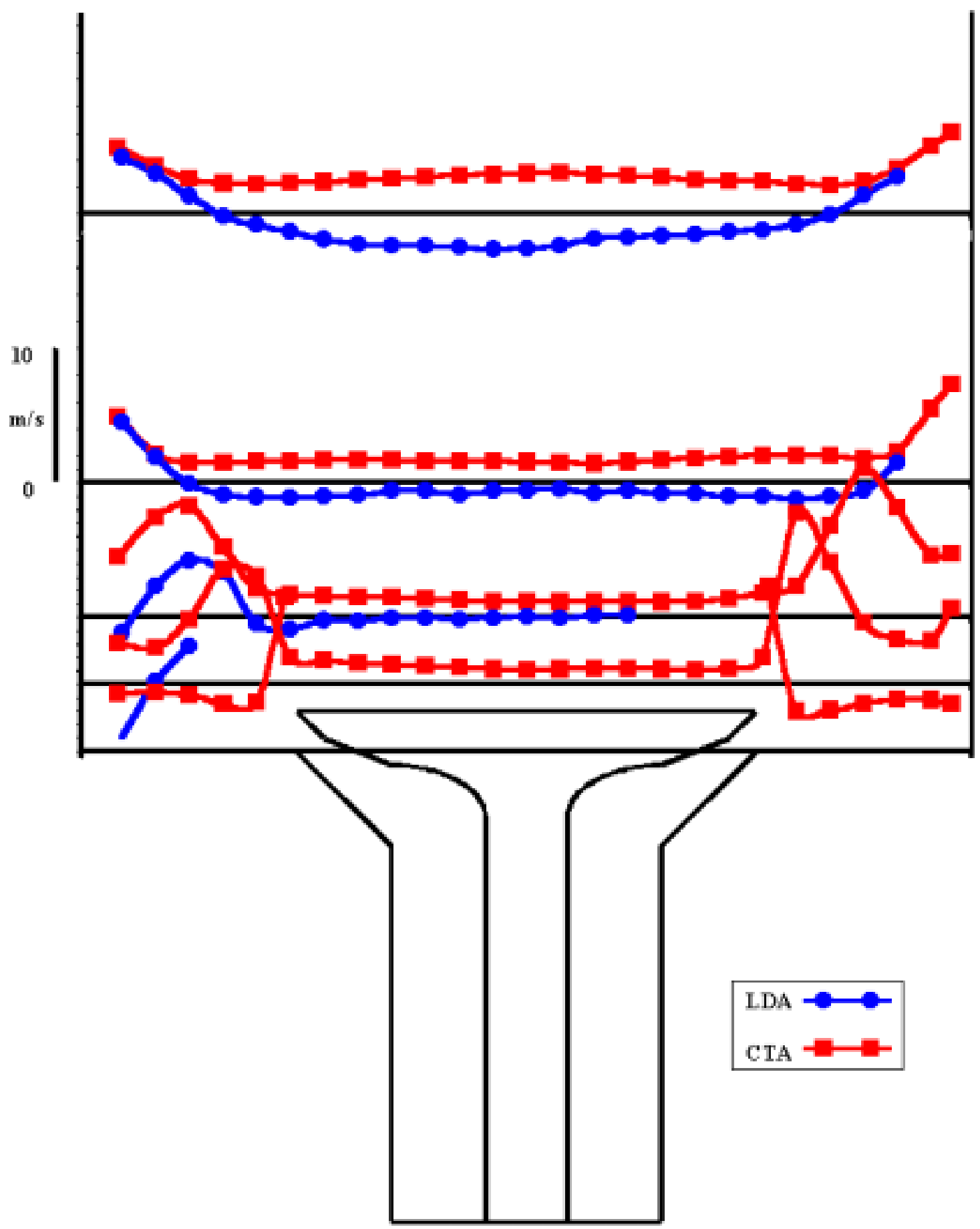

Figure 5.31: Comparison between LDA axial mean velocity and CTA axial/radial mean velocity measurements with $4 \mathrm{~mm}$ valve lift and swirl intake. 


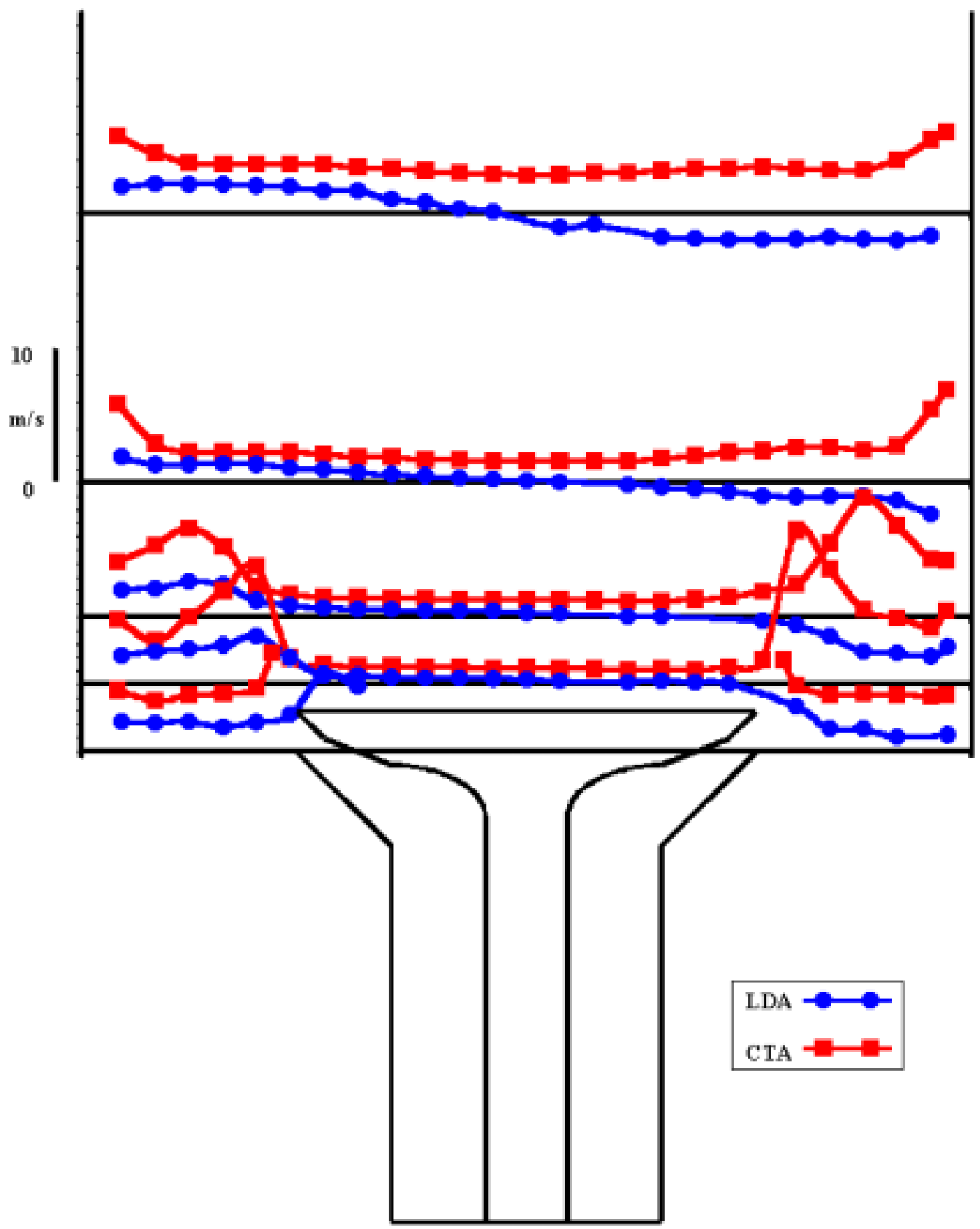

Figure 5.32: Comparison between LDA swirl mean velocity and CTA axial/swirl mean velocity measurements with $4 \mathrm{~mm}$ valve lift and swirl intake. 


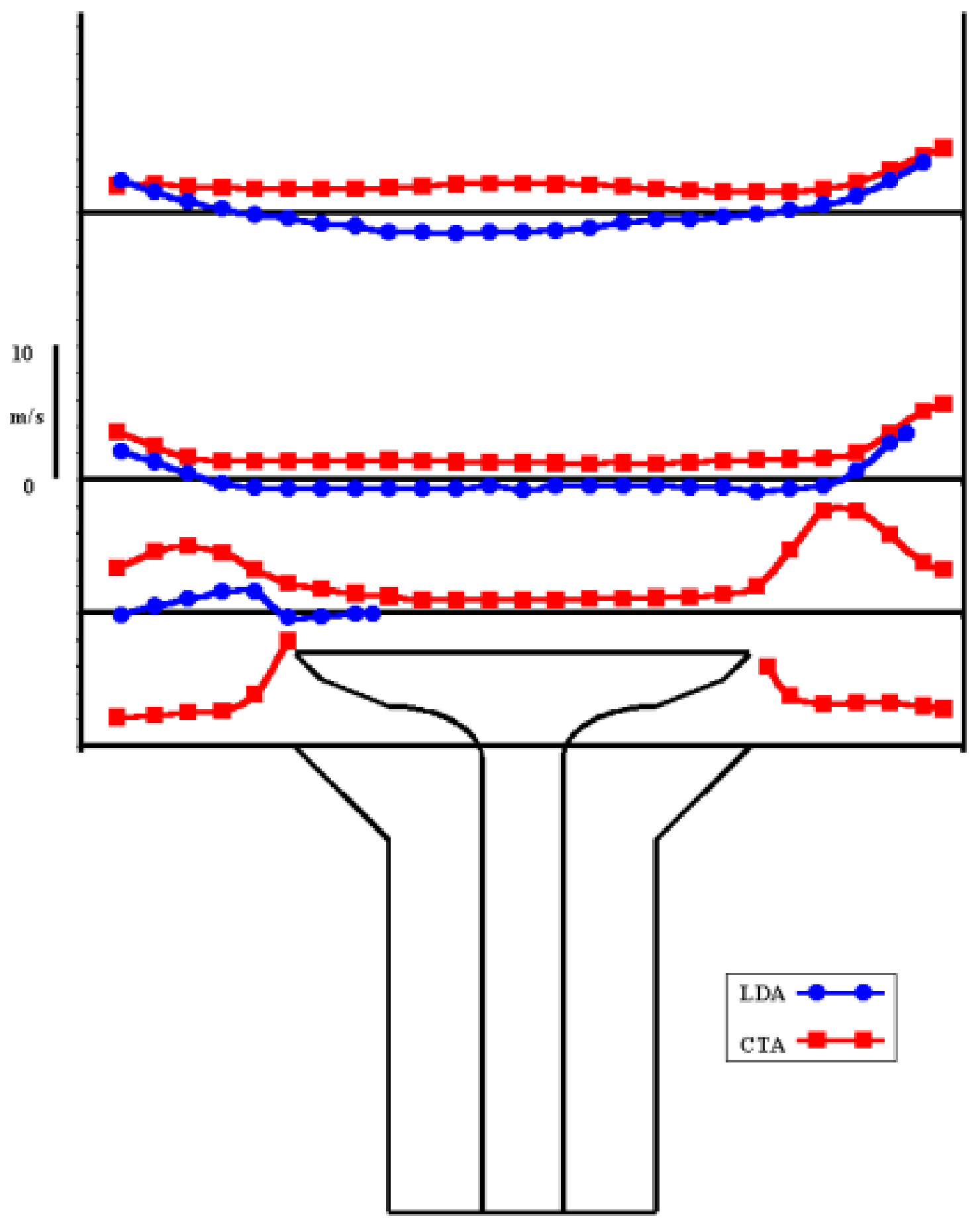

Figure 5.33: Comparison between LDA axial mean velocity and CTA axial/radial mean velocity measurements with $9 \mathrm{~mm}$ valve lift and swirl intake. 


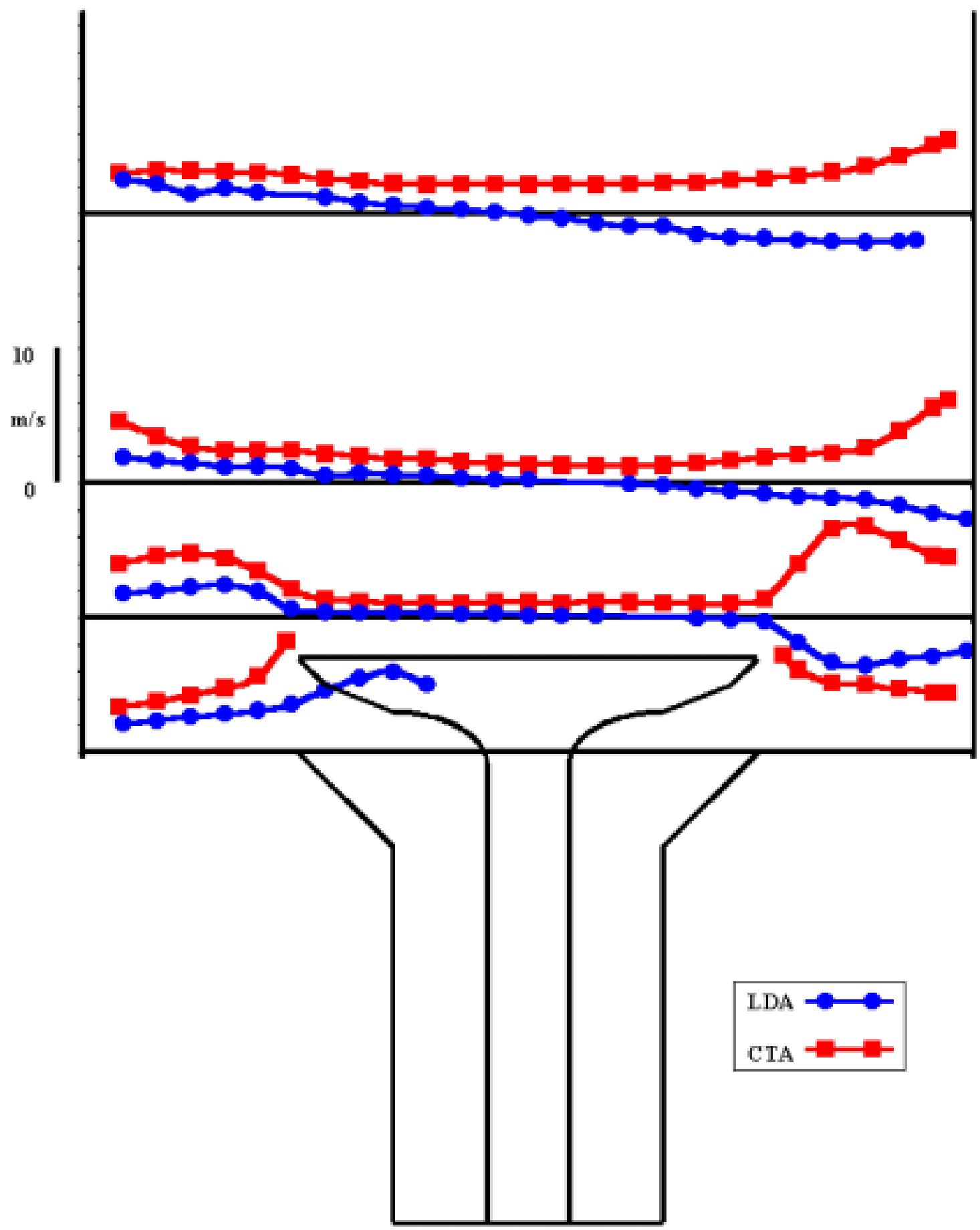

Figure 5.34: Comparison between LDA swirl mean velocity and CTA axial/swirl mean velocity measurements with $9 \mathrm{~mm}$ valve lift and swirl intake. 


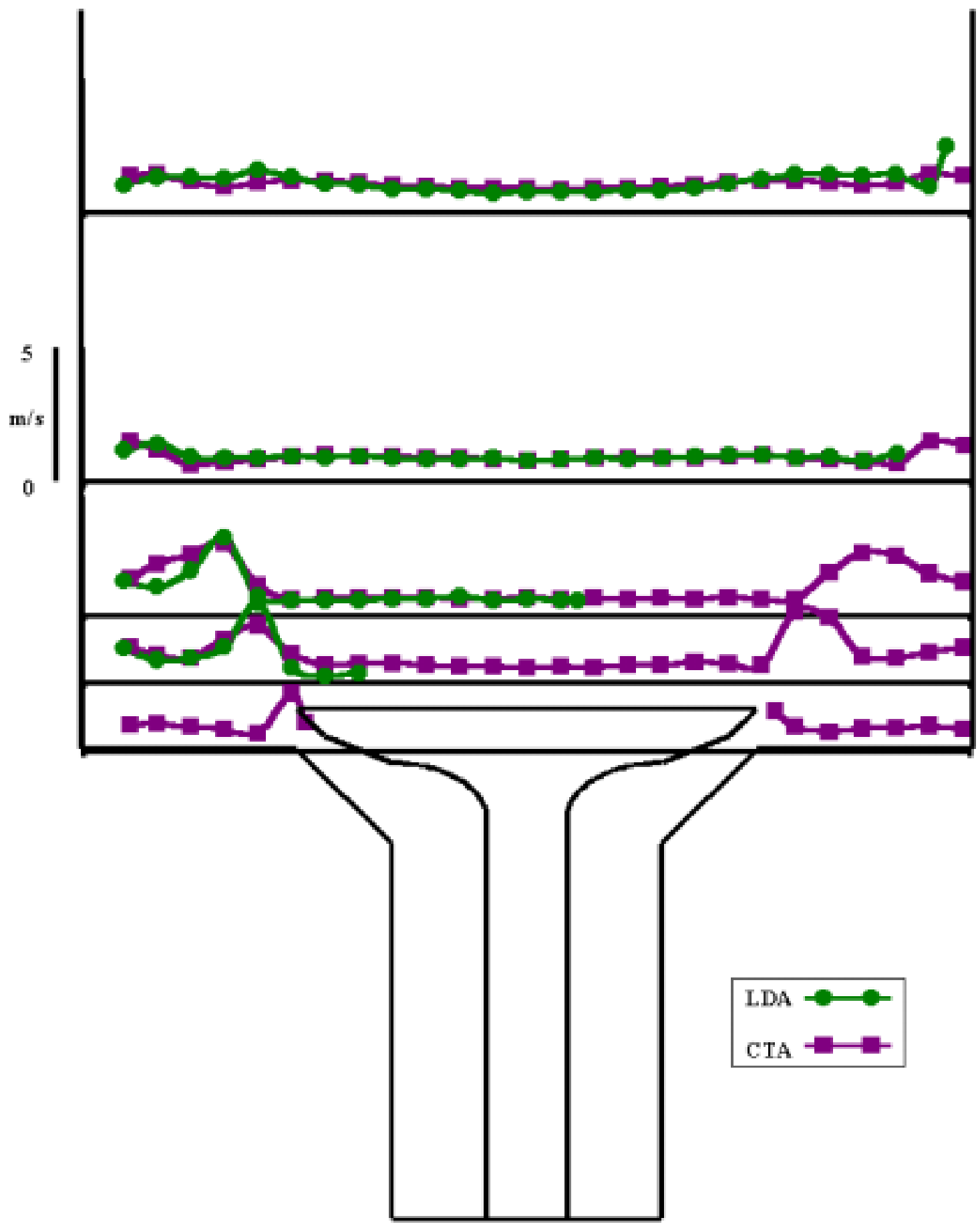

Figure 5.35: Comparison between LDA axial standard deviation and CTA axial/radial standard deviation measurements with $4 \mathrm{~mm}$ valve lift and straight intake. 


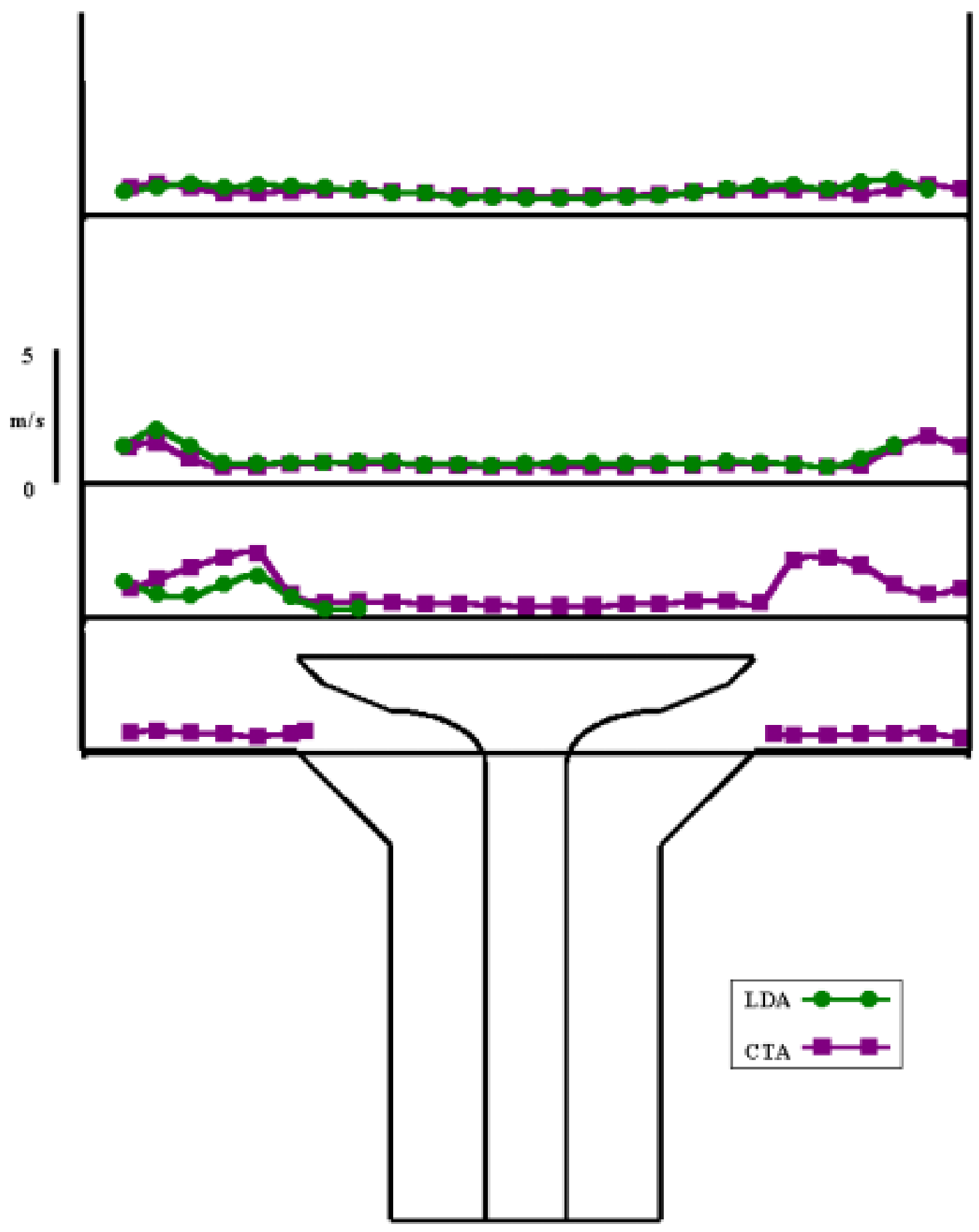

Figure 5.36: Comparison between LDA axial standard deviation and CTA axial/radial standard deviation measurements with $9 \mathrm{~mm}$ valve lift and straight intake. 


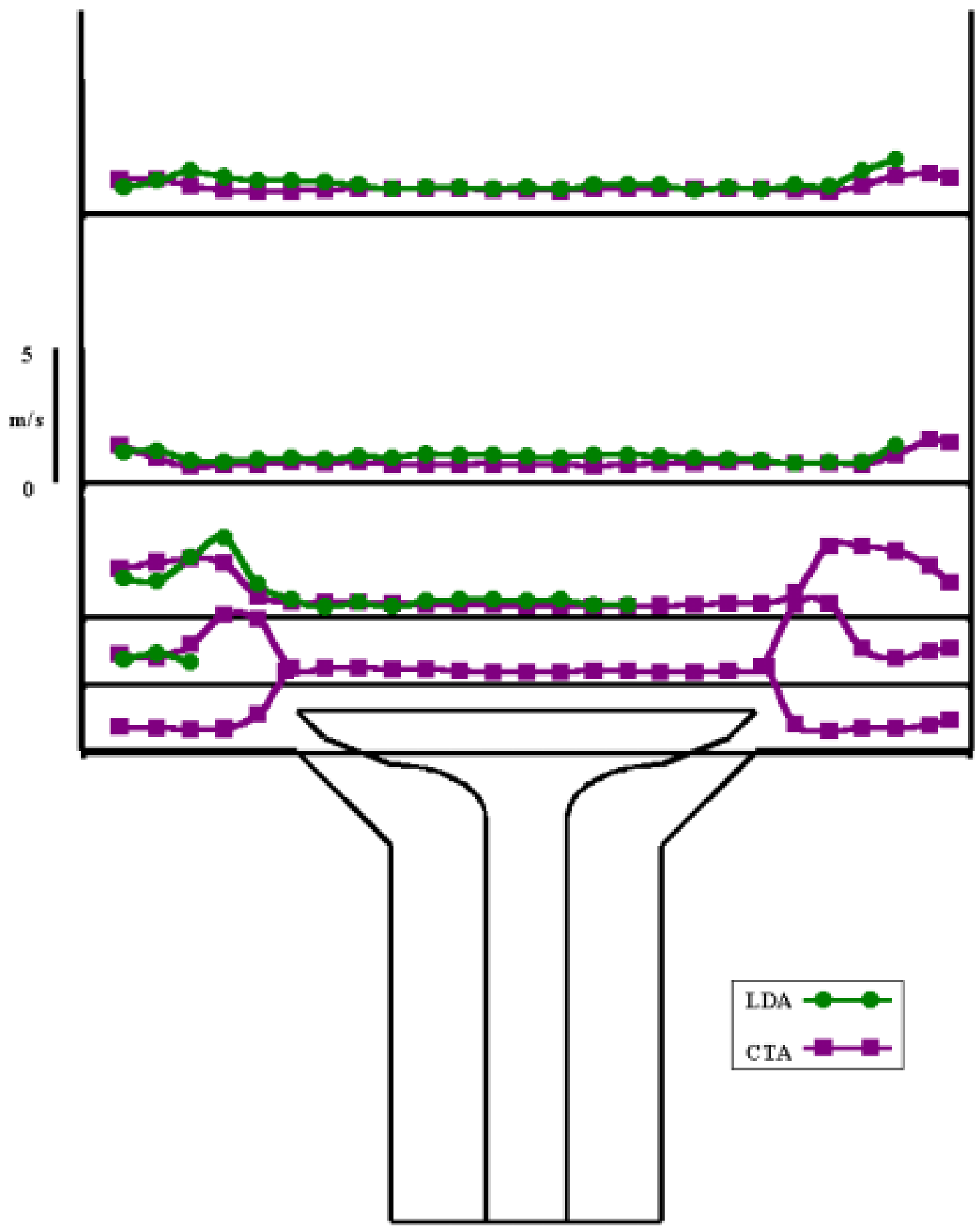

Figure 5.37: Comparison between LDA axial standard deviation and CTA axial/radial standard deviation measurements with $4 \mathrm{~mm}$ valve lift and swirl intake. 


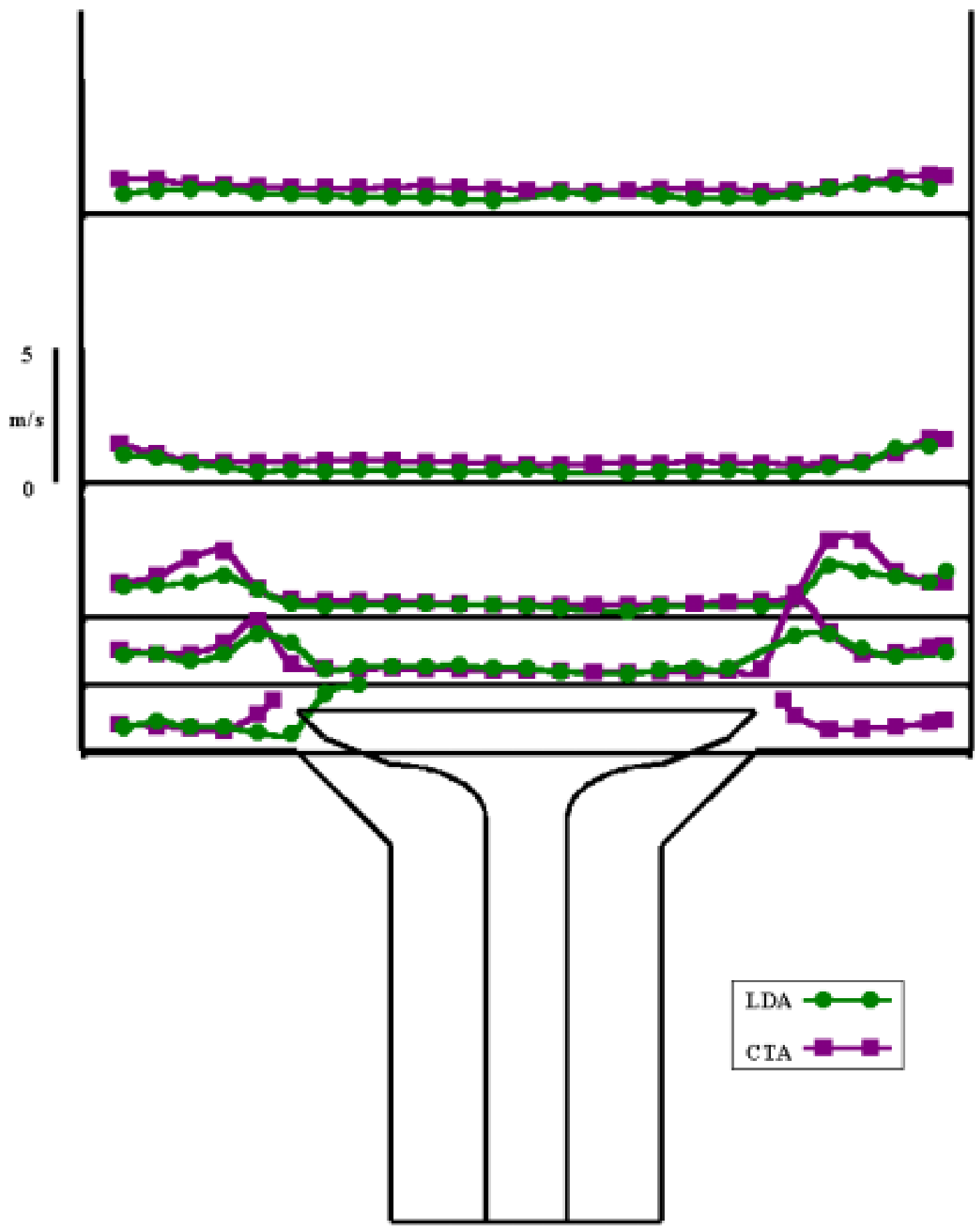

Figure 5.38: Comparison between LDA swirl standard deviation and CTA axial/swirl standard deviation measurements with $4 \mathrm{~mm}$ valve lift and swirl intake. 


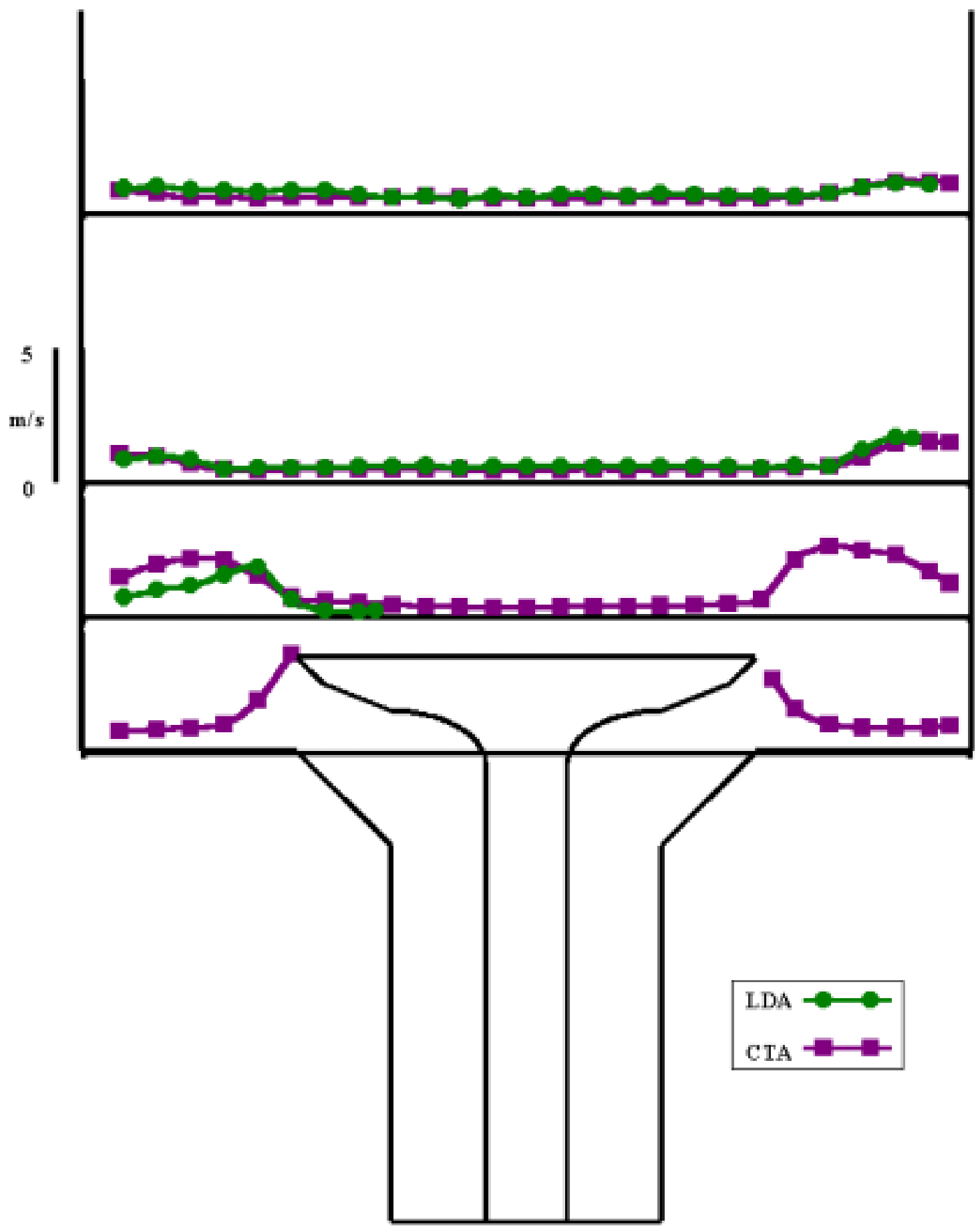

Figure 5.39: Comparison between LDA axial standard deviation and CTA axial/radial standard deviation measurements with $9 \mathrm{~mm}$ valve lift and swirl intake. 


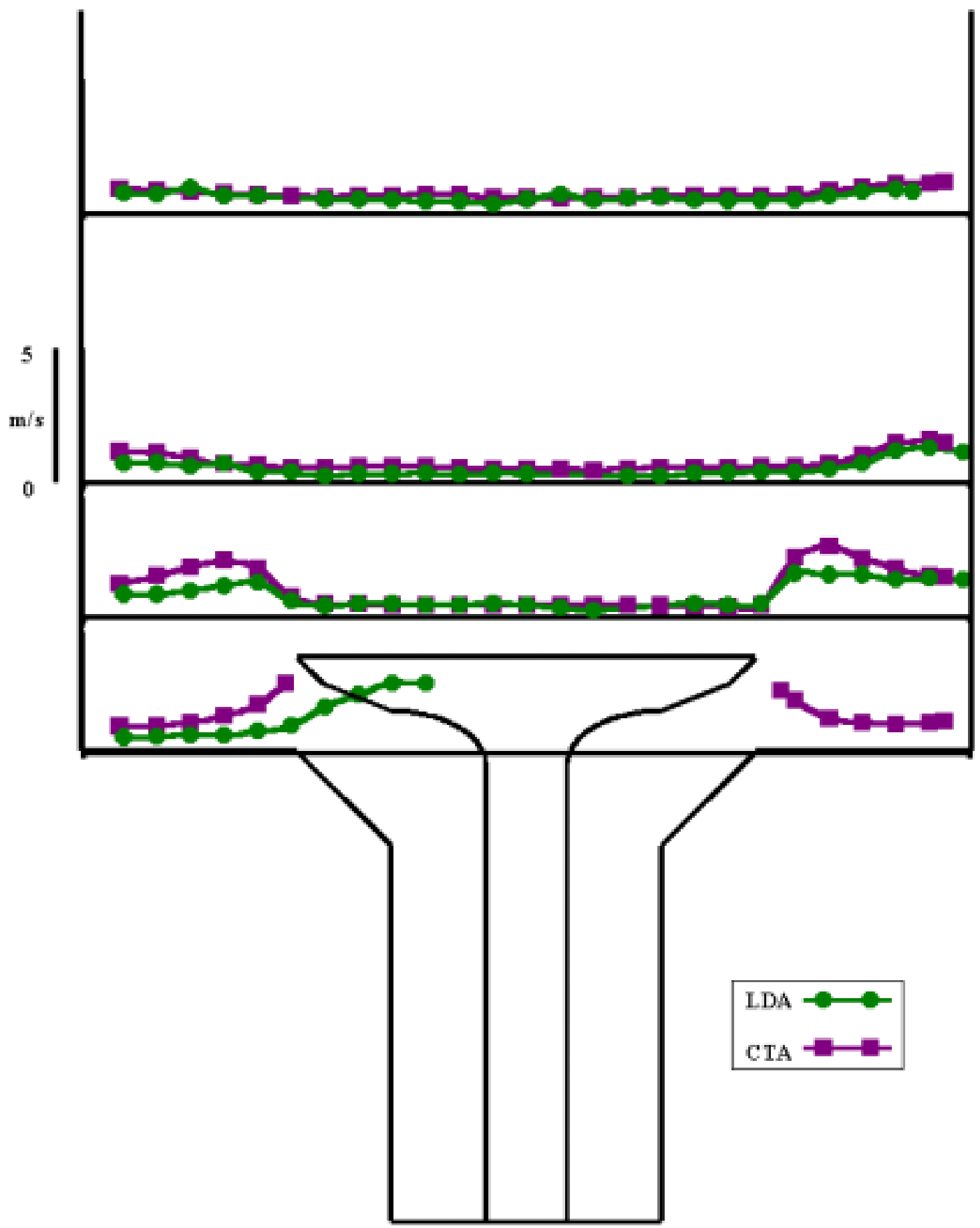

Figure 5.40: Comparison between LDA swirl standard deviation and CTA axial/swirl standard deviation measurements with $9 \mathrm{~mm}$ valve lift and swirl intake. 


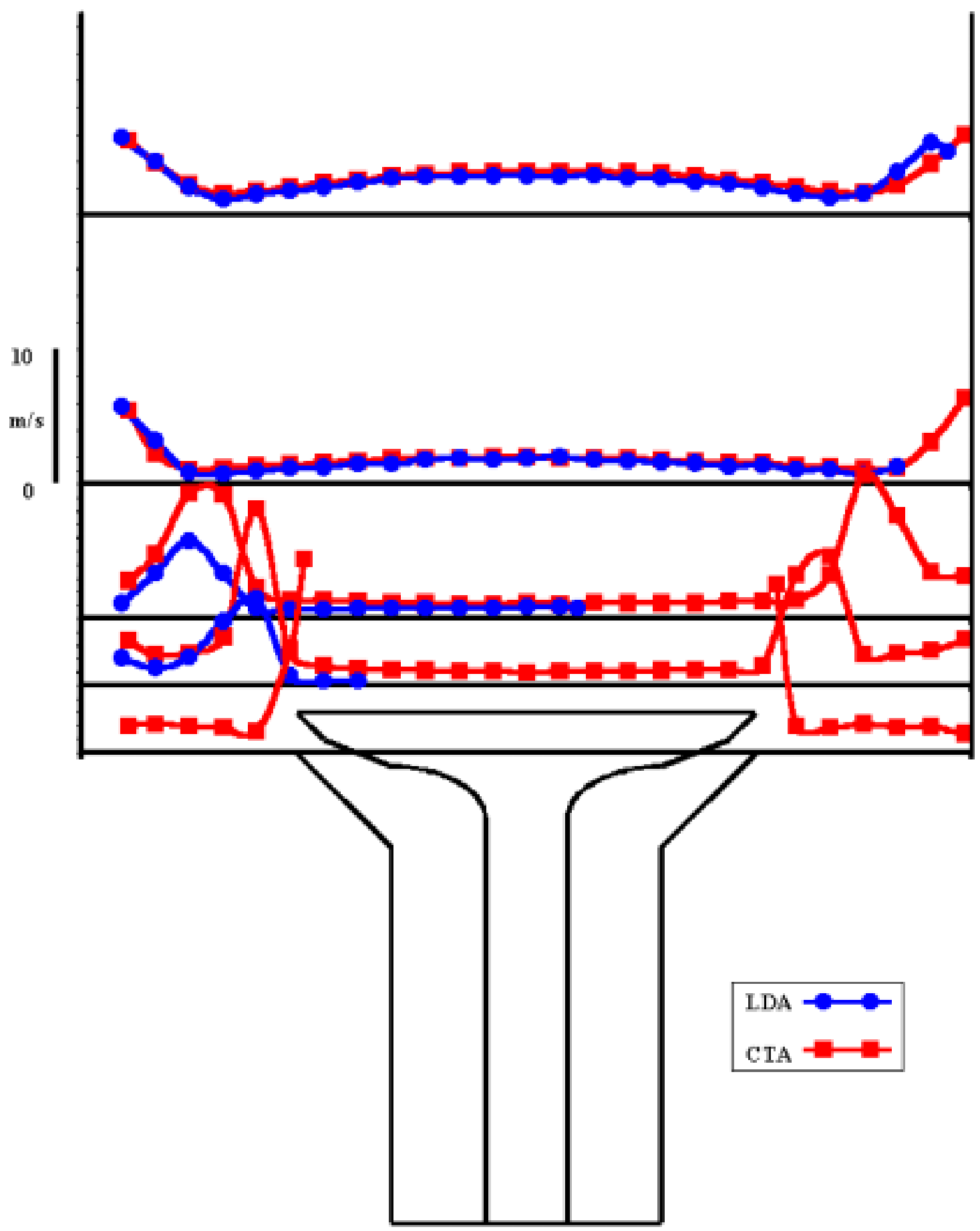

Figure 5.41: Comparison between LDA instantaneous absolute axial mean velocity and CTA axial/radial mean velocity measurements with $4 \mathrm{~mm}$ valve lift and straight intake. 


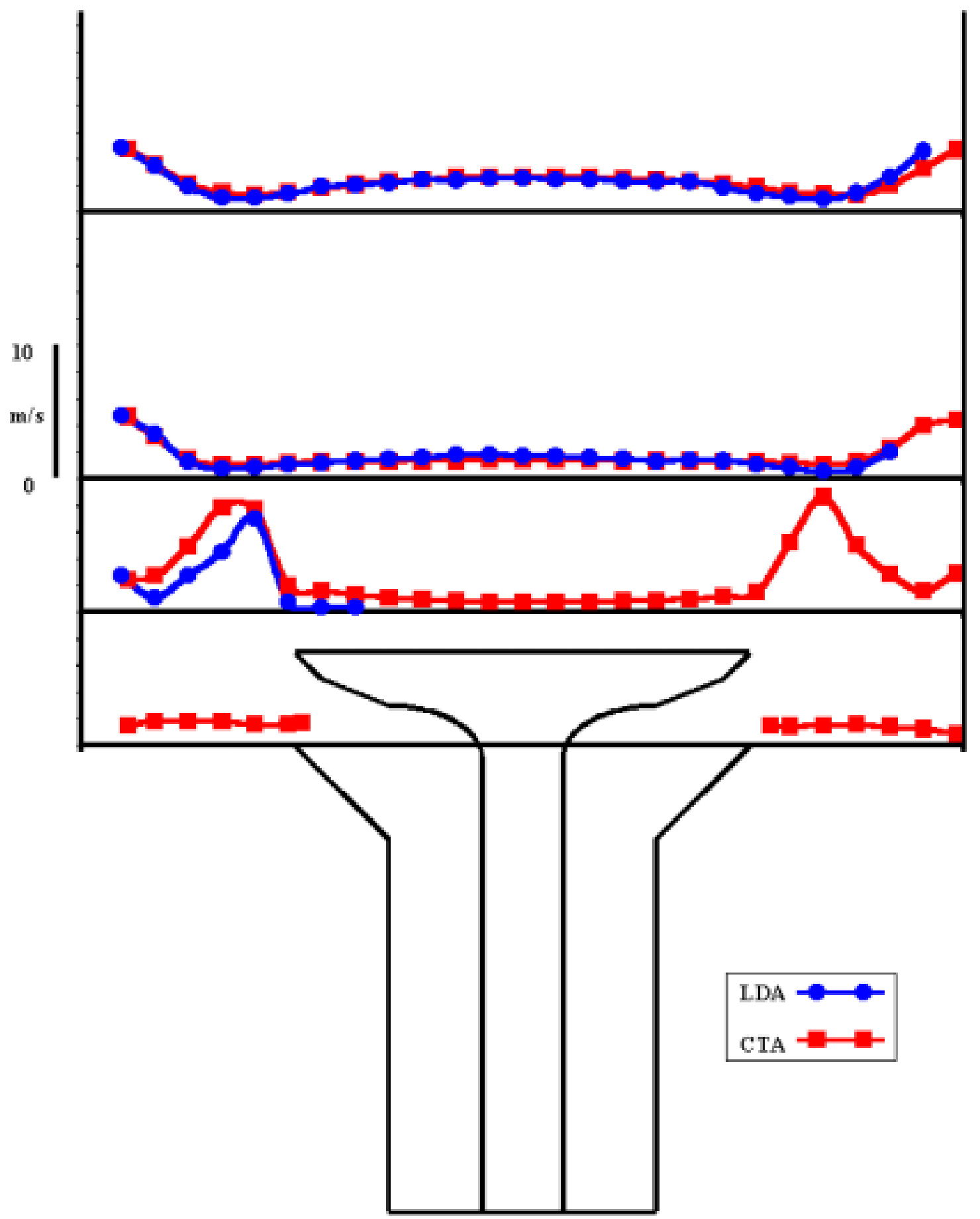

Figure 5.42: Comparison between LDA instantaneous absolute axial mean velocity and CTA axial/radial mean velocity measurements with $9 \mathrm{~mm}$ valve lift and straight intake. 


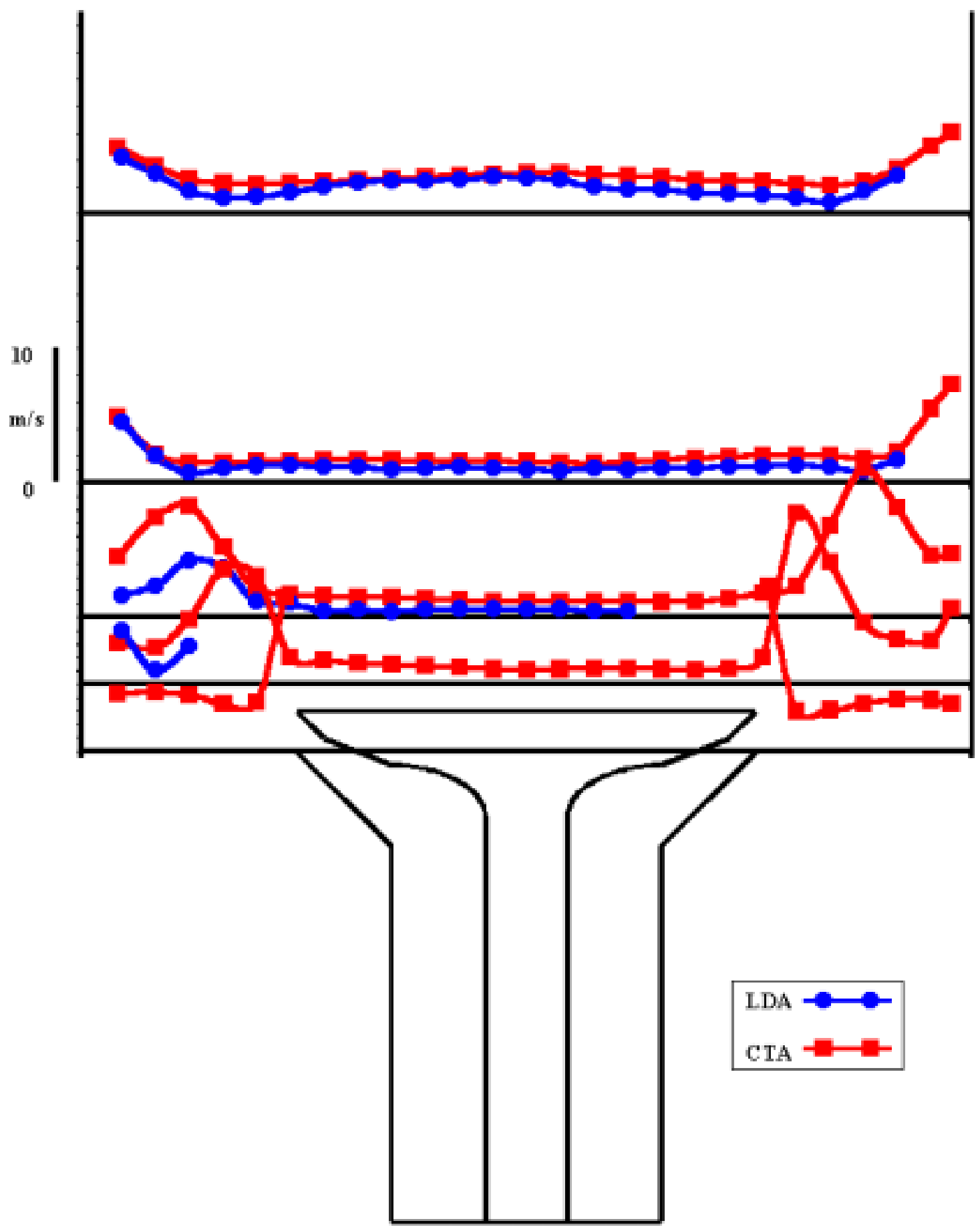

Figure 5.43: Comparison between LDA instantaneous absolute axial mean velocity and CTA axial/radial mean velocity measurements with $4 \mathrm{~mm}$ valve lift and swirl intake. 


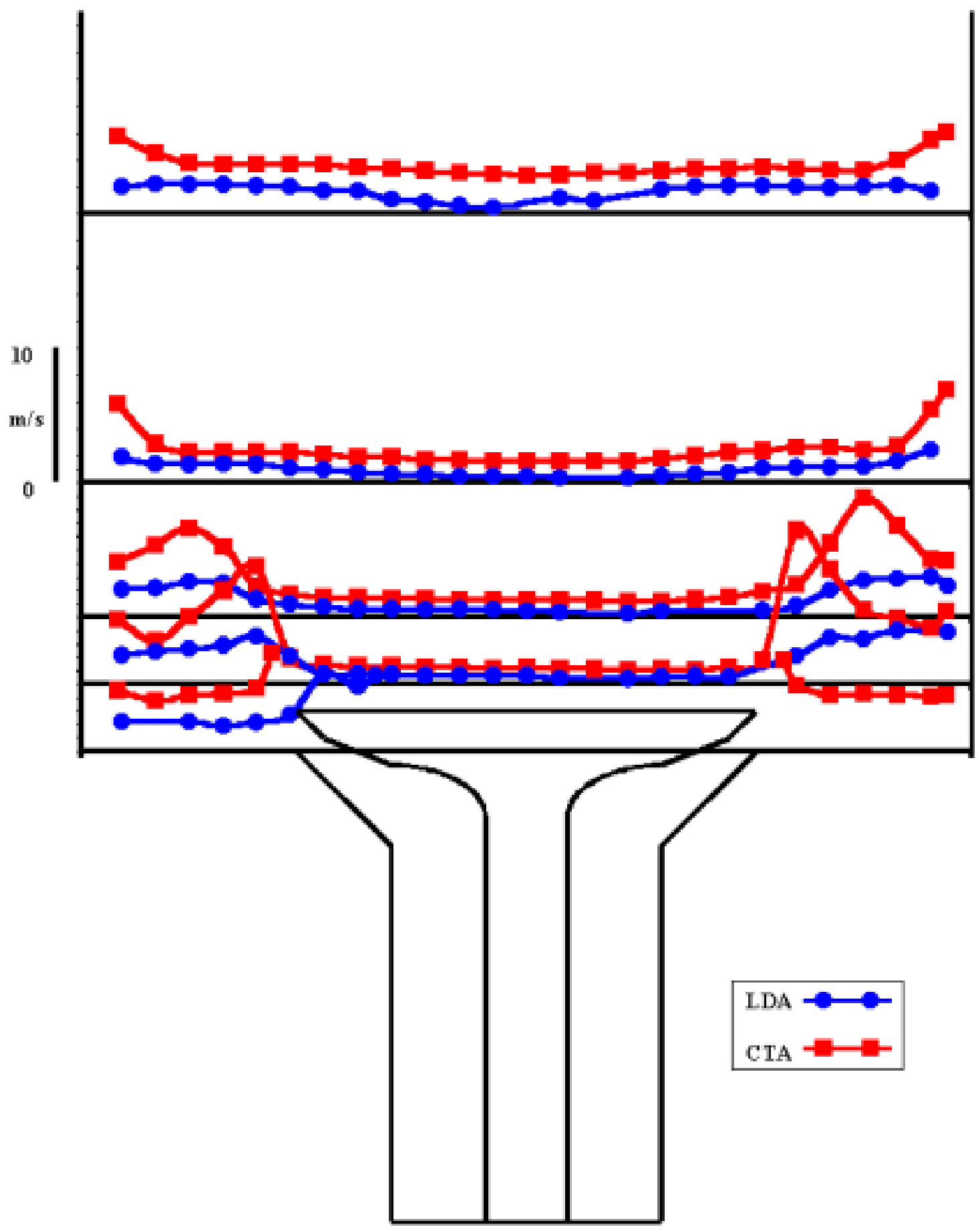

Figure 5.44: Comparison between LDA instantaneous absolute swirl mean velocity and CTA axial/swirl mean velocity measurements with $4 \mathrm{~mm}$ valve lift and swirl intake. 


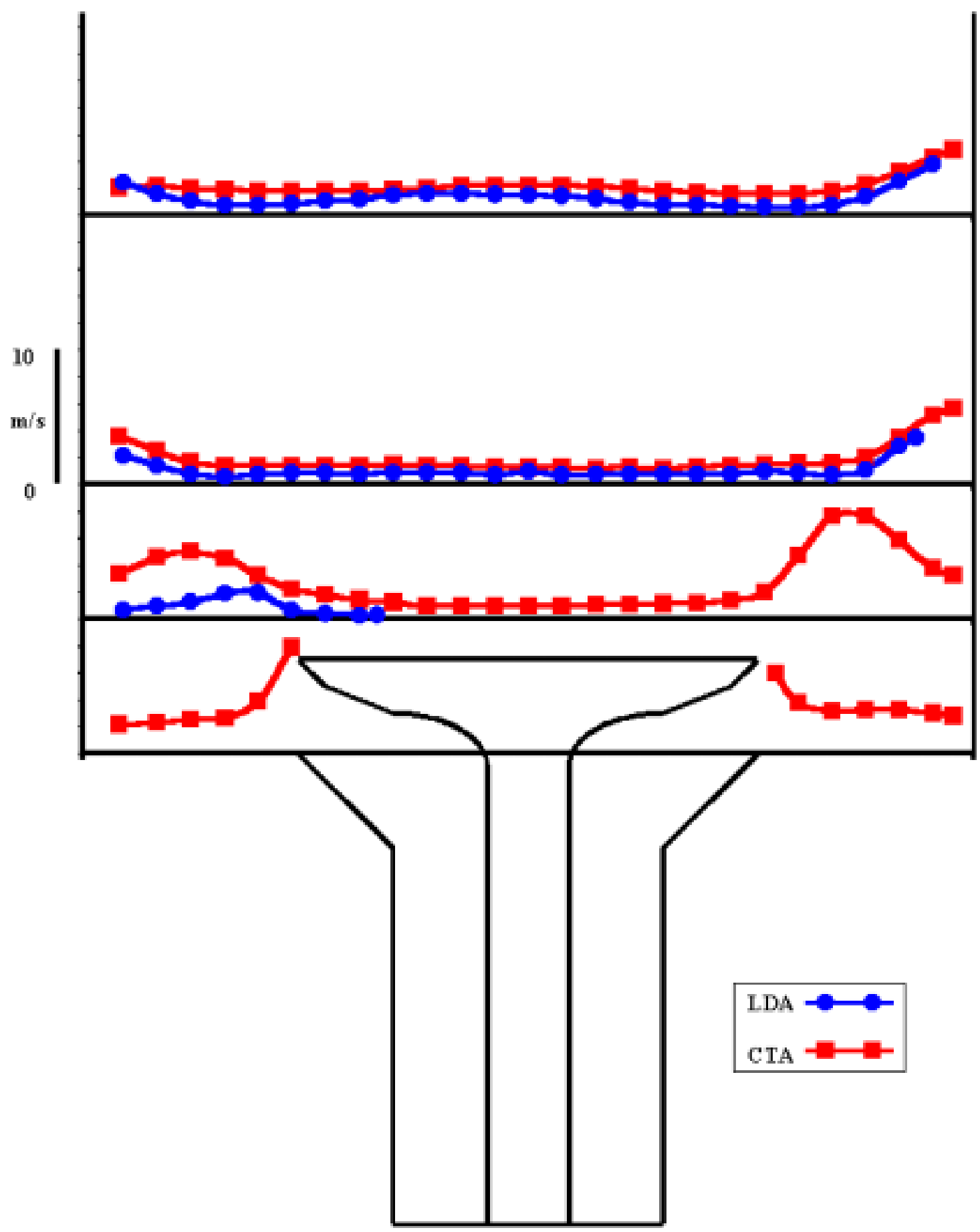

Figure 5.45: Comparison between LDA instantaneous absolute axial mean velocity and CTA axial/radial mean velocity measurements with $9 \mathrm{~mm}$ valve lift and swirl intake. 


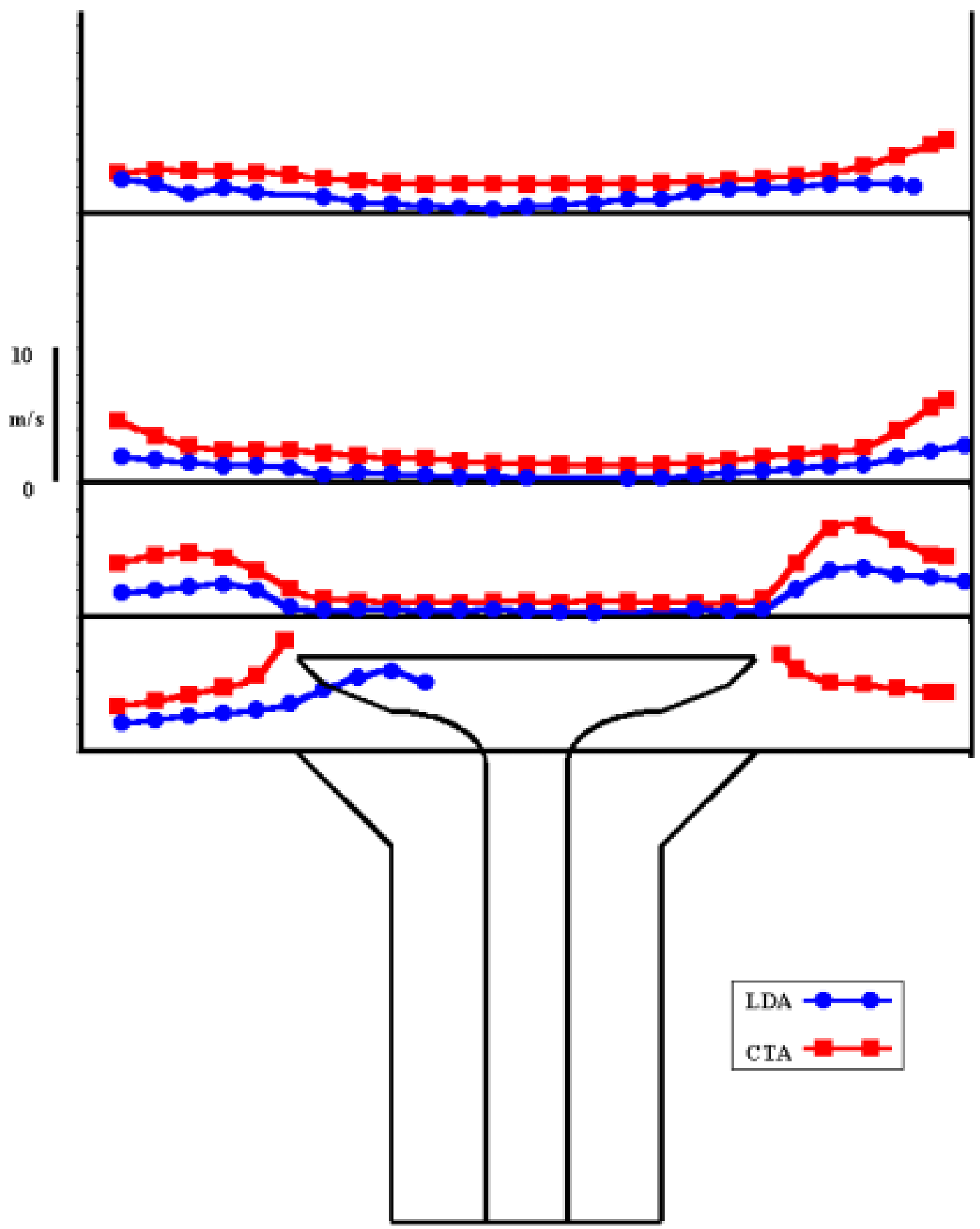

Figure 5.46: Comparison between LDA instantaneous absolute swirl mean velocity and CTA axial/swirl mean velocity measurements with $9 \mathrm{~mm}$ valve lift and swirl intake. 


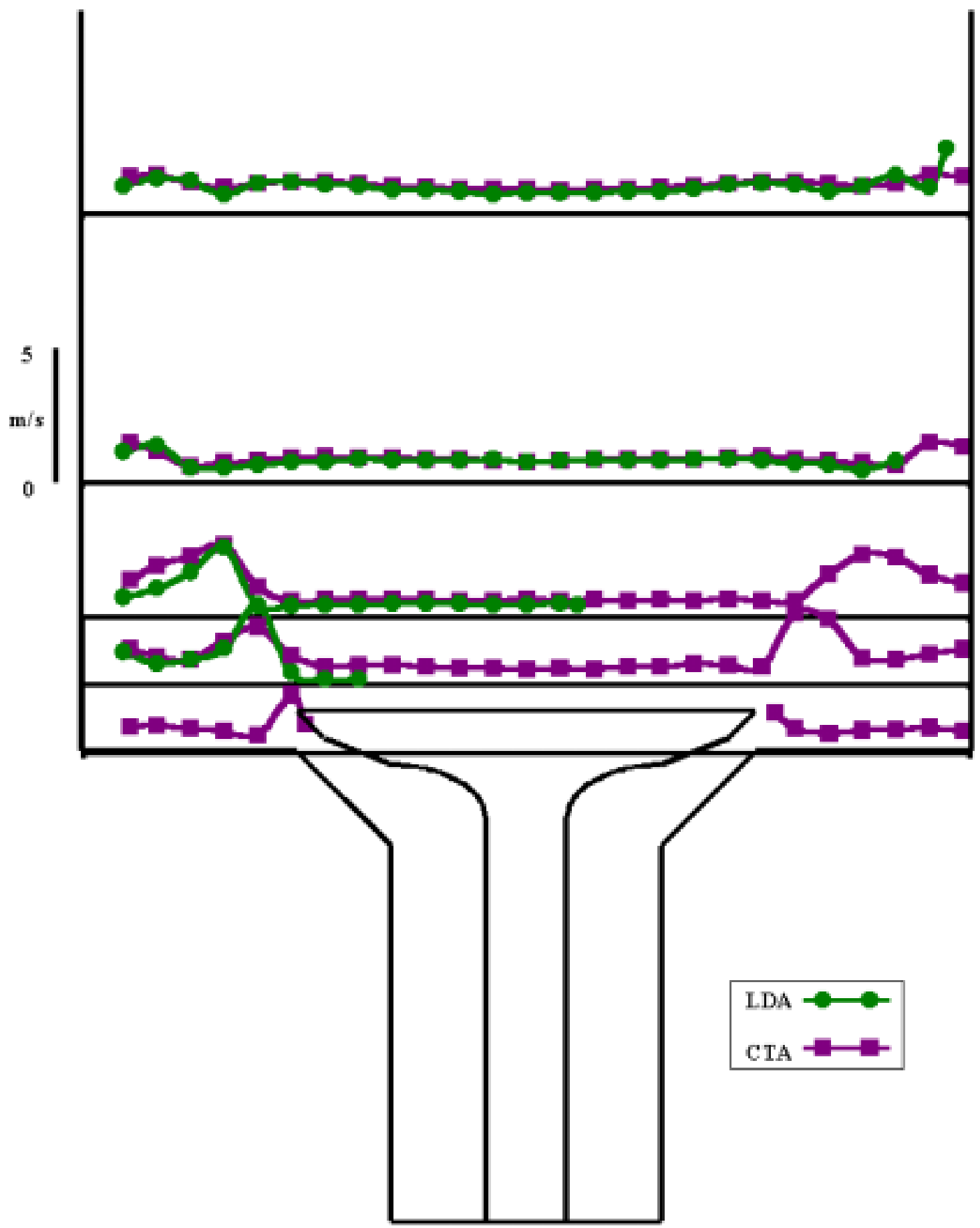

Figure 5.47: Comparison between LDA instantaneous absolute axial standard deviation and CTA axial/radial standard deviation measurements with $4 \mathrm{~mm}$ valve lift and straight intake. 


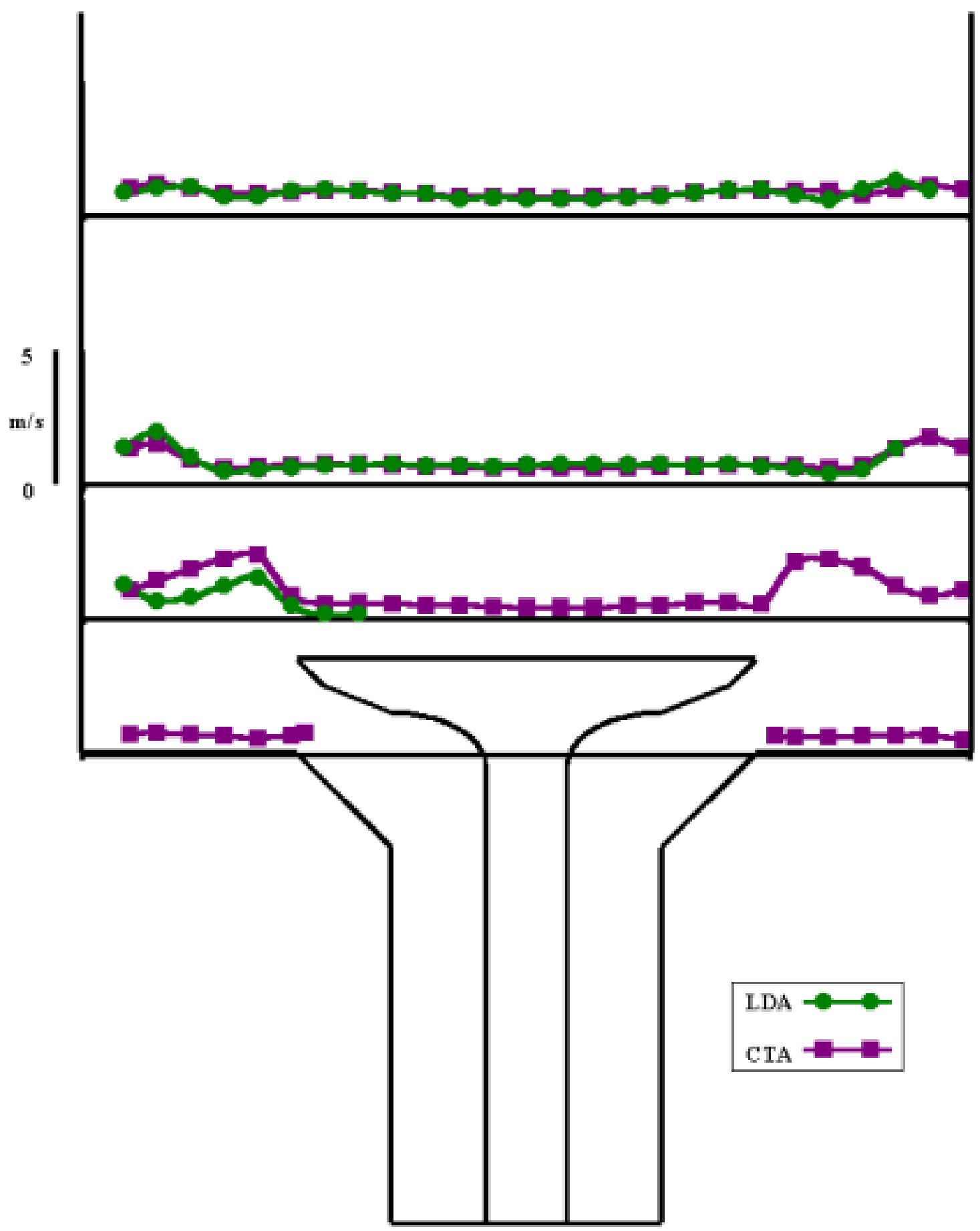

Figure 5.48: Comparison between LDA instantaneous absolute axial standard deviation and CTA axial/radial standard deviation measurements with $9 \mathrm{~mm}$ valve lift and straight intake. 


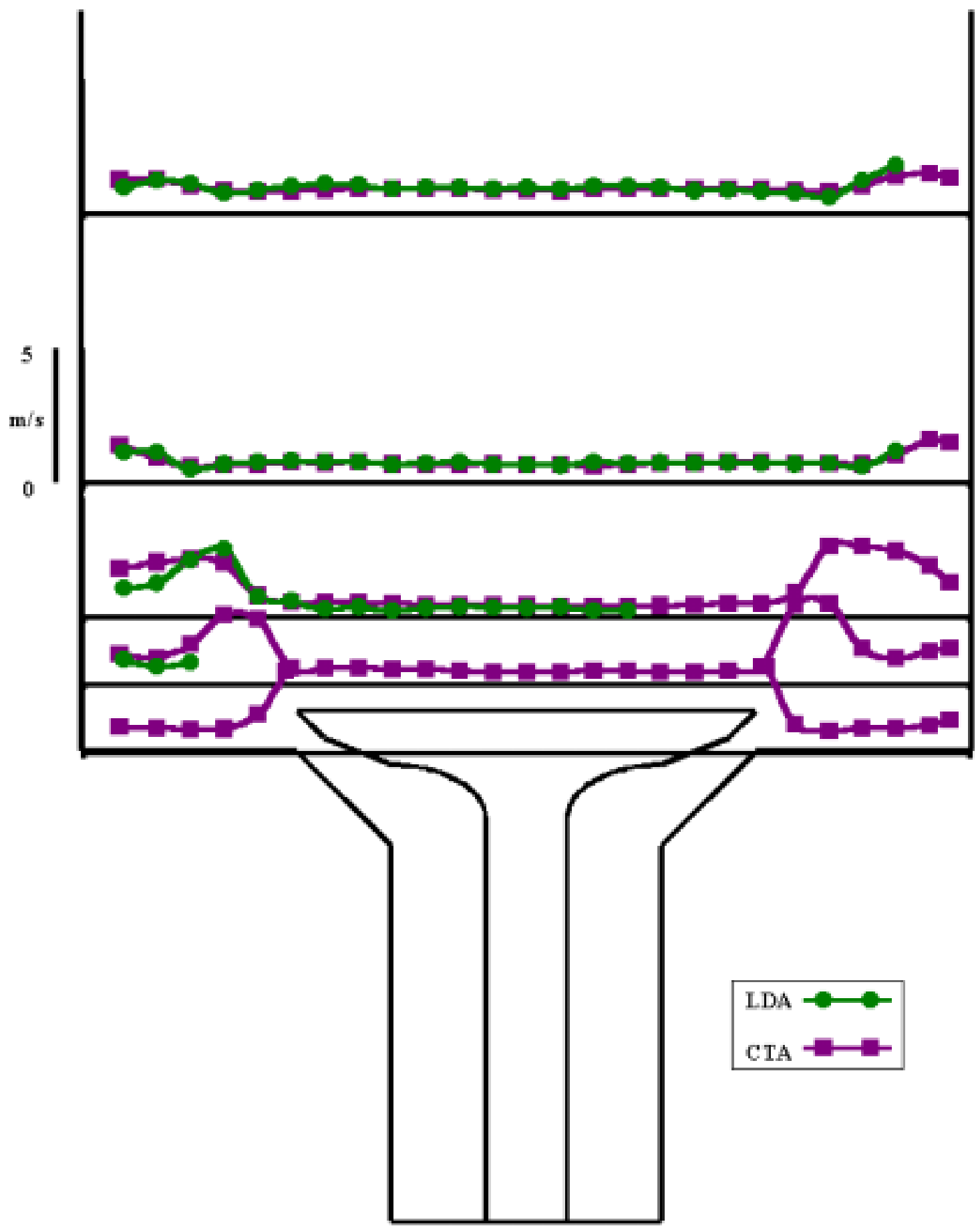

Figure 5.49: Comparison between LDA instantaneous absolute axial standard deviation and CTA axial/radial standard deviation measurements with $4 \mathrm{~mm}$ valve lift and swirl intake. 


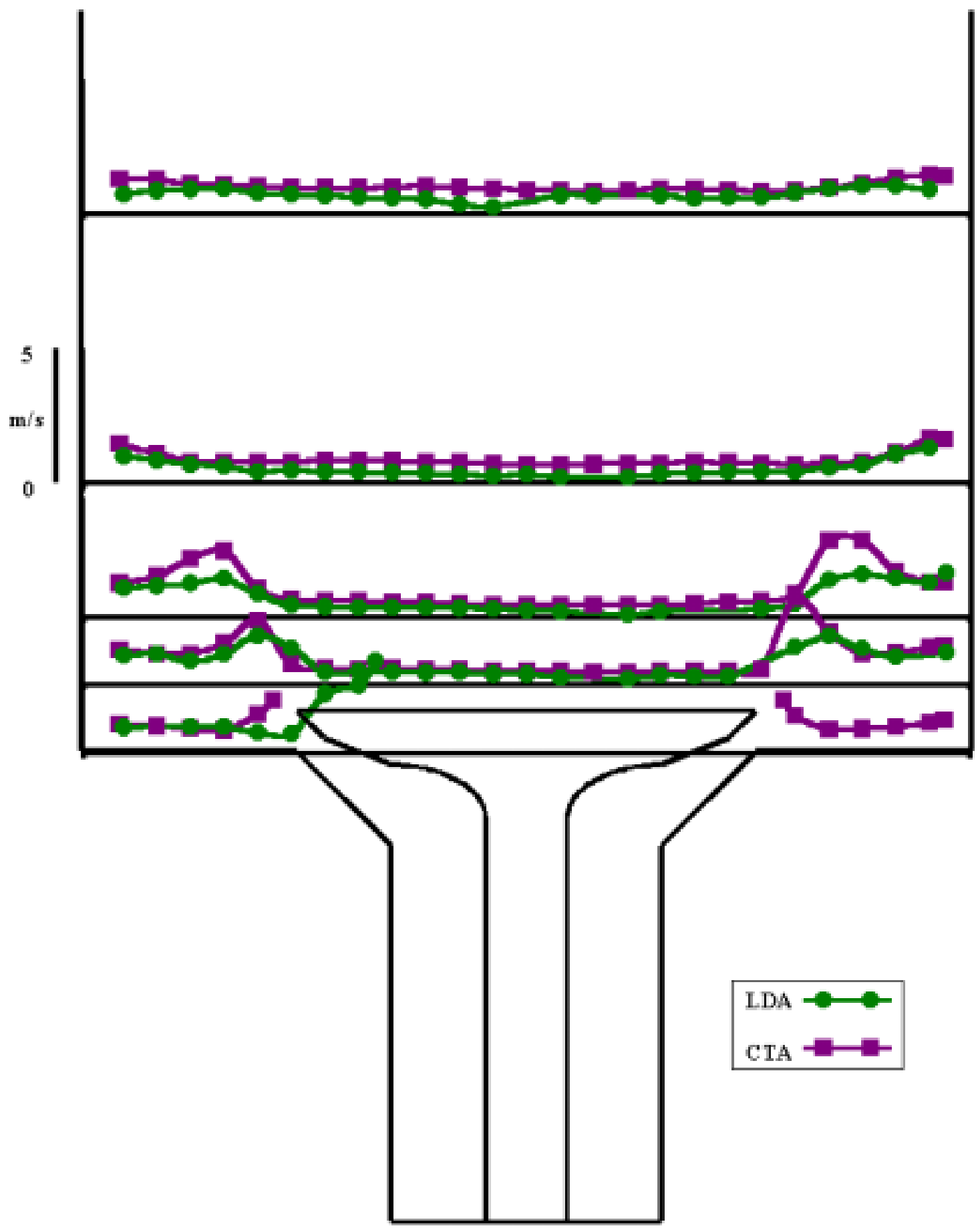

Figure 5.50: Comparison between LDA instantaneous absolute swirl standard deviation and CTA axial/swirl standard deviation measurements with $4 \mathrm{~mm}$ valve lift and swirl intake. 


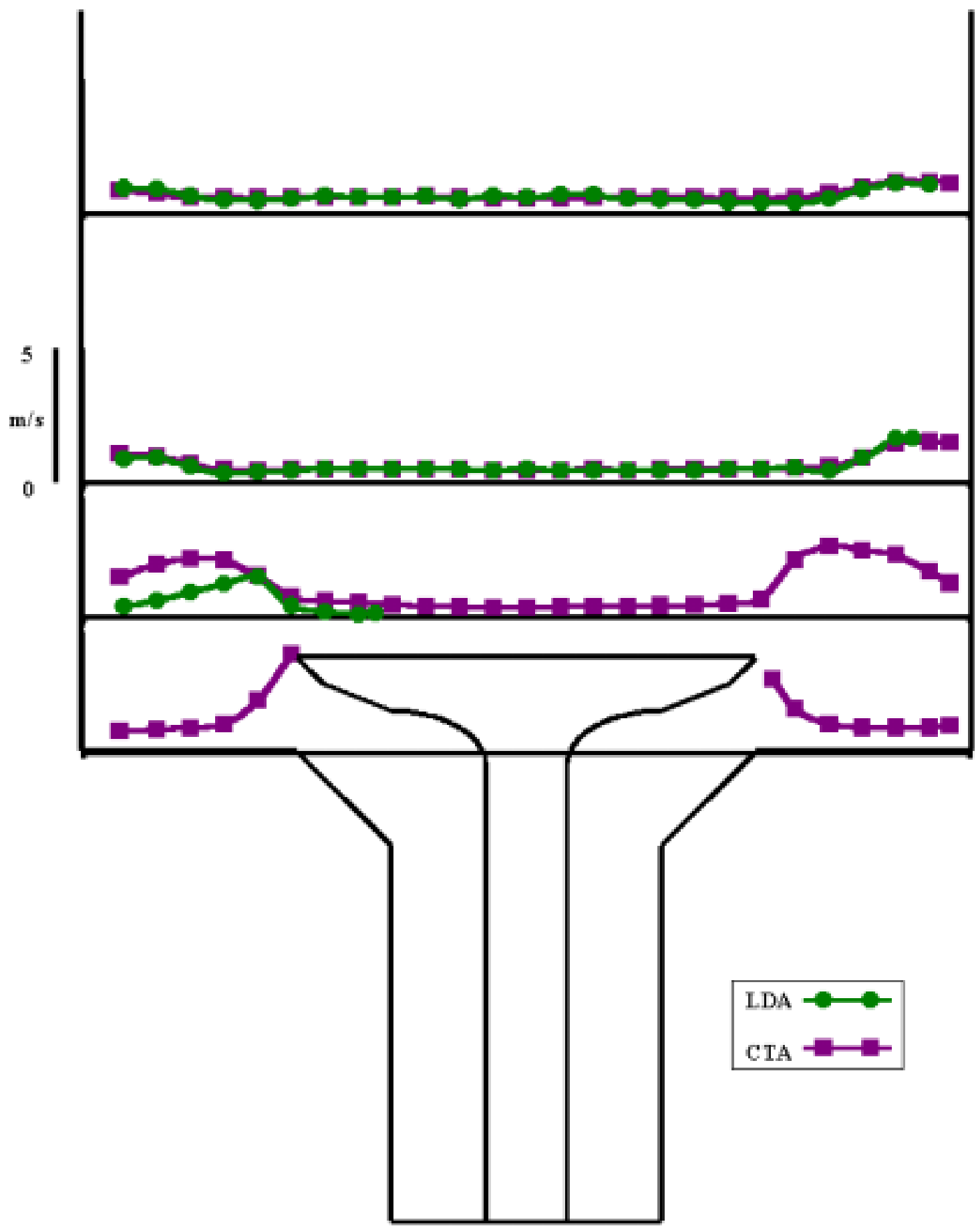

Figure 5.51: Comparison between LDA instantaneous absolute axial standard deviation and CTA axial/radial standard deviation measurements with $9 \mathrm{~mm}$ valve lift and swirl intake. 


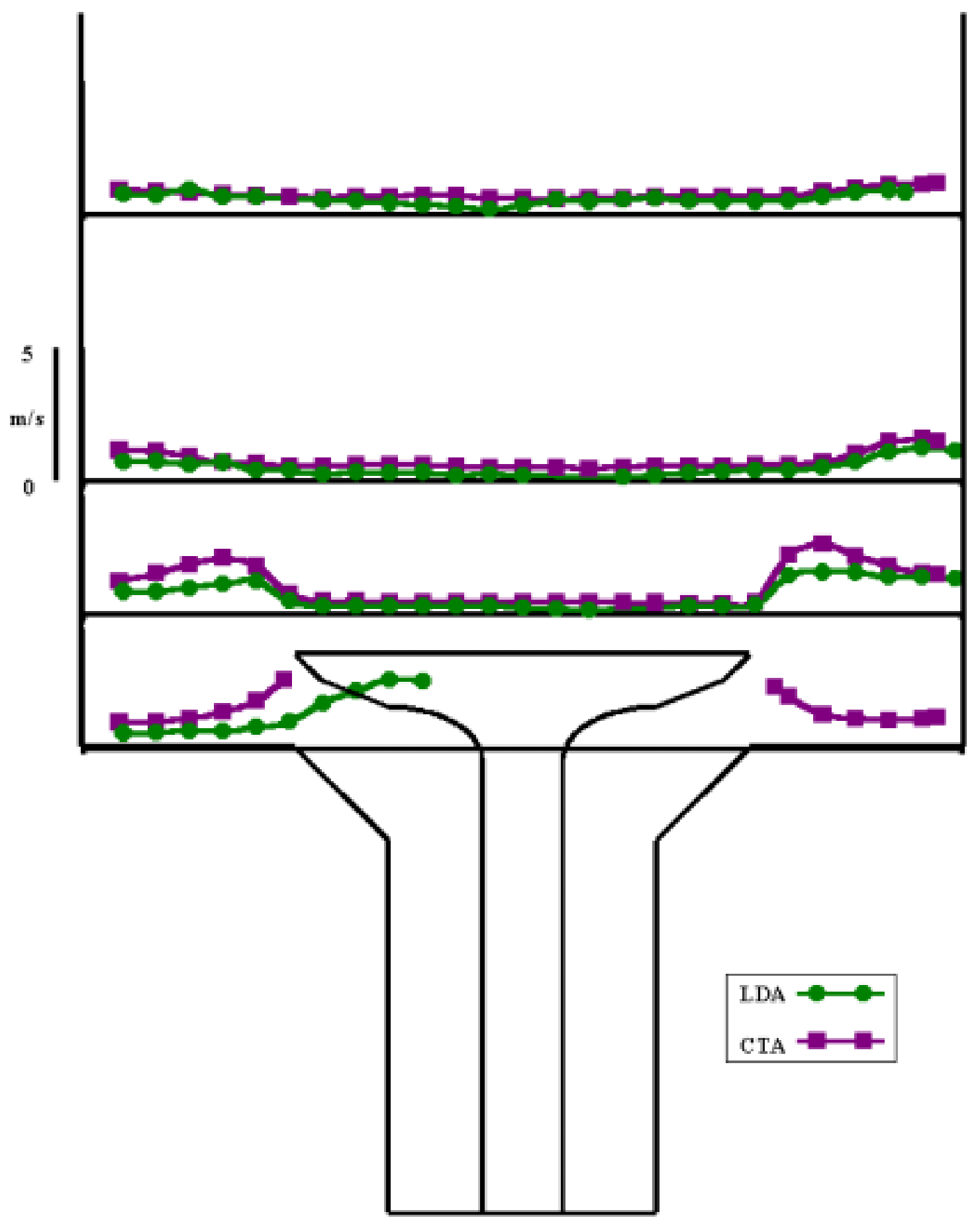

Figure 5.52: Comparison between LDA instantaneous absolute swirl standard deviation and CTA axial/swirl standard deviation measurements with $9 \mathrm{~mm}$ valve lift and swirl intake. 


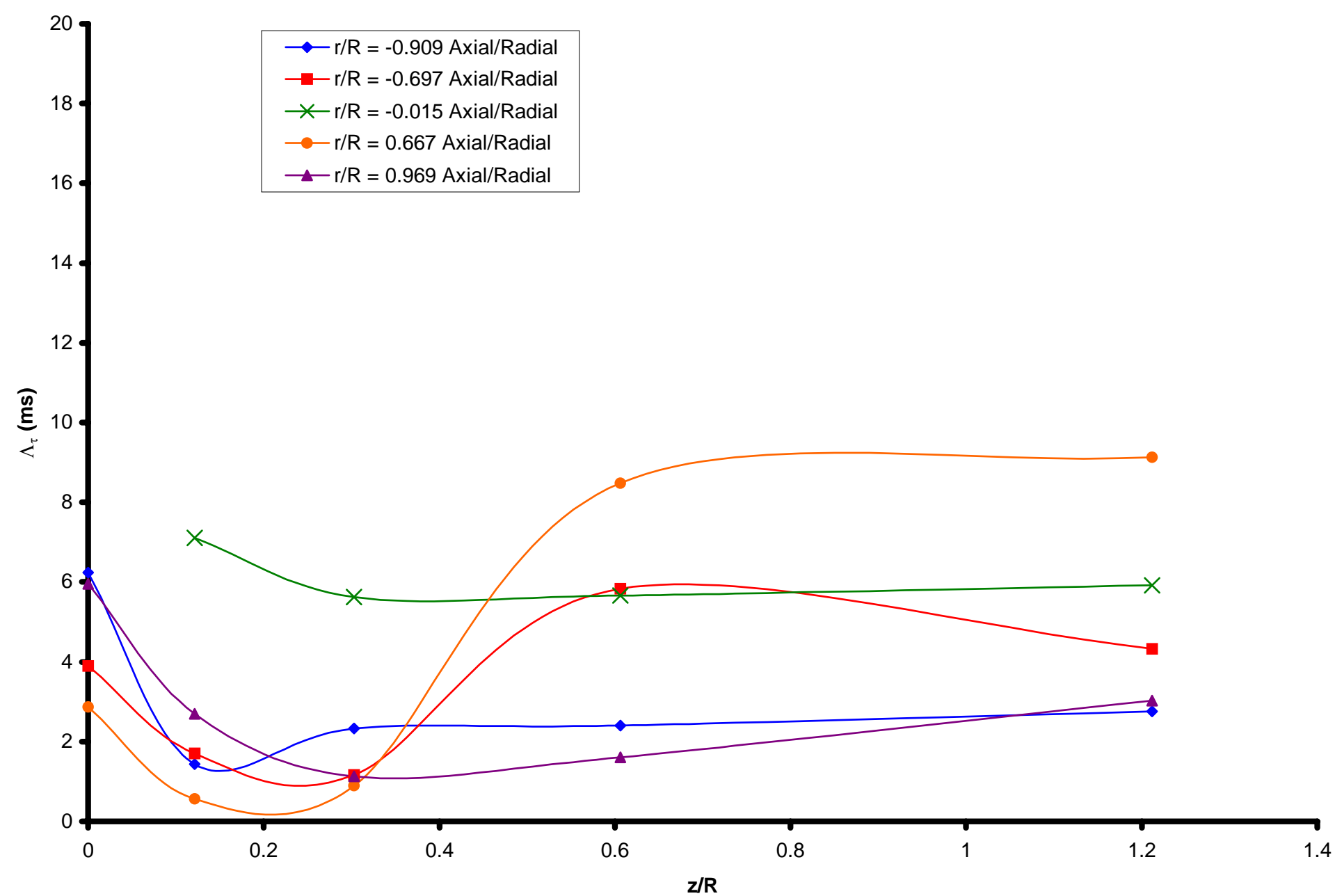

Figure 5.53: Integral time scales for CTA measurements of straight intake with $4 \mathrm{~mm}$ of valve lift. 


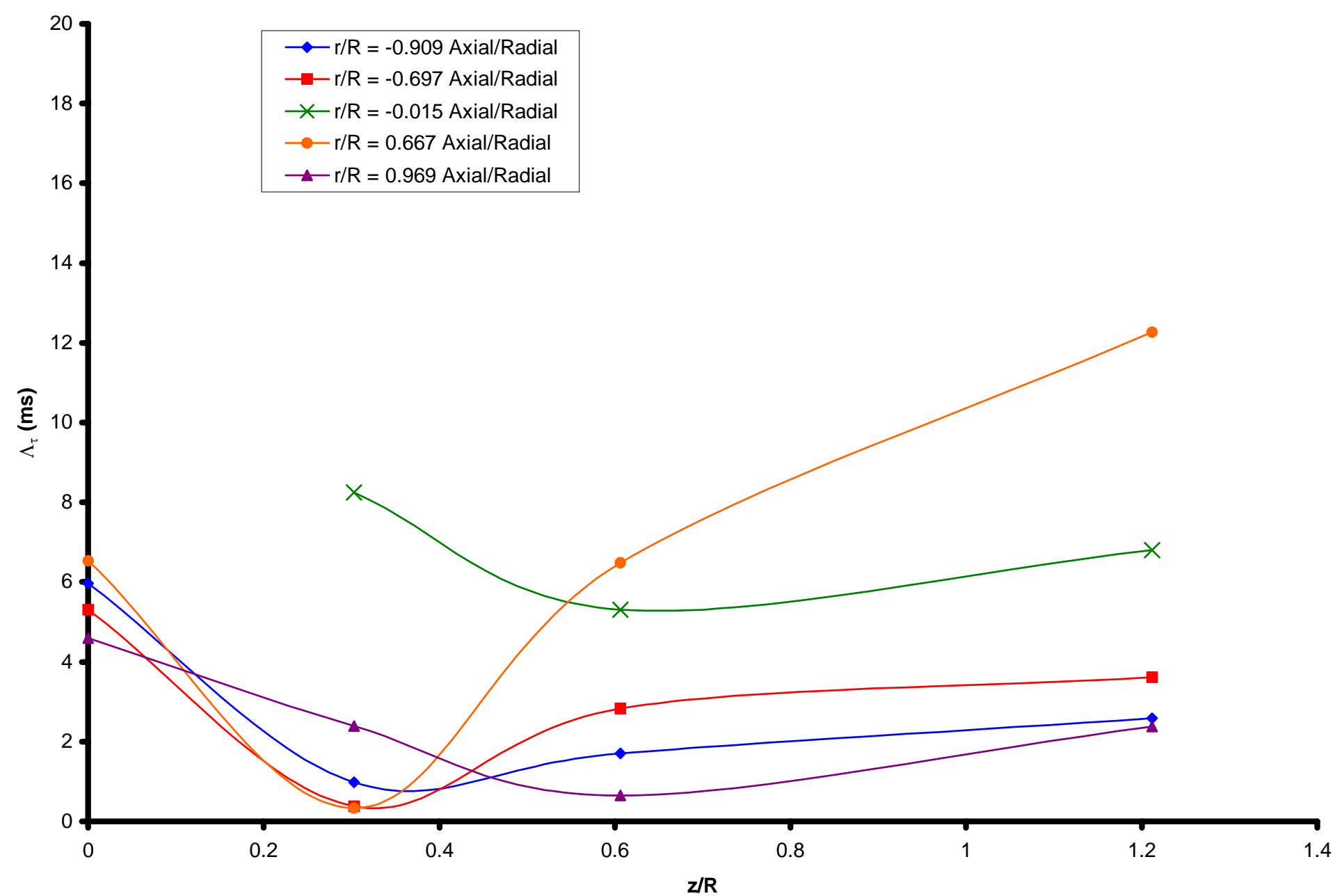

Figure 5.54: Integral time scales for CTA measurements of straight intake with $9 \mathrm{~mm}$ of valve lift. 


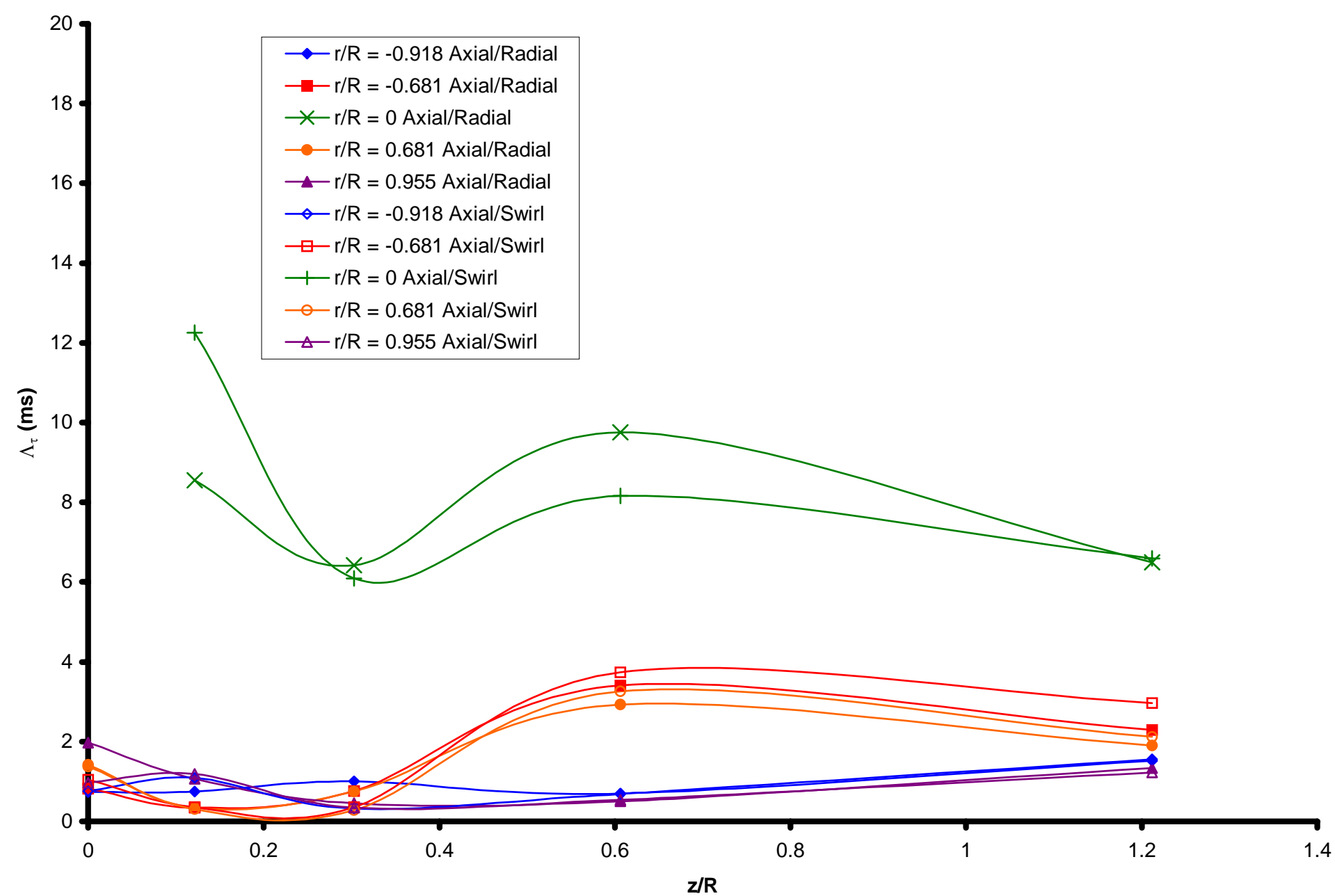

Figure 5.55: Integral time scales for CTA measurements of swirl intake with $4 \mathrm{~mm}$ of valve lift. 


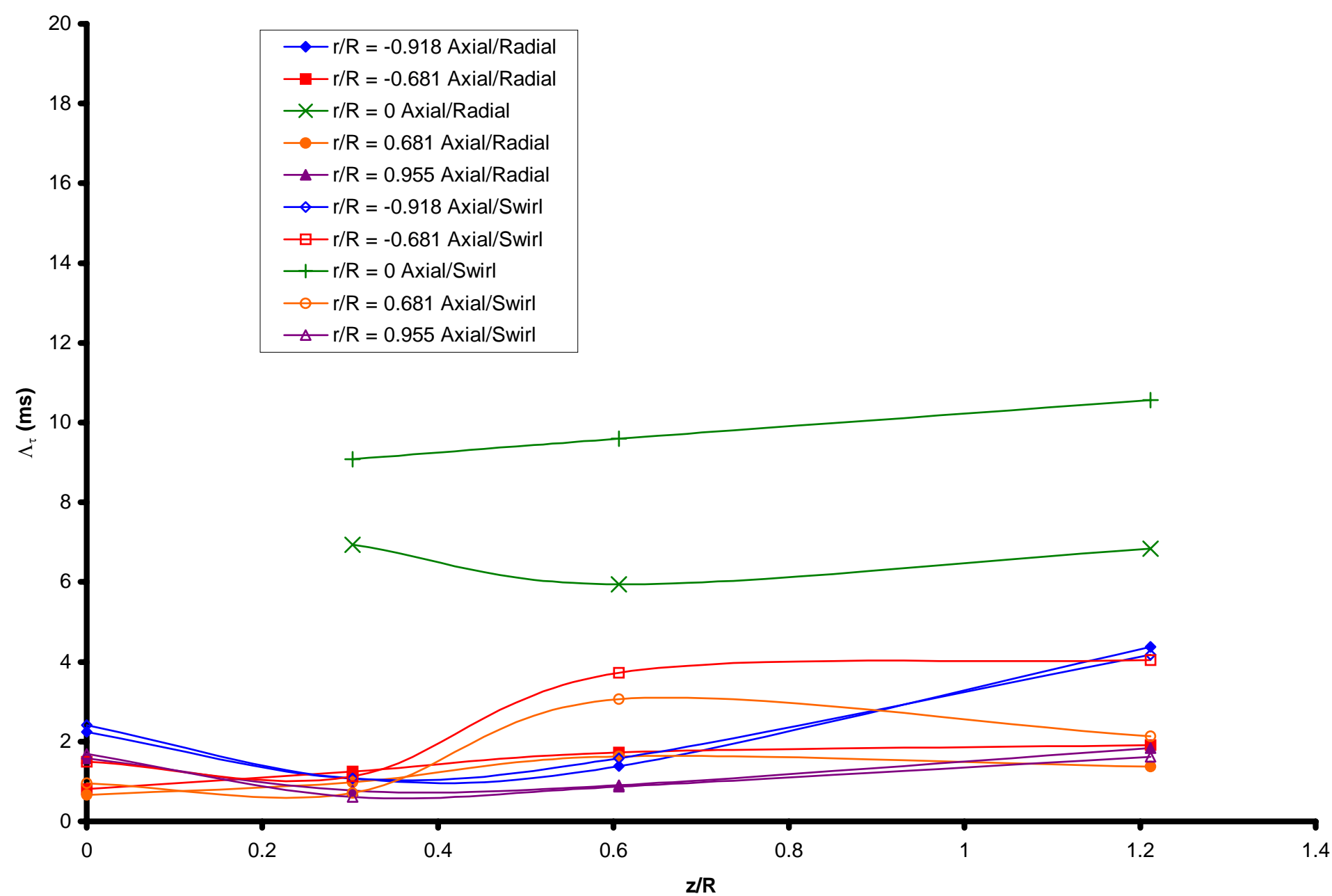

Figure 5.56: Integral time scales for CTA measurements of swirl intake with $9 \mathrm{~mm}$ of valve lift. 


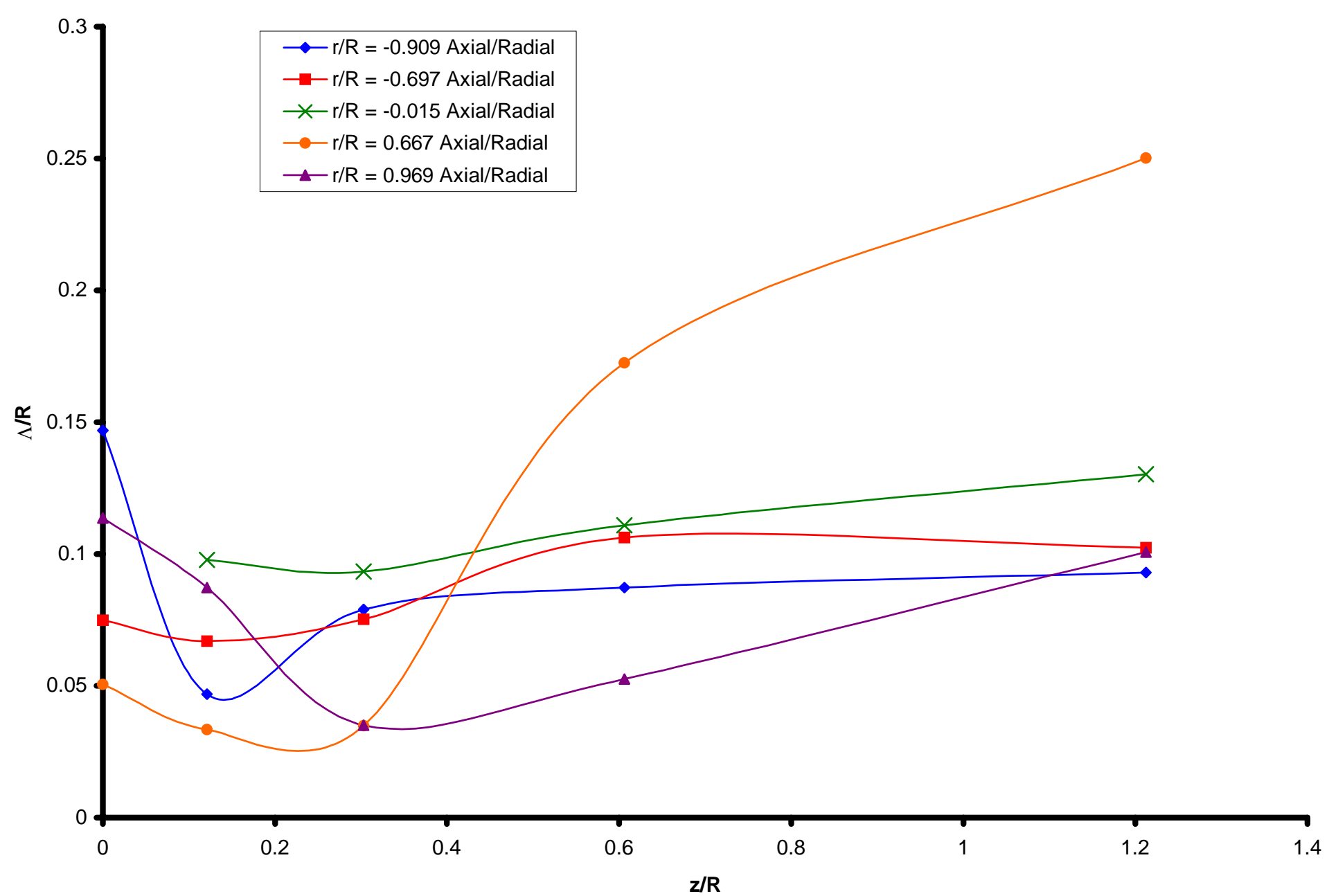

Figure 5.57: Integral length scales for CTA measurements of straight intake with $4 \mathrm{~mm}$ of valve lift. 


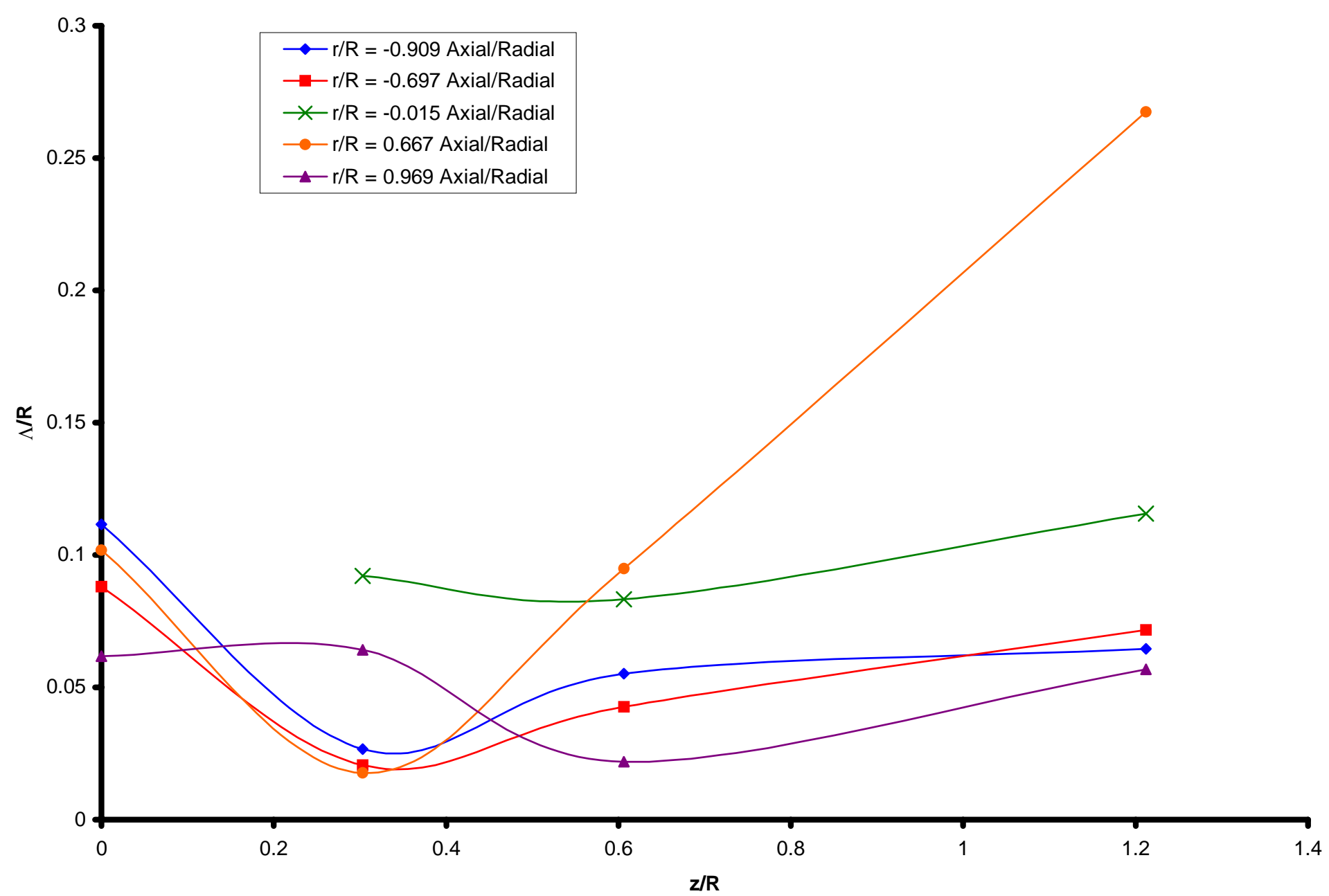

Figure 5.58: Integral length scales for CTA measurements of straight intake with $9 \mathrm{~mm}$ of valve lift. 


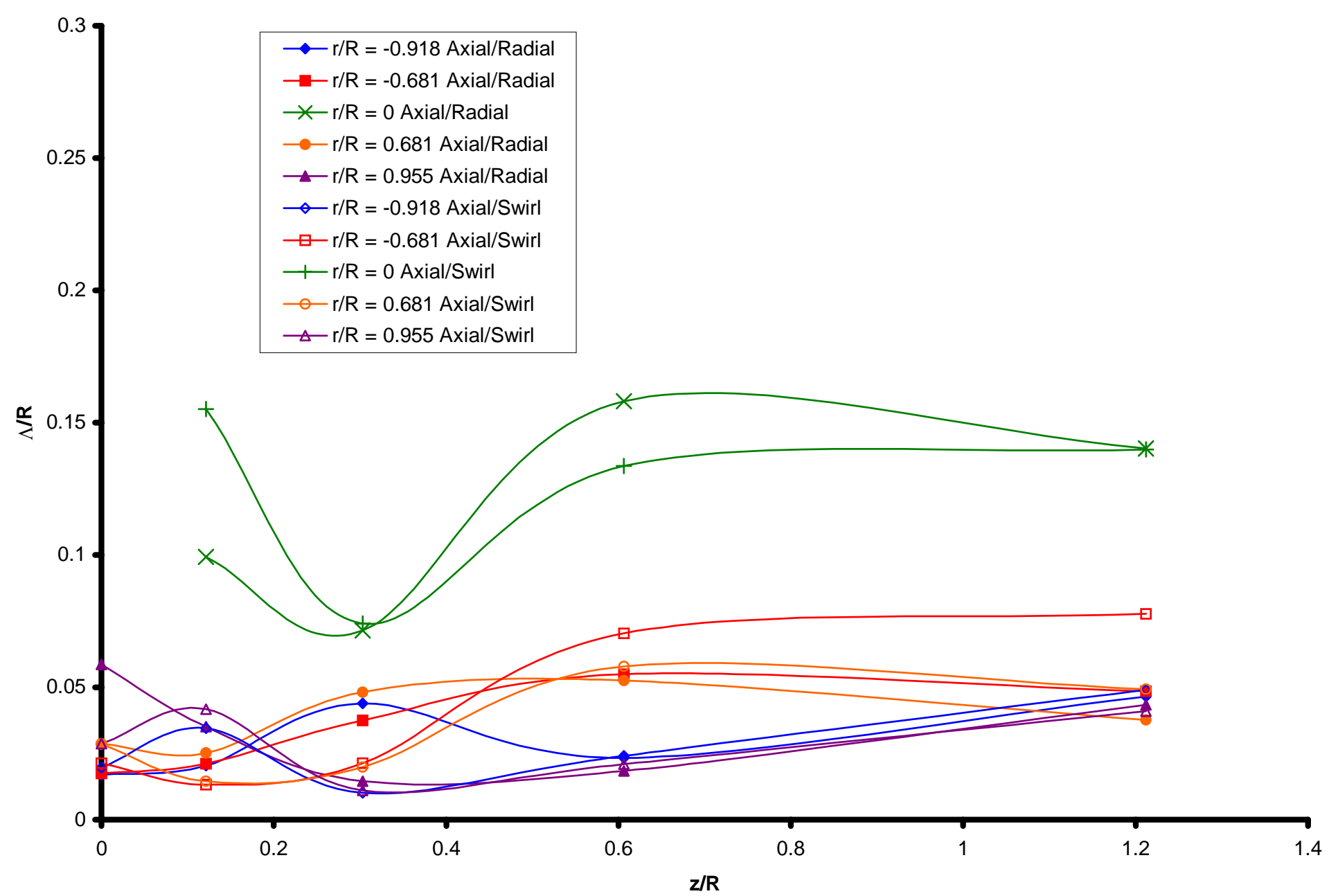

Figure 5.59: Integral length scales for CTA measurements of swirl intake with $4 \mathrm{~mm}$ of valve lift. 


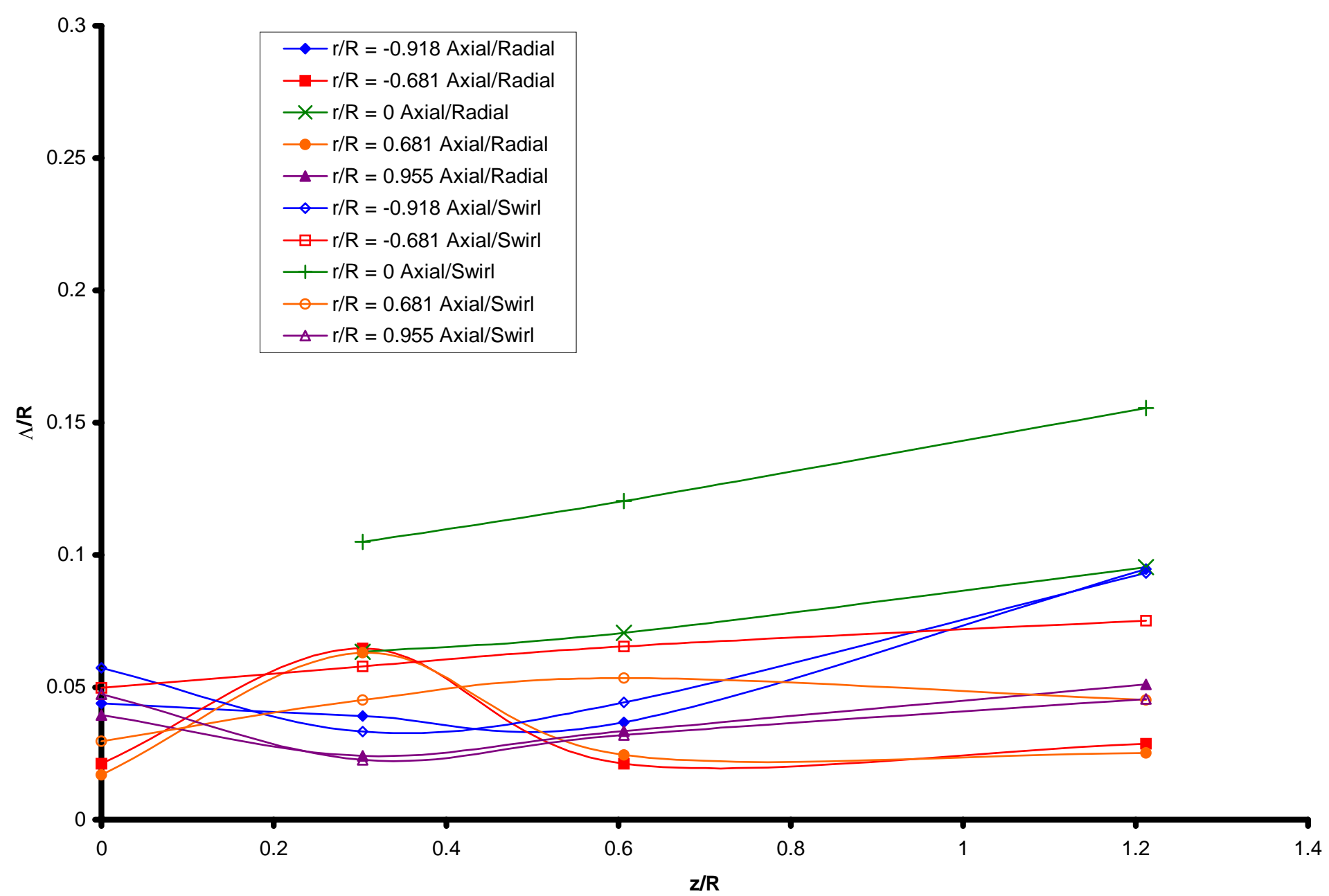

Figure 5.60: Integral length scales for CTA measurements of swirl intake with $9 \mathrm{~mm}$ of valve lift. 


\section{APPENDIX}

Data Sheets 
Table A.1: Test conditions for measurements of straight intake using CTA equipment.

\begin{tabular}{|c|c|c|c|c|c|c|c|c|c|c|c|c|c|c|}
\hline \multirow{2}{*}{ 芩 } & \multirow{2}{*}{ Date } & \multirow{2}{*}{ Time } & \multirow{2}{*}{ File Name } & \multirow{2}{*}{$\begin{array}{c}\text { \# of } \\
\text { Points }\end{array}$} & \multirow{2}{*}{ Start Point } & \multirow{2}{*}{$\begin{array}{l}\text { End } \\
\text { Point }\end{array}$} & \multirow{2}{*}{$\Delta \mathrm{x}$} & \multirow{2}{*}{$\begin{array}{c}\text { Valve } \\
\text { Lift }\end{array}$} & \multirow{2}{*}{$\begin{array}{c}\Delta \mathrm{P} \\
\left({ }^{\circ} \mathrm{H}_{2} \mathrm{O}\right)\end{array}$} & \multicolumn{2}{|c|}{$\begin{array}{c}\text { Atmospheric } \\
\text { Conditions }\end{array}$} & \multicolumn{3}{|c|}{ Power Supply } \\
\hline & & & & & & & & & & $\begin{array}{c}\text { Temp } \\
\left({ }^{\circ} \mathrm{C}\right)\end{array}$ & $\begin{array}{l}\text { Pressure } \\
(\mathrm{mmHg})\end{array}$ & Variac & $\begin{array}{l}\text { Volt } \\
\text { (V) }\end{array}$ & $\begin{array}{l}\text { Current } \\
\text { (amps) }\end{array}$ \\
\hline \multirow[t]{2}{*}{1} & $3 / 8 / 00$ & $\begin{array}{c}2: 17 \\
\text { PM }\end{array}$ & GBHAAPHA & 14 & $x=0.90 "$ & $4.00 ”$ & $1 / 8^{\prime \prime}$ & $4 \mathrm{~mm}$ & 0.27 & 25 & 735.8 & 2.6 & 5.32 & 6 \\
\hline & & $2: 22$ & & & $\mathrm{y}=85.0 \mathrm{~mm}$ & & & & & & & & & \\
\hline \multirow{3}{*}{2} & $3 / 8 / 00$ & $2 \cdot 27$ & CPHA RDHA & 26 & y-0 00" & $40 \Omega "$ & $1 / Q^{\prime}$ & $4 \mathrm{~mm}$ & 027 & & & & & \\
\hline & & $2: 32$ & & & $\mathrm{y}=80.0 \mathrm{~mm}$ & & & & & & & & & \\
\hline & & & & & & & & & & & & & & \\
\hline \multirow[t]{3}{*}{2} & $3 / 8 / 00$ & $2: 34$ & GBHACPHA & 26 & $x=0.90 "$ & $4.00 "$ & $1 / 8^{\prime \prime}$ & $4 \mathrm{~mm}$ & 0.27 & & & & & \\
\hline & & $2: 41$ & & & $\mathrm{y}=74.6 \mathrm{~mm}$ & & & & & & & & & \\
\hline & & & & & & & & & & & & & & \\
\hline \multirow[t]{2}{*}{2} & $3 / 8 / 00$ & $2: 42$ & GBHADPHA & 26 & $x=0.90^{\prime \prime}$ & $4.00 ”$ & $1 / 8^{\prime \prime}$ & $4 \mathrm{~mm}$ & 0.27 & & & & & \\
\hline & & $2: 49$ & & & $\mathrm{y}=61.9 \mathrm{~mm}$ & & & & & & & & & \\
\hline \multirow{3}{*}{2} & $3 / 8 / 00$ & $2: 50$ & GBHAEPHA & 26 & $x=0.90^{\prime \prime}$ & $4.00 "$ & $1 / 8^{\prime \prime}$ & $4 \mathrm{~mm}$ & 0.27 & & & 2.6 & 5.32 & 6 \\
\hline & & $2: 57$ & & & $\mathrm{y}=36.5 \mathrm{~mm}$ & & & & & & & & & \\
\hline & & & & & & & & & & & & & & \\
\hline \multirow[t]{3}{*}{1} & $3 / 8 / 00$ & $3: 06$ & GBHBAPHA & 14 & $x=0.90 "$ & $4.00 "$ & $1 / 8^{\prime \prime}$ & $9 \mathrm{~mm}$ & 0.27 & & & 2.1 & 4.86 & 6 \\
\hline & & $3: 11$ & & & $\mathrm{y}=85.0 \mathrm{~mm}$ & & & & & & & & & \\
\hline & & & & & & & & & & & & & & \\
\hline \multirow[t]{3}{*}{2} & $3 / 8 / 00$ & $3: 12$ & GBHBCPHA & 26 & $x=0.90 "$ & $4.00 "$ & $1 / 8^{\prime \prime}$ & $9 \mathrm{~mm}$ & 0.27 & & & & & \\
\hline & & $3: 19$ & & & $\mathrm{y}=74.6 \mathrm{~mm}$ & & & & & & & & & \\
\hline & & & & & & & & & & & & & & \\
\hline \multirow[t]{2}{*}{2} & $3 / 8 / 00$ & $3: 20$ & GBHBDPHA & 26 & $\mathrm{x}=0.90^{\prime \prime}$ & $4.00 "$ & $1 / 8^{\prime \prime}$ & $9 \mathrm{~mm}$ & 0.27 & & & & & \\
\hline & & $3: 27$ & & & $\mathrm{y}=61.9 \mathrm{~mm}$ & & & & & & & & & \\
\hline
\end{tabular}




\begin{tabular}{|c|c|c|c|c|c|c|c|c|c|c|c|c|c|c|}
\hline \multirow{2}{*}{ 过 } & \multirow{2}{*}{ Date } & \multirow{2}{*}{ Time } & \multirow{2}{*}{ File Name } & \multirow{2}{*}{$\begin{array}{c}\text { \# of } \\
\text { Points }\end{array}$} & \multirow{2}{*}{ Start Point } & \multirow{2}{*}{$\begin{array}{l}\text { End } \\
\text { Point }\end{array}$} & \multirow{2}{*}{$\Delta \mathrm{x}$} & \multirow{2}{*}{$\begin{array}{c}\text { Valve } \\
\text { Lift }\end{array}$} & \multirow{2}{*}{$\begin{array}{c}\Delta \mathrm{P} \\
\left({ }^{\left(' \mathrm{H}_{2} \mathrm{O}\right)}\right.\end{array}$} & \multicolumn{2}{|c|}{$\begin{array}{l}\text { Atmospheric } \\
\text { Conditions }\end{array}$} & \multicolumn{3}{|c|}{ Power Supply } \\
\hline & & & & & & & & & & $\begin{array}{l}\text { Temp } \\
\left({ }^{\circ} \mathrm{C}\right)\end{array}$ & $\begin{array}{l}\text { Pressure } \\
(\mathrm{mmHg})\end{array}$ & Variac & $\begin{array}{l}\text { Volt } \\
\text { (V) }\end{array}$ & $\begin{array}{l}\text { Current } \\
\text { (amps) }\end{array}$ \\
\hline 2 & $3 / 8 / 00$ & $3: 28$ & GBHBEPHA & 26 & $x=0.90^{\prime \prime}$ & $4.00 ”$ & $1 / 8^{\prime \prime}$ & $9 \mathrm{~mm}$ & 0.27 & 26 & 735 & 2.1 & 4.86 & 6 \\
\hline & & $3: 35$ & & & $\mathrm{y}=36.5 \mathrm{~mm}$ & & & & & & & & & \\
\hline
\end{tabular}

Calibration file: GB030600.cl

Sampling frequency: $20,000 \mathrm{~Hz}$

Sample size: $128 \mathrm{kpts}$

Sample time: 6.5536 seconds

File size: 263,982 bytes

Note 1: Pt 1, $\mathrm{x}=0.90 "$

Pt 2, $x=1.0$ "

Pt 2-6, $\Delta x=1 / 8 "$

Pt 7, $x=1.55$ "

Pt 8, $x=3.30$ "

Pt 9, $x=3.375 "$

Pt 9-end, $\Delta x=1 / 8$ "
Note 2: Pt $1, \mathrm{x}=0.90$ "

Pt 2, $x=1.0$ '”

Pt 2-end, $\Delta \mathrm{x}=1 / 8^{\prime \prime}$ 
Table A.2: Test conditions for measurements of swirl intake using CTA equipment.

\begin{tabular}{|c|c|c|c|c|c|c|c|c|c|c|c|c|c|c|}
\hline \multirow{2}{*}{$\begin{array}{l}0 \\
\tilde{d} \\
0 \\
z\end{array}$} & \multirow{2}{*}{ Date } & \multirow{2}{*}{ Time } & \multirow{2}{*}{ File Name } & \multirow{2}{*}{$\begin{array}{c}\text { \# of } \\
\text { Points }\end{array}$} & \multirow{2}{*}{ Start Point } & \multirow{2}{*}{$\begin{array}{l}\text { End } \\
\text { Point }\end{array}$} & \multirow{2}{*}{$\Delta \mathrm{x}$} & \multirow{2}{*}{$\begin{array}{c}\text { Valve } \\
\text { Lift }\end{array}$} & \multirow{2}{*}{$\begin{array}{c}\Delta \mathrm{P} \\
\left({ }^{(} \mathrm{H}_{2} \mathrm{O}\right)\end{array}$} & \multicolumn{2}{|c|}{$\begin{array}{c}\text { Atmospheric } \\
\text { Conditions }\end{array}$} & \multicolumn{3}{|c|}{ Power Supply } \\
\hline & & & & & & & & & & $\begin{array}{c}\text { Temp } \\
\left({ }^{\circ} \mathrm{C}\right)\end{array}$ & $\begin{array}{l}\text { Pressure } \\
(\mathrm{mmHg})\end{array}$ & Variac & $\begin{array}{l}\text { Volt } \\
\text { (V) }\end{array}$ & $\begin{array}{l}\text { Current } \\
\text { (amps) }\end{array}$ \\
\hline & $4 / 19 / 00$ & $\begin{array}{c}11: 30 \\
\text { AM }\end{array}$ & GB041900.cl & 17 & & & & & & 22.5 & 737.9 & & & \\
\hline & & $\begin{array}{l}12: 00 \\
\text { noon }\end{array}$ & & & & & & & & & & & & \\
\hline & & & & & & & & & & & & & & \\
\hline \multirow[t]{2}{*}{1} & $4 / 19 / 00$ & $\begin{array}{l}2: 25 \\
\text { PM }\end{array}$ & GBAAAOGA & 13 & $x=0.86 "$ & $3.95^{\prime \prime}$ & $1 / 8^{\prime \prime}$ & $4 \mathrm{~mm}$ & 0.27 & 21.0 & 737.4 & 3.1 & 6.55 & 6 \\
\hline & & $2: 30$ & & & $\mathrm{y}=85 \mathrm{~mm}$ & & & & & & & & & \\
\hline & & & & & & & & & & & & & & \\
\hline \multirow[t]{3}{*}{2} & $4 / 19 / 00$ & $2: 30$ & GBAABOGA & 26 & $\mathrm{x}=0.86^{\prime \prime}$ & $3.95 "$ & $1 / 8 "$ & $4 \mathrm{~mm}$ & & & & & & \\
\hline & & $2: 40$ & & & $\mathrm{y}=79.95 \mathrm{~mm}$ & & & & & & & & & \\
\hline & & & & & & & & & & & & & & \\
\hline \multirow[t]{3}{*}{2} & $4 / 19 / 00$ & $2: 45$ & GBAACOGA & 26 & $\mathrm{x}=0.86^{\prime \prime}$ & $3.95^{\prime \prime}$ & $1 / 8^{\prime \prime}$ & $4 \mathrm{~mm}$ & & & & & & \\
\hline & & $2: 55$ & & & $\mathrm{y}=74.55 \mathrm{~mm}$ & & & & & & & & & \\
\hline & & & & & & & & & & & & & & \\
\hline \multirow[t]{3}{*}{2} & $4 / 19 / 00$ & $2: 55$ & GBAADOGA & 26 & $\mathrm{x}=0.86^{\prime \prime}$ & $3.95^{\prime \prime}$ & $1 / 8^{\prime \prime}$ & $4 \mathrm{~mm}$ & & & & & & \\
\hline & & $3: 00$ & & & $\mathrm{y}=61.85 \mathrm{~mm}$ & & & & & & & & & \\
\hline & & & & & & & & & & & & & & \\
\hline \multirow[t]{3}{*}{2} & $4 / 19 / 00$ & $3: 05$ & GBAAEOGA & 26 & $\mathrm{x}=0.86^{\prime \prime}$ & $3.95^{\prime \prime}$ & $1 / 8^{\prime \prime}$ & $4 \mathrm{~mm}$ & & & & & & \\
\hline & & $3: 10$ & & & $\mathrm{y}=36.45 \mathrm{~mm}$ & & & & & & & & & \\
\hline & & & & & & & & & & & & & & \\
\hline \multirow[t]{3}{*}{3} & $4 / 19 / 00$ & $3: 25$ & GBBAAOGA & 13 & $\mathrm{x}=0.86^{\prime \prime}$ & $3.93^{\prime \prime}$ & $1 / 8^{\prime \prime}$ & $4 \mathrm{~mm}$ & & & & & & \\
\hline & & $3: 35$ & & & $\mathrm{y}=85 \mathrm{~mm}$ & & & & & & & & & \\
\hline & & & & & & & & & & & & & & \\
\hline
\end{tabular}




\begin{tabular}{|c|c|c|c|c|c|c|c|c|c|c|c|c|c|c|}
\hline \multirow{2}{*}{ 竎 } & \multirow{2}{*}{ Date } & \multirow{2}{*}{ Time } & \multirow{2}{*}{ File Name } & \multirow{2}{*}{$\begin{array}{c}\text { \# of } \\
\text { Points }\end{array}$} & \multirow{2}{*}{ Start Point } & \multirow{2}{*}{$\begin{array}{l}\text { End } \\
\text { Point }\end{array}$} & \multirow{2}{*}{$\Delta \mathrm{x}$} & \multirow{2}{*}{$\begin{array}{c}\text { Valve } \\
\text { Lift }\end{array}$} & \multirow{2}{*}{$\begin{array}{c}\Delta \mathrm{P} \\
\left({ }^{(“} \mathrm{H}_{2} \mathrm{O}\right)\end{array}$} & \multicolumn{2}{|c|}{$\begin{array}{l}\text { Atmospheric } \\
\text { Conditions }\end{array}$} & \multicolumn{3}{|c|}{ Power Supply } \\
\hline & & & & & & & & & & $\begin{array}{c}\text { Temp } \\
\left({ }^{\circ} \mathrm{C}\right)\end{array}$ & $\begin{array}{l}\text { Pressure } \\
(\mathrm{mmHg})\end{array}$ & Variac & $\begin{array}{l}\text { Volt } \\
\text { (V) }\end{array}$ & $\begin{array}{l}\text { Current } \\
\text { (amps) }\end{array}$ \\
\hline \multirow[t]{3}{*}{4} & $4 / 19 / 00$ & $3: 40$ & GBBABOGA & 26 & $\mathrm{x}=0.86^{\prime \prime}$ & $3.93 "$ & $1 / 8^{\prime \prime}$ & $4 \mathrm{~mm}$ & & & & & & \\
\hline & & $3: 50$ & & & $\mathrm{y}=79.95 \mathrm{~mm}$ & & & & & & & & & \\
\hline & & & & & & & & & & & & & & \\
\hline \multirow[t]{3}{*}{4} & $4 / 19 / 00$ & $3: 50$ & GBBACOGA & 26 & $\mathrm{x}=0.86^{\prime \prime}$ & $3.93 "$ & $1 / 8^{\prime \prime}$ & $4 \mathrm{~mm}$ & & & & & & \\
\hline & & $4: 00$ & & & $\mathrm{y}=74.55 \mathrm{~mm}$ & & & & & & & & & \\
\hline & & & & & & & & & & & & & & \\
\hline \multirow[t]{3}{*}{4} & $4 / 19 / 00$ & $4: 00$ & GBBADOGA & 26 & $\mathrm{x}=0.86^{\prime \prime}$ & $3.93 "$ & $1 / 8^{\prime \prime}$ & $4 \mathrm{~mm}$ & & & & & & \\
\hline & & $4: 05$ & & & $\mathrm{y}=61.85 \mathrm{~mm}$ & & & & & & & & & \\
\hline & & & & & & & & & & & & & & \\
\hline \multirow[t]{3}{*}{4} & $4 / 19 / 00$ & $4: 10$ & GBBAEOGA & 26 & $\mathrm{x}=0.86^{\prime \prime}$ & $3.93 "$ & $1 / 8^{\prime \prime}$ & $4 \mathrm{~mm}$ & 0.27 & 20 & 737.4 & 3.1 & 6.55 & 6 \\
\hline & & $4: 15$ & & & $\mathrm{y}=36.45 \mathrm{~mm}$ & & & & & & & & & \\
\hline & & & & & & & & & & & & & & \\
\hline \multirow[t]{3}{*}{5} & $4 / 19 / 00$ & $5: 05$ & GBBBAOGA & 13 & $\mathrm{x}=0.86^{\prime \prime}$ & 3.93 & $1 / 8^{\prime \prime}$ & $9 \mathrm{~mm}$ & 0.27 & 21 & 737.4 & 3.1 & 6.55 & 6 \\
\hline & & $5: 15$ & & & $\mathrm{y}=85 \mathrm{~mm}$ & & & & & & & & & \\
\hline & & & & & & & & & & & & & & \\
\hline \multirow[t]{3}{*}{4} & $4 / 19 / 00$ & $5: 15$ & GBBBCOGA & 26 & $\mathrm{x}=0.86^{\prime \prime}$ & 3.93 & $1 / 8^{\prime \prime}$ & $9 \mathrm{~mm}$ & & & & & & \\
\hline & & $5: 25$ & & & $\mathrm{y}=74.55 \mathrm{~mm}$ & & & & & & & & & \\
\hline & & & & & & & & & & & & & & \\
\hline \multirow[t]{3}{*}{4} & $4 / 19 / 00$ & $5: 25$ & GBBBDOGA & 26 & $\mathrm{x}=0.86^{\prime \prime}$ & 3.93 & $1 / 8^{\prime \prime}$ & $9 \mathrm{~mm}$ & & & & & & \\
\hline & & $5: 30$ & & & $\mathrm{y}=61.85 \mathrm{~mm}$ & & & & & & & & & \\
\hline & & & & & & & & & & & & & & \\
\hline \multirow[t]{4}{*}{4} & $4 / 19 / 00$ & $5: 35$ & GBBBEOGA & 26 & $\mathrm{x}=0.86^{\prime \prime}$ & 3.93 & $1 / 8^{\prime \prime}$ & $9 \mathrm{~mm}$ & & & & & & \\
\hline & & $5: 40$ & & & $\mathrm{y}=36.45 \mathrm{~mm}$ & & & & & & & & & \\
\hline & & & & & & & & & & & & & & \\
\hline & & & & & & & & & & & & & & \\
\hline
\end{tabular}




\begin{tabular}{|c|c|c|c|c|c|c|c|c|c|c|c|c|c|c|}
\hline \multirow{2}{*}{$\begin{array}{l}\stackrel{2}{0} \\
\text { z }\end{array}$} & \multirow{2}{*}{ Date } & \multirow{2}{*}{ Time } & \multirow{2}{*}{ File Name } & \multirow{2}{*}{$\begin{array}{c}\text { \# of } \\
\text { Points }\end{array}$} & \multirow{2}{*}{ Start Point } & \multirow{2}{*}{$\begin{array}{l}\text { End } \\
\text { Point }\end{array}$} & \multirow{2}{*}{$\Delta \mathrm{x}$} & \multirow{2}{*}{$\begin{array}{l}\text { Valve } \\
\text { Lift }\end{array}$} & \multirow{2}{*}{$\begin{array}{c}\Delta \mathrm{P} \\
\left({ }^{("} \mathrm{H}_{2} \mathrm{O}\right)\end{array}$} & \multicolumn{2}{|c|}{$\begin{array}{l}\text { Atmospheric } \\
\text { Conditions }\end{array}$} & \multicolumn{3}{|c|}{ Power Supply } \\
\hline & & & & & & & & & & $\begin{array}{l}\text { Temp } \\
\left({ }^{\circ} \mathrm{C}\right)\end{array}$ & $\begin{array}{l}\text { Pressure } \\
(\mathrm{mmHg})\end{array}$ & Variac & $\begin{array}{l}\text { Volt } \\
(\mathrm{V})\end{array}$ & $\begin{array}{l}\text { Current } \\
\text { (amps) }\end{array}$ \\
\hline \multirow[t]{3}{*}{6} & $4 / 19 / 00$ & $5: 45$ & GBABAOGA & & $\mathrm{x}=0.86^{\prime \prime}$ & $3.95^{\prime \prime}$ & $1 / 8 "$ & $9 \mathrm{~mm}$ & & & & & & \\
\hline & & $5: 50$ & & & $\mathrm{y}=85 \mathrm{~mm}$ & & & & & & & & & \\
\hline & & & & & & & & & & & & & & \\
\hline \multirow[t]{3}{*}{2} & $4 / 19 / 00$ & $5: 50$ & GBABCOGA & & $x=0.86 "$ & $3.95^{\prime \prime}$ & $1 / 8^{\prime \prime}$ & $9 \mathrm{~mm}$ & & & & & & \\
\hline & & $5: 55$ & & & $\mathrm{y}=74.55 \mathrm{~mm}$ & & & & & & & & & \\
\hline & & & & & & & & & & & & & & \\
\hline \multirow[t]{3}{*}{2} & $4 / 19 / 00$ & $6: 00$ & GBABDOGA & & $\mathrm{x}=0.86^{\prime \prime}$ & $3.95^{\prime \prime}$ & $1 / 8^{\prime \prime}$ & $9 \mathrm{~mm}$ & & & & & & \\
\hline & & $6: 05$ & & & $\mathrm{y}=61.85 \mathrm{~mm}$ & & & & & & & & & \\
\hline & & & & & & & & & & & & & & \\
\hline \multirow[t]{2}{*}{2} & $4 / 19 / 00$ & $6: 10$ & GBABEOGA & & $X=0.86 "$ & $3.95 "$ & $1 / 8^{\prime \prime}$ & $9 \mathrm{~mm}$ & 0.27 & & & 3.1 & 6.55 & 6 \\
\hline & & $6: 15$ & & & $y=36.45 \mathrm{~mm}$ & & & & & & & & & \\
\hline
\end{tabular}

Sample frequency: $10 \mathrm{kHz}$ Sample size: 64 kpts. Sample time: 6.5536 seconds

Note 1: Pt $1, \mathrm{x}=0.86$ " Pt 2, $x=1.00 "$ Pt $2-5, \Delta x=1 / 8 "$ Pt 6, $x=1.48 "$ Pt 7, $x=3.27$ " Pt 8, $x=3.375$ " Pt $8-12, \Delta x=1 / 8 "$ Pt 13, $x=3.95$ "
Note 2: Pt 1, $\mathrm{x}=0.86$ " Pt 2, $x=1.00$ " Pt 2-25, $\Delta x=1 / 8$ " Pt 26, $x=3.95 "$

Note 3: Pt 1, $\mathrm{x}=0.86$ " Pt 2, $x=1.00 "$ Pt 2-5, $\Delta x=1 / 8$ " Pt 6, $x=1.43$ " Pt 7, $x=3.33$ " Pt $8, \mathrm{x}=3.375$ ", Pt $8-12, \Delta x=1 / 8 "$ Pt 13, $x=3.93$ "
Note 4: Pt 1, $\mathrm{x}=0.86$ " Pt 2, $x=1.00$ " Pt 2-25, $\Delta x=1 / 8 "$ Pt 26, $x=3.93$ "

Note 5: Pt 1, $\mathrm{x}=0.86$ " Pt 2, $x=1.00 "$ Pt 2-5, $\Delta x=1 / 8 "$ Pt 6, $\mathrm{x}=1.48$ " Pt 7, $x=3.32 "$ Pt $8, x=3.375$ " Pt 8-12, $\Delta x=1 / 8 "$ Pt 13, $x=3.93 "$
Note 6: Pt 1, $\mathrm{x}=0.86$ " Pt 2, $x=1.00 "$ Pt 2-5, $\Delta x=1 / 8$ " Pt 6, $x=1.50$ "' Pt 7, $x=3.29$ " Pt 8, $x=3.375$ " Pt 8-12, $\Delta \mathrm{x}=1 / 8$ " Pt 13, $x=3.95$ " 
Table A.3: Test conditions for axial velocity measurements of straight intake using LDA equipment with 9 mm of valve lift.

\begin{tabular}{|c|c|c|c|c|c|c|c|c|c|c|c|c|c|c|}
\hline \multirow{2}{*}{\begin{tabular}{|l} 
\\
$\tilde{d}$ \\
0 \\
$z$ \\
$z$
\end{tabular}} & \multirow{2}{*}{ Date } & \multirow{2}{*}{ Time } & \multirow{2}{*}{ File Name } & \multirow{2}{*}{$\begin{array}{c}\text { \# of } \\
\text { Points }\end{array}$} & \multirow{2}{*}{ Start Point } & \multirow{2}{*}{$\begin{array}{l}\text { End } \\
\text { Point }\end{array}$} & \multirow{2}{*}{$\Delta \mathrm{x}$} & \multirow{2}{*}{$\begin{array}{l}\text { Valve } \\
\text { Lift }\end{array}$} & \multirow{2}{*}{$\begin{array}{c}\Delta \mathrm{P} \\
\left({ }^{*} \mathrm{H}_{2} \mathrm{O}\right)\end{array}$} & \multicolumn{2}{|c|}{$\begin{array}{l}\text { Atmospheric } \\
\text { Conditions }\end{array}$} & \multicolumn{3}{|c|}{ Power Supply } \\
\hline & & & & & & & & & & $\begin{array}{c}\text { Temp } \\
\left({ }^{\circ} \mathrm{C}\right)\end{array}$ & $\begin{array}{l}\text { Pressure } \\
(\mathrm{mmHg})\end{array}$ & Variac & $\begin{array}{l}\text { Volt } \\
\text { (V) }\end{array}$ & $\begin{array}{c}\text { Current } \\
\text { (amps) }\end{array}$ \\
\hline & $2 / 12 / 01$ & $\begin{array}{l}4: 55 \\
\text { PM }\end{array}$ & GBGBCZCA & 8 & $x=-1.5$ & & $1 / 8^{\prime \prime}$ & $9 \mathrm{~mm}$ & 0.27 & 22.5 & 742.5 & 2.4 & 4.67 & 5.5 \\
\hline & & $5: 00$ & & & & & & & & & & & & \\
\hline & & & & & & & & & & & & & & \\
\hline 1 & $2 / 12 / 01$ & $5: 05$ & GBGBDZCA & 25 & $x=-1.5$ & & $1 / 8^{\prime \prime}$ & $9 \mathrm{~mm}$ & 0.27 & & & & & \\
\hline & & $5: 25$ & & & & & & & & & & & & \\
\hline & & & & & & & & & & & & & & \\
\hline & $2 / 12 / 01$ & $5: 30$ & GBGBEZCA & 25 & $x=-1.5$ & & $1 / 8^{\prime \prime}$ & $9 \mathrm{~mm}$ & 0.27 & & & 2.4 & 4.67 & 5.5 \\
\hline & & & & & & & & & & & & & & \\
\hline
\end{tabular}

Note 1: Pt $13=$ center

Pt 25, bad (?) 
Table A.4: Test conditions for axial velocity measurements of swirl intake using LDA equipment.

\begin{tabular}{|c|c|c|c|c|c|c|c|c|c|c|c|c|c|c|}
\hline \multirow{2}{*}{ 告 } & \multirow{2}{*}{ Date } & \multirow{2}{*}{ Time } & \multirow{2}{*}{ File Name } & \multirow{2}{*}{$\begin{array}{c}\text { \# of } \\
\text { Points }\end{array}$} & \multirow{2}{*}{ Start Point } & \multirow{2}{*}{$\begin{array}{l}\text { End } \\
\text { Point }\end{array}$} & \multirow{2}{*}{$\Delta \mathrm{x}$} & \multirow{2}{*}{$\begin{array}{l}\text { Valve } \\
\text { Lift }\end{array}$} & \multirow{2}{*}{$\begin{array}{c}\Delta \mathrm{P} \\
\left({ }^{("} \mathrm{H}_{2} \mathrm{O}\right)\end{array}$} & \multicolumn{2}{|c|}{$\begin{array}{l}\text { Atmospheric } \\
\text { Conditions }\end{array}$} & \multicolumn{3}{|c|}{ Power Supply } \\
\hline & & & & & & & & & & $\begin{array}{l}\text { Temp } \\
\left({ }^{\circ} \mathrm{C}\right)\end{array}$ & $\begin{array}{l}\text { Pressure } \\
(\mathrm{mmHg})\end{array}$ & Variac & $\begin{array}{l}\text { Volt } \\
(\mathrm{V})\end{array}$ & $\begin{array}{c}\text { Current } \\
\text { (amps) }\end{array}$ \\
\hline \multirow[t]{2}{*}{1} & $2 / 14 / 01$ & $\begin{array}{l}3: 55 \\
\text { PM }\end{array}$ & GBJBCZCA & $9 *$ & $x=-1.5$ & & $1 / 8^{\prime \prime}$ & $9 \mathrm{~mm}$ & 0.27 & & & 3.05 & 6.64 & 6 \\
\hline & & $4: 00$ & & & & & & & & & & & & \\
\hline & & & & & & & & & & & & & & \\
\hline \multirow[t]{3}{*}{2} & $2 / 14 / 01$ & $4: 05$ & GBJBDZCA & 25 & $x=-1.5$ & & $1 / 8^{\prime \prime}$ & $9 \mathrm{~mm}$ & 0.27 & & & & & \\
\hline & & $4: 15$ & & & & & & & & & & & & \\
\hline & & & & & & & & & & & & & & \\
\hline \multirow[t]{3}{*}{3} & $2 / 14 / 01$ & $4: 15$ & GBJBEZCA & $26^{*}$ & $x=-1.5$ & & $1 / 8^{\prime \prime}$ & $9 \mathrm{~mm}$ & 0.27 & & & 3.05 & 6.64 & 6 \\
\hline & & $4: 25$ & & & & & & & & & & & & \\
\hline & & & & & & & & & & & & & & \\
\hline \multirow[t]{3}{*}{4} & $2 / 14 / 01$ & $4: 40$ & GBJAEZCA & 25 & $x=-1.5$ & & $1 / 8^{\prime \prime}$ & $4 \mathrm{~mm}$ & 0.27 & & & 3.25 & 7.14 & 6 \\
\hline & & $4: 45$ & & & & & & & & & & & & \\
\hline & & & & & & & & & & & & & & \\
\hline \multirow[t]{6}{*}{4} & $2 / 14 / 01$ & $4: 45$ & GBJADZCA & 25 & $x=-1.5$ & & $1 / 8^{\prime \prime}$ & $4 \mathrm{~mm}$ & 0.27 & & & & & \\
\hline & & $4: 55$ & & & & & & & & & & & & \\
\hline & & & & & & & & & & & & & & \\
\hline & $2 / 14 / 01$ & $4: 55$ & GBJACZCA & 16 & $x=-1.5$ & & $1 / 8^{\prime \prime}$ & $4 \mathrm{~mm}$ & 0.27 & & & & & \\
\hline & & $5: 05$ & & & & & & & & & & & & \\
\hline & & & & & & & & & & & & & & \\
\hline \multirow[t]{3}{*}{5} & $2 / 14 / 01$ & $5: 10$ & GBJABZCA & $2 *$ & $x=-1.5$ & & $1 / 8^{\prime \prime}$ & $4 \mathrm{~mm}$ & 0.27 & & & & & \\
\hline & & $5: 15$ & & & & & & & & & & & & \\
\hline & & & & & & & & & & & & & & \\
\hline 6 & $2 / 14 / 01$ & $5: 20$ & GBJABZCA & $3 *$ & $x=-1.5$ & & $1 / 8^{\prime \prime}$ & $4 \mathrm{~mm}$ & 0.27 & 22 & 731.7 & 3.25 & 7.14 & 6 \\
\hline
\end{tabular}


Note 1: Pt 8-9, $\Delta \mathrm{x}=1 / 16$ "

Pt 10-18, repeat of Pt 1-9

Note 2: Pt 24-25, $\Delta \mathrm{x}=1 / 16 "$

Note 3: Pt 26, bad

Note 4: Pt 25, bad

Note 5: Pt 1-2, $1^{\text {st }}$ two positions

Pt 3-6, 1-4 positions

Note 6: Repeat $\mathrm{z}=0.3$ ", Starting. R07 for position 1 
Table A.5: Test conditions for axial velocity measurements of straight intake using LDA equipment with 4 mm of valve lift.

\begin{tabular}{|c|c|c|c|c|c|c|c|c|c|c|c|c|c|c|}
\hline \multirow{2}{*}{$\begin{array}{l}\stackrel{0}{0} \\
\text { z }\end{array}$} & \multirow{2}{*}{ Date } & \multirow{2}{*}{ Time } & \multirow{2}{*}{ File Name } & \multirow{2}{*}{$\begin{array}{c}\text { \# of } \\
\text { Points }\end{array}$} & \multirow{2}{*}{ Start Point } & \multirow{2}{*}{$\begin{array}{l}\text { End } \\
\text { Point }\end{array}$} & \multirow{2}{*}{$\Delta \mathrm{x}$} & \multirow{2}{*}{$\begin{array}{l}\text { Valve } \\
\text { Lift }\end{array}$} & \multirow{2}{*}{$\frac{\Delta \mathrm{P}}{\left({ }^{\circ} \mathrm{H}_{2} \mathrm{O}\right)}$} & \multicolumn{2}{|c|}{$\begin{array}{l}\text { Atmospheric } \\
\text { Conditions }\end{array}$} & \multicolumn{3}{|c|}{ Power Supply } \\
\hline & & & & & & & & & & $\begin{array}{c}\text { Temp } \\
\left({ }^{\circ} \mathrm{C}\right)\end{array}$ & $\begin{array}{l}\text { Pressure } \\
(\mathrm{mmHg})\end{array}$ & Variac & $\begin{array}{l}\text { Volt } \\
\text { (V) }\end{array}$ & $\begin{array}{c}\text { Current } \\
\text { (amps) }\end{array}$ \\
\hline \multirow[t]{3}{*}{1} & $2 / 28 / 01$ & $\begin{array}{l}3: 10 \\
\text { PM }\end{array}$ & GBGAEZCA & 26 & $x=-1.5$ & & $1 / 8 "$ & $4 \mathrm{~mm}$ & 0.27 & 20 & 736.1 & 2.4 & 4.83 & 6 \\
\hline & & $3: 15$ & & & & & & & & & & & & \\
\hline & & & & & & & & & & & & & & \\
\hline \multirow[t]{3}{*}{2} & $2 / 28 / 01$ & $3: 20$ & GBGADZCA & 25 & $x=-1.5$ & & $1 / 8^{\prime \prime}$ & $4 \mathrm{~mm}$ & 0.27 & & & & & \\
\hline & & $3: 25$ & & & & & & & & & & & & \\
\hline & & & & & & & & & & & & & & \\
\hline \multirow[t]{5}{*}{3} & $2 / 28 / 01$ & $3: 30$ & GBGACZCA & 16 & $x=-1.5$ & & $1 / 8^{\prime \prime}$ & $4 \mathrm{~mm}$ & 0.27 & & & & & \\
\hline & & $3: 35$ & & & & & & & & & & & & \\
\hline & & & & & & & & & & & & & & \\
\hline & $2 / 28 / 01$ & $3: 40$ & GBGABZCA & 8 & $x=-1.5$ & & $1 / 8^{\prime \prime}$ & $4 \mathrm{~mm}$ & 0.27 & 21 & 735.4 & 2.4 & 4.83 & 6 \\
\hline & & $3: 45$ & & & & & & & & & & & & \\
\hline
\end{tabular}

Note 1: Pt 25-26, $\Delta x=1 / 16 "$

Note 2: Pt 25, bad

Note 3: Pt 15, bad (?) (not full beam/ partially blocked by valve) Pt 16, back 1/16" from Pt 15 
Table A.6: Test conditions for swirl velocity measurements of swirl intake using LDA equipment with 9 mm of valve lift.

\begin{tabular}{|c|c|c|c|c|c|c|c|c|c|c|c|c|c|c|}
\hline \multirow{2}{*}{ 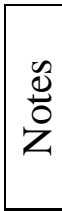 } & \multirow{2}{*}{ Date } & \multirow{2}{*}{ Time } & \multirow{2}{*}{ File Name } & \multirow{2}{*}{$\begin{array}{c}\text { \# of } \\
\text { Points }\end{array}$} & \multirow{2}{*}{ Start Point } & \multirow{2}{*}{$\begin{array}{l}\text { End } \\
\text { Point }\end{array}$} & \multirow{2}{*}{$\Delta \mathrm{x}$} & \multirow{2}{*}{$\begin{array}{c}\text { Valve } \\
\text { Lift }\end{array}$} & \multirow{2}{*}{$\begin{array}{c}\Delta \mathrm{P} \\
\left(" \mathrm{H}_{2} \mathrm{O}\right)\end{array}$} & \multicolumn{2}{|c|}{$\begin{array}{c}\text { Atmospheric } \\
\text { Conditions }\end{array}$} & \multicolumn{3}{|c|}{ Power Supply } \\
\hline & & & & & & & & & & $\begin{array}{c}\text { Temp } \\
\left({ }^{\circ} \mathrm{C}\right)\end{array}$ & $\begin{array}{l}\text { Pressure } \\
(\mathrm{mmHg})\end{array}$ & Variac & $\begin{array}{l}\text { Volt } \\
\text { (V) }\end{array}$ & $\begin{array}{l}\text { Current } \\
\text { (amps) }\end{array}$ \\
\hline \multirow[t]{3}{*}{1} & $3 / 8 / 01$ & $\begin{array}{l}2: 35 \\
\text { PM }\end{array}$ & GBKBEZCA & 25 & $x=-1.5$ & & $1 / 8^{\prime \prime}$ & $9 \mathrm{~mm}$ & 0.27 & 22 & 732.7 & 2.75 & 5.72 & 6 \\
\hline & & $2: 45$ & & & & & & & & & & & & \\
\hline & & & & & & & & & & & & & & \\
\hline \multirow[t]{3}{*}{2} & $3 / 8 / 01$ & $2: 45$ & GBKBDZCA & 26 & $x=-1.5$ & & $1 / 8^{\prime \prime}$ & $9 \mathrm{~mm}$ & 0.27 & & & & & \\
\hline & & $2: 55$ & & & & & & & & & & & & \\
\hline & & & & & & & & & & & & & & \\
\hline \multirow[t]{5}{*}{3} & $3 / 8 / 01$ & $3: 00$ & GBKBCZCA & 26 & $x=-1.5$ & & $1 / 8^{\prime \prime}$ & $9 \mathrm{~mm}$ & 0.27 & & & & & \\
\hline & & $3: 12$ & & & & & & & & & & & & \\
\hline & & & & & & & & & & & & & & \\
\hline & $3 / 8 / 01$ & $3: 20$ & GBKBAZCA & 10 & $x=-1.5$ & & $1 / 8^{\prime \prime}$ & $9 \mathrm{~mm}$ & 0.27 & 22 & 732.7 & 2.75 & 5.72 & 6 \\
\hline & & $3: 30$ & & & & & & & & & & & & \\
\hline
\end{tabular}

Note 1: Pt 6, bad

Pt $24-25, \Delta x=1 / 16 "$

Note 2: Pt 14, bad

Pt 15, bad

Note 3: Pt 16, bad

Pt 17, bad (?) 
Table A.7: Test conditions for swirl velocity measurements of swirl intake using LDA equipment with 4 mm of valve lift.

\begin{tabular}{|c|c|c|c|c|c|c|c|c|c|c|c|c|c|c|}
\hline \multirow{2}{*}{$\begin{array}{l} \\
\tilde{o} \\
0 \\
z\end{array}$} & \multirow{2}{*}{ Date } & \multirow{2}{*}{ Time } & \multirow{2}{*}{ File Name } & \multirow{2}{*}{$\begin{array}{c}\text { \# of } \\
\text { Points }\end{array}$} & \multirow{2}{*}{ Start Point } & \multirow{2}{*}{$\begin{array}{l}\text { End } \\
\text { Point }\end{array}$} & \multirow{2}{*}{$\Delta \mathrm{x}$} & \multirow{2}{*}{$\begin{array}{c}\text { Valve } \\
\text { Lift }\end{array}$} & \multirow{2}{*}{$\begin{array}{c}\Delta \mathrm{P} \\
\left({ }^{*} \mathrm{H}_{2} \mathrm{O}\right)\end{array}$} & \multicolumn{2}{|c|}{$\begin{array}{l}\text { Atmospheric } \\
\text { Conditions }\end{array}$} & \multicolumn{3}{|c|}{ Power Supply } \\
\hline & & & & & & & & & & $\begin{array}{c}\text { Temp } \\
\left({ }^{\circ} \mathrm{C}\right)\end{array}$ & $\begin{array}{l}\text { Pressure } \\
(\mathrm{mmHg})\end{array}$ & Variac & $\begin{array}{l}\text { Volt } \\
\text { (V) }\end{array}$ & $\begin{array}{c}\text { Current } \\
\text { (amps) }\end{array}$ \\
\hline \multirow[t]{2}{*}{1} & $3 / 15 / 01$ & $\begin{array}{l}1: 50 \\
\text { PM }\end{array}$ & GBKAAZCA & $11^{*}$ & $x=-1.5$ & & $1 / 8^{\prime \prime}$ & $4 \mathrm{~mm}$ & 0.27 & 22 & 730.7 & 2.9 & 6.08 & 6 \\
\hline & & $2: 00$ & & & & & & & & & & & & \\
\hline & & & & & & & & & & & & & & \\
\hline \multirow[t]{3}{*}{2} & $3 / 15 / 01$ & $2: 10$ & GBKABZCA & 26 & $x=-1.5$ & & $1 / 8^{\prime \prime}$ & $4 \mathrm{~mm}$ & 0.27 & & & & & \\
\hline & & $2: 30$ & & & & & & & & & & & & \\
\hline & & & & & & & & & & & & & & \\
\hline \multirow[t]{3}{*}{3} & $3 / 15 / 01$ & $2: 40$ & GBKACZCA & 26 & $x=-1.5$ & & $1 / 8^{\prime \prime}$ & $4 \mathrm{~mm}$ & 0.27 & & & & & \\
\hline & & $2: 50$ & & & & & & & & & & & & \\
\hline & & & & & & & & & & & & & & \\
\hline \multirow[t]{2}{*}{4} & $3 / 15 / 01$ & $2: 55$ & GBKADZCA & 27 & $x=-1.5$ & & $1 / 8 "$ & $4 \mathrm{~mm}$ & 0.27 & & & & & \\
\hline & & $3: 05$ & & & & & & & & & & & & \\
\hline \multirow[t]{2}{*}{5} & $3 / 15 / 01$ & $3: 15$ & GBKAEZCA & 25 & $x=-1.5$ & & $1 / 8 "$ & $4 \mathrm{~mm}$ & 0.27 & 22 & 730.1 & 2.9 & 6.08 & 6 \\
\hline & & $3: 20$ & & & & & & & & & & & & \\
\hline
\end{tabular}

Note 1: Pt 2, bad

Pt 8-9, $\Delta x=1 / 16 "$

Pt 9, bad

Pt $10,9^{\text {th }}$ position

Pt $11,2^{\text {nd }}$ position
Note 2: Pt 15, bad (?)

Pt 20, bad

Pt 25, bad (?)

Pt $25-26, \Delta x=1 / 16$ '

Note 3: Pt 15, bad (?)

Pt 18, bad (?)
Pt 19, bad (?)

Pt 25-26, $\Delta x=1 / 16$ "

Note 4: Pt 15, bad (?)

Pt 16, bad (?)

Pt $16-17, \Delta \mathrm{x}=0$

Pt $17-18, \Delta x=1 / 8$ "
Pt $26-27, \Delta x=1 / 16 "$

Pt 27, bad (?)

Note 5: Pt 13, bad (?)

Pt 16, bad (?) 
Table A.8: Test conditions for swirl velocity measurements of straight intake using LDA equipment with 4 mm of valve lift.

\begin{tabular}{|c|c|c|c|c|c|c|c|c|c|c|c|c|c|c|}
\hline \multirow{2}{*}{$\begin{array}{l}0 \\
\tilde{d} \\
0 \\
z\end{array}$} & \multirow{2}{*}{ Date } & \multirow{2}{*}{ Time } & \multirow{2}{*}{ File Name } & \multirow{2}{*}{$\begin{array}{c}\text { \# of } \\
\text { Points }\end{array}$} & \multirow{2}{*}{ Start Point } & \multirow{2}{*}{$\begin{array}{l}\text { End } \\
\text { Point }\end{array}$} & \multirow{2}{*}{$\Delta \mathrm{x}$} & \multirow{2}{*}{$\begin{array}{c}\text { Valve } \\
\text { Lift }\end{array}$} & \multirow{2}{*}{$\begin{array}{c}\Delta \mathrm{P} \\
\left({ }^{(} \mathrm{H}_{2} \mathrm{O}\right)\end{array}$} & \multicolumn{2}{|c|}{$\begin{array}{l}\text { Atmospheric } \\
\text { Conditions }\end{array}$} & \multicolumn{3}{|c|}{ Power Supply } \\
\hline & & & & & & & & & & $\begin{array}{c}\text { Temp } \\
\left({ }^{\circ} \mathrm{C}\right)\end{array}$ & $\begin{array}{l}\text { Pressure } \\
(\mathrm{mmHg})\end{array}$ & Variac & $\begin{array}{l}\text { Volt } \\
\text { (V) }\end{array}$ & $\begin{array}{l}\text { Current } \\
\text { (amps) }\end{array}$ \\
\hline & $3 / 20 / 01$ & $\begin{array}{l}9: 15 \\
\text { AM }\end{array}$ & GBHAEZCA & 25 & $x=-1.5$ & & $1 / 8^{\prime \prime}$ & $4 \mathrm{~mm}$ & 0.27 & 22 & 742.9 & 2.6 & 5.36 & 6 \\
\hline & & $9: 40$ & & & & & & & & & & & & \\
\hline & & & & & & & & & & & & & & \\
\hline \multirow[t]{3}{*}{1} & $3 / 20 / 01$ & $9: 45$ & GBHADZCA & 26 & $x=-1.5$ & & $1 / 8^{\prime \prime}$ & $4 \mathrm{~mm}$ & 0.27 & & & & & \\
\hline & & $10: 10$ & & & & & & & & & & & & \\
\hline & & & & & & & & & & & & & & \\
\hline \multirow[t]{3}{*}{2} & $3 / 20 / 01$ & $10: 15$ & GBHACZCA & 26 & $x=-1.5$ & & $1 / 8^{\prime \prime}$ & $4 \mathrm{~mm}$ & 0.27 & & & & & \\
\hline & & $10: 35$ & & & & & & & & & & & & \\
\hline & & & & & & & & & & & & & & \\
\hline \multirow[t]{5}{*}{3} & $3 / 20 / 01$ & $10: 40$ & GBHABZCA & 26 & $x=-1.5$ & & $1 / 8^{\prime \prime}$ & $4 \mathrm{~mm}$ & 0.27 & & & & & \\
\hline & & $10: 45$ & & & & & & & & & & & & \\
\hline & & & & & & & & & & & & & & \\
\hline & $3 / 20 / 01$ & $10: 50$ & GBHAAZCA & 8 & $x=-1.5$ & & $1 / 8^{\prime \prime}$ & $4 \mathrm{~mm}$ & 0.27 & 22 & 743.1 & 2.6 & 5.36 & 6 \\
\hline & & $10: 55$ & & & & & & & & & & & & \\
\hline
\end{tabular}

Note 1: Pt 15, bad

Pt 26, bad

Pt 25-26, $\Delta x=1 / 16 "$
Note 2: Pt 14, bad

Pt 16, bad

Pt 24, bad

Pt $25-26, \Delta x=1 / 16 "$
Note 3: Pt 25-26, $\Delta \mathrm{x}=1 / 16 "$ 
Table A.9: Test conditions for swirl velocity measurements of straight intake using LDA equipment with 9 mm of valve lift.

\begin{tabular}{|c|c|c|c|c|c|c|c|c|c|c|c|c|c|c|}
\hline \multirow{2}{*}{$\begin{array}{l}\text { 0े } \\
\text { Z }\end{array}$} & \multirow{2}{*}{ Date } & \multirow{2}{*}{ Time } & \multirow{2}{*}{ File Name } & \multirow{2}{*}{$\begin{array}{c}\text { \# of } \\
\text { Points }\end{array}$} & \multirow{2}{*}{ Start Point } & \multirow{2}{*}{$\begin{array}{l}\text { End } \\
\text { Point }\end{array}$} & \multirow{2}{*}{$\Delta \mathrm{x}$} & \multirow{2}{*}{$\begin{array}{c}\text { Valve } \\
\text { Lift }\end{array}$} & \multirow{2}{*}{$\begin{array}{c}\Delta \mathrm{P} \\
\left({ }^{*} \mathrm{H}_{2} \mathrm{O}\right)\end{array}$} & \multicolumn{2}{|c|}{$\begin{array}{l}\text { Atmospheric } \\
\text { Conditions }\end{array}$} & \multicolumn{3}{|c|}{ Power Supply } \\
\hline & & & & & & & & & & $\begin{array}{c}\text { Temp } \\
\left({ }^{\circ} \mathrm{C}\right)\end{array}$ & $\begin{array}{l}\text { Pressure } \\
(\mathrm{mmHg})\end{array}$ & Variac & $\begin{array}{l}\text { Volt } \\
\text { (V) }\end{array}$ & $\begin{array}{c}\text { Current } \\
\text { (amps) }\end{array}$ \\
\hline \multirow[t]{2}{*}{1} & $5 / 15 / 01$ & $\begin{array}{c}10: 25 \\
\text { AM }\end{array}$ & GBHBAZCA & 12 & $x=-1.5$ & & $1 / 8^{\prime \prime}$ & $9 \mathrm{~mm}$ & 0.27 & 22 & 736.6 & 2.2 & 4.35 & 6 \\
\hline & & $10: 30$ & & & & & & & & & & & & \\
\hline & & & & & & & & & & & & & & \\
\hline \multirow[t]{3}{*}{2} & $5 / 15 / 01$ & $10: 40$ & GBHBCZCA & 26 & $x=-1.5$ & & $1 / 8^{\prime \prime}$ & $9 \mathrm{~mm}$ & 0.27 & & & & & \\
\hline & & $10: 55$ & & & & & & & & & & & & \\
\hline & & & & & & & & & & & & & & \\
\hline \multirow[t]{3}{*}{3} & $5 / 15 / 01$ & $11: 00$ & GBHBDZCA & 25 & $x=-1.5$ & & $1 / 8^{\prime \prime}$ & $9 \mathrm{~mm}$ & 0.27 & & & & & \\
\hline & & $11: 20$ & & & & & & & & & & & & \\
\hline & & & & & & & & & & & & & & \\
\hline \multirow[t]{2}{*}{4} & $5 / 15 / 01$ & $11: 25$ & GBHBEZCA & 27 & $x=-1.5$ & & $1 / 8^{\prime \prime}$ & $9 \mathrm{~mm}$ & 0.27 & 22 & 735.7 & 2.2 & 4.35 & 6 \\
\hline & & $11: 40$ & & & & & & & & & & & & \\
\hline
\end{tabular}

Note 1: Pt 5, bad

Pt 5-6, $\Delta x=0$

Pt 11-12, $\Delta \mathrm{x}=1 / 16 "$

Note 2: Pt 25-26, $\Delta x=1 / 16 "$

Note 3: Pt 24-25, $\Delta x=1 / 16 "$

Note 4: Pt 15, bad

Pt 15-16, $\Delta x=0$

Pt 26-27, $\Delta x=1 / 16 "$ 